\title{
The management of type 1 diabetes in adults. A consensus report by the American Diabetes Association (ADA) and the European Association for the Study of Diabetes (EASD)
}

\author{
Richard I. G. Holt ${ }^{1,2}$ • J. Hans DeVries ${ }^{3,4} \cdot$ Amy Hess-Fischl $^{5}$ • Irl B. Hirsch ${ }^{6}$ - M. Sue Kirkman ${ }^{7} \cdot$ Tomasz Klupa $^{8}$.

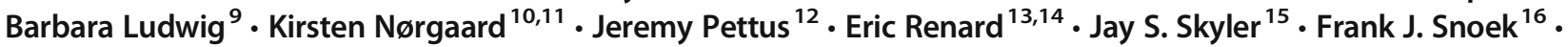 \\ Ruth S. Weinstock ${ }^{17} \cdot$ Anne L. Peters ${ }^{18}$
}

(C) 2021 European Association for the Study of Diabetes and American Diabetes Association , corrected publication 2021

\begin{abstract}
The American Diabetes Association (ADA) and the European Association for the Study of Diabetes (EASD) convened a writing group to develop a consensus statement on the management of type 1 diabetes in adults. The writing group has considered the rapid development of new treatments and technologies and addressed the following topics: diagnosis, aims of management, schedule of care, diabetes selfmanagement education and support, glucose monitoring, insulin therapy, hypoglycaemia, behavioural considerations, psychosocial care, diabetic ketoacidosis, pancreas and islet transplantation, adjunctive therapies, special populations, inpatient management and future perspectives. Although we discuss the schedule for follow-up examinations and testing, we have not included the evaluation and treatment of the chronic microvascular and macrovascular complications of diabetes as these are well-reviewed and discussed elsewhere. The writing group was aware of both national and international guidance on type 1 diabetes and did not seek to replicate this but rather aimed to highlight the major areas that healthcare professionals should consider when managing adults with type 1 diabetes. Though evidencebased where possible, the recommendations in the report represent the consensus opinion of the authors.
\end{abstract}

Keywords Adjunctive therapy · Diabetic ketoacidosis · Diagnosis · Exercise $\cdot$ Glucose monitoring $\cdot$ Hypoglycaemia $\cdot$ Insulin $\cdot$ Nutrition $\cdot$ Psychosocial care $\cdot$ Schedule of care $\cdot$ Transplantation $\cdot$ Type 1 diabetes

$\begin{array}{ll}\text { Abbreviations } \\ \text { App } & \text { Application } \\ \text { BGAT } & \text { Blood glucose awareness training } \\ \text { BGM } & \text { Blood glucose monitoring }\end{array}$

This Consensus Report is jointly published in Diabetologia, published by Springer-Verlag, $\mathrm{GmbH}$, on behalf of the European Association for the Study of Diabetes https://doi.org/10.1007/s00125-021-05568-3; and Diabetes Care, published by the American Diabetes Association https:// doi.org/10.2337/DCi21-0043.

A consensus report of a particular topic contains a comprehensive examination and is authored by an expert panel and represents the panel's collective analysis, evaluation, and opinion. The article was reviewed for EASD by its Committee on Clinical Affairs and approved by its Executive Board and for ADA by its Professional Practice Committee.

Richard I. G. Holt

righ@soton.ac.uk

Extended author information available on the last page of the article
CGM Continuous glucose monitoring

COVID-19 Coronavirus disease-2019

DKA Diabetic ketoacidosis

DSMES Diabetes self-management education and support

EDIC Epidemiology of Diabetes Interventions and Complications

FDA US Food and Drug Administration

GLP-1 RA Glucagon like peptide-1 receptor agonists

GMI Glucose management indicator

IAH Impaired awareness of hypoglycaemia

is-CGM Intermittently scanned continuous glucose monitoring

MDI Multiple daily injections

PTA Pancreas transplants alone

rt-CGM Real-time continuous glucose monitoring

SGLT Sodium-glucose cotransporter

SPK

TBR

TIR
Simultaneous pancreas and kidney

Time below range

Time in range 


\section{Section 1: Introduction and rationale for the consensus report}

Type 1 diabetes is a condition caused by autoimmune damage of the insulin-producing beta cells of the pancreatic islets, usually leading to severe endogenous insulin deficiency. Type 1 diabetes accounts for approximately $5-10 \%$ of all cases of diabetes. Although the incidence peaks in puberty and early adulthood, new-onset type 1 diabetes occurs in all age groups and people with type 1 diabetes live for many decades after onset of the disease, such that the overall prevalence of type 1 diabetes is higher in adults than in children, justifying our focus on type 1 diabetes in adults [1]. The global prevalence of type 1 diabetes is 5.9 per 10,000 people, while the incidence has risen rapidly over the last 50 years and is currently estimated to be 15 per 100,000 people per year [2].

Prior to the discovery of insulin a century ago, type 1 diabetes was associated with a life expectancy as short as a few months. Beginning in 1922, relatively crude extracts of exogenous insulin, derived from animal pancreases, were used to treat people with type 1 diabetes. Over the ensuing decades, insulin concentrations were standardised, insulin solutions became more pure, resulting in reduced immunogenicity, and additives, such as zinc and protamine, were incorporated into insulin solutions to increase the duration of action. In the 1980s, semi-synthetic and recombinant human insulins were developed and in the mid 1990s, insulin analogues became available. Basal insulin analogues were designed with prolonged duration of action and reduced pharmacodynamic variability compared with protaminebased (NPH) human insulin, while rapid-acting analogues were introduced with quicker onset and shorter duration than shortacting ('regular') human insulin, resulting in reduced early postprandial hyperglycaemia and less later hypoglycaemia several hours after the meal [3].

The discovery of insulin transformed the lives of many people, but it soon became apparent that type 1 diabetes is associated with the development of long-term complications and shortened life expectancy. Over the last 100 years, developments in insulin, its delivery, and technologies to measure glycaemic indices have markedly changed the management of type 1 diabetes. Despite these advances, many people with type 1 diabetes do not reach the glycaemic targets necessary to prevent or slow the progression of diabetes complications, which continue to exert a high clinical and emotional burden.

Recognising the ongoing challenge of type 1 diabetes and the rapid development of new treatments and technologies, the European Association for the Study of Diabetes (EASD) and the American Diabetes Association (ADA) convened a writing group to develop a consensus report on the management of type 1 diabetes in adults, aged 18 years and over. The writing group was aware of both national and international guidance on type 1 diabetes and did not seek to replicate this, but rather aimed to highlight the major areas of care that healthcare professionals should consider when managing adults with type 1 diabetes. The consensus report has focused predominantly on current and future glycaemic management strategies and metabolic emergencies. Recent advances in the diagnosis of type 1 diabetes have been considered. Unlike many other chronic conditions, type 1 diabetes places a unique burden of management on the individual with the condition. In addition to complex medication regimens, other behavioural modification is also needed; all of this requires considerable knowledge and skill to navigate between hyper- and hypoglycaemia. The importance of diabetes self-management education and support (DSMES) and psychosocial care are rightly documented in the report. While acknowledging the major significance and cost of screening, diagnosing and managing the chronic microvascular and macrovascular complications of diabetes, a detailed description of the management of these complications is beyond the scope of this report.

Two members of the writing group, one from the ADA and one from the EASD, were assigned to be the primary authors of each section. The chosen individuals had specific knowledge of the area and were tasked with reviewing and summarising the available literature. Each section, in turn, was reviewed and approved by the entire writing group. The draft consensus report was peer reviewed (see the Acknowledgements section) and suggestions were incorporated as deemed appropriate by the authors. The revised draft report was presented at the virtual ADA Scientific Sessions in 2021, after which public comments were invited. The report was further revised in light of this consultation. Large areas of clinical practice in type 1 diabetes are based on expert opinion and cohort studies rather than RCTs and so the writing group considered both observational and clinical trial findings, rather than relying solely on unbiased RCTs and meta-analyses. The report represents the consensus opinion of the authors, given that the available evidence is incomplete.

\section{Section 2: Diagnosis of type 1 diabetes}

Adults with new-onset type 1 diabetes can present with a short duration of illness of 1-4 weeks or a more slowly evolving process that can be mistaken for type 2 diabetes. Several other types of diabetes, for example monogenic diabetes, can be misdiagnosed as type 1 diabetes. In older adults, pancreatic cancer may present with diabetes and weight loss. A new and emerging issue is the development of profound insulin deficiency associated with the use of immune check-point inhibitors, which may present with hyperglycaemia and diabetic ketoacidosis (DKA) [4].

Most of the available data discussed below are derived from White European populations and may not be representative of other ethnic groups. The clinical presentation may differ, but the classical triad of thirst and polydipsia, polyuria and weight loss are common symptoms of type 1 diabetes. Accurate classifica- 
tion of the type of diabetes has implications beyond the use of insulin treatment; education, insulin regimen, use of adjuvant therapies, access to newer technologies, need for psychosocial support to address the profound psychological impact of the diagnosis of diabetes and concurrent disease screening may all depend on the diagnosis an individual receives. Furthermore, accurate diagnosis allows an assessment of the risk of diabetes in first-degree relatives and appropriate counselling. Although profound insulin deficiency is the hallmark of type 1 diabetes, some adults with type 1 diabetes maintain some insulin secretion for years after diagnosis and may not require insulin treatment at diagnosis [5], leading to diagnostic uncertainty about the type of diabetes and its management.

\section{Differentiating type 1 diabetes from type 2 diabetes}

Identifying whether an adult with newly diagnosed diabetes has type 1 diabetes may be challenging where the individual has features pointing towards both type 1 diabetes and type 2 diabetes, such as an older adult with a low or normal BMI or young adult with an elevated BMI. Ketoacidosis, once considered pathognomonic of type 1 diabetes, may occur in ketosis-prone type 2 diabetes. Misclassification of type 1 diabetes in adults is common and over $40 \%$ of those developing type 1 diabetes after age 30 years are initially treated as having type 2 diabetes [6-8]. From a patient perspective, a misdiagnosis of type 2 diabetes can cause confusion and misunderstanding, especially for those with type 1 diabetes who have overweight or obesity. This can impair the acceptance of the diagnosis and future management plans. No single clinical feature confirms type 1 diabetes in isolation $[9,10]$. The most discriminative feature is younger age at diagnosis ( $<35$ years), with lower BMI $\left(<25 \mathrm{~kg} / \mathrm{m}^{2}\right)$, unintentional weight loss, ketoacidosis and glucose $>20 \mathrm{mmol} / \mathrm{l}(>360 \mathrm{mg} / \mathrm{dl})$ at presentation also being informative. Other features classically associated with type 1 diabetes, such as ketosis without acidosis, osmotic symptoms, family history or a history of autoimmune diseases are weak discriminators [8-10].

The very strong relationship between type 2 diabetes incidence and age means that even 'classical' features of type 1 diabetes may have a limited predictive value in older adults, as type 2 diabetes in this age group is so common [11]. The majority of older adults with low BMI will have type 2 diabetes $[9,12,13]$, even more so when a person's ethnicity is associated with high type 2 diabetes risk [14]. Rapid progression to insulin treatment ( $<3$ years) is strongly suggestive of type 1 diabetes at any age $[6,8,15]$. The diagnosis of type 1 diabetes can be more difficult in adults who progress to insulin therapy more slowly. Controversy remains as to whether latent autoimmune diabetes of adulthood (LADA) is a discrete subtype, a milder form of type 1 diabetes, or a mixture of some individuals with type 1 diabetes and others with type 2 diabetes $[16,17]$.

\section{Differentiating type 1 diabetes from monogenic diabetes}

Monogenic diabetes is found in approximately $4 \%$ of those diagnosed with diabetes before the age of 30 years; the likelihood of monogenic diabetes rises to $20 \%$ where islet antibodies are negative and C-peptide secretion is maintained [18]. Monogenic diabetes is commonly mistaken for type 1 diabetes because of the young age at onset. A diagnosis of monogenic diabetes allows specific treatment with discontinuation of insulin in many cases and has implications for family members and screening for concurrent conditions $[19,20]$.

\section{Investigation of an adult with suspected type 1 diabetes}

An algorithm for the investigation of adults with suspected type 1 diabetes is shown in Fig. 1.

Islet autoantibodies An assessment of islet autoantibodies at diagnosis is recommended as the primary investigation of an adult with suspected type 1 diabetes. GAD should be the primary antibody measured and, if negative, should be followed by islet tyrosine phosphatase 2 (IA2) and/or zinc transporter 8 (ZNT8) where these tests are available. Islet cell antibody (ICA) measurement is no longer recommended because it is an imprecise biological assay that has been superseded by the direct measurement of single antibodies [21,22].

In people with clinical features suggesting type 1 diabetes, the presence of one or more positive islet autoantibodies is highly predictive of rapid progression and severe insulin deficiency and these individuals should be considered to have type 1 diabetes, even if they did not require insulin at diagnosis [23, 24]. As positive GAD antibodies may be found at a low level in adults without autoimmune diabetes and false positive results may occur, GAD should only be measured in those suspected to have type 1 diabetes [24].

The absence of autoantibodies does not exclude type 1 diabetes, since approximately 5-10\% of White European people with new-onset type 1 diabetes have negative islet antibodies $[8,9$, $25]$, and further consideration of the diagnosis is necessary. Furthermore, antibodies may disappear over time [26]. In those diagnosed below the age of 35 years, type 1 diabetes is still the most likely diagnosis, particularly if there are no clinical features of type 2 diabetes or monogenic diabetes. In those aged over 35 years, type 2 diabetes becomes increasingly likely with absent islet autoantibodies and older age. However, it can be hard to differentiate between type 1 diabetes and type 2 diabetes based on age and clinical features in non-White European populations.

It is important to make a clinical decision about how to treat the person with diabetes. Regardless of any features of type 2 diabetes or absence of islet antibodies, if there is a clinical suspicion of type 1 diabetes, the individual should be treated with 


\section{Flow chart for investigation of suspected type 1 diabetes in newly diagnosed adults, based on data from White European populations}

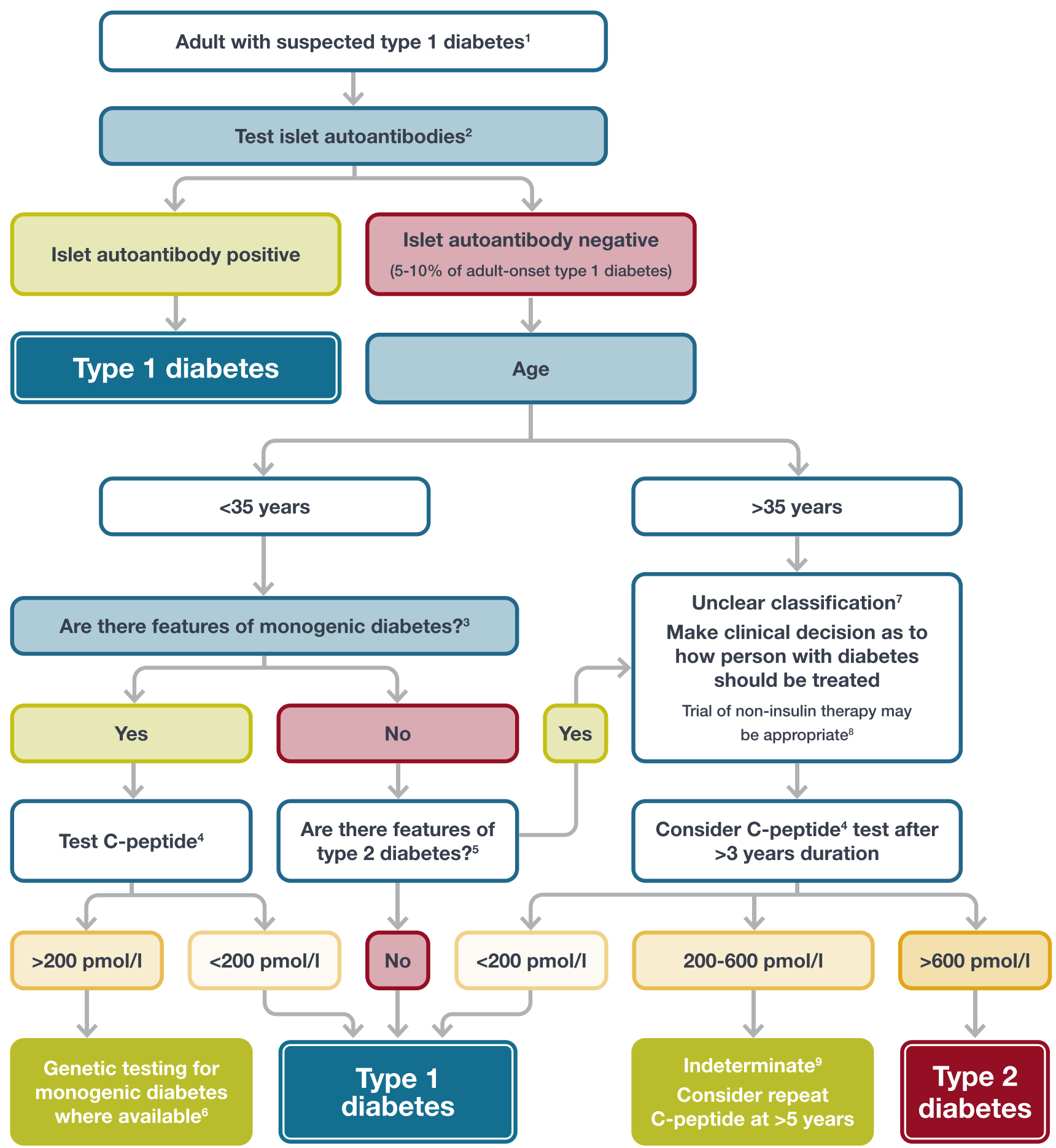

insulin. However, in some individuals, where the clinical course is more suggestive of type 2 diabetes, a trial of non-insulin therapy may be appropriate. Those whose diabetes is treated without insulin will require careful monitoring and education so that insulin can be rapidly initiated in the event of glycaemic deterioration. Type 2 diabetes and other types of diabetes should be considered in all age groups, but in those aged under 35 years, negative islet antibodies should raise the suspicion of monogenic diabetes. 
Fig. 1 Flow chart for investigation of suspected type 1 diabetes in newly diagnosed adults, based on data from White European populations. ${ }^{1}$ No single clinical feature confirms type 1 diabetes in isolation. The most discriminative feature is younger age at diagnosis $(<35$ years), with lower BMI $\left(<25 \mathrm{~kg} / \mathrm{m}^{2}\right)$, unintentional weight loss, ketoacidosis, and glucose $>20 \mathrm{mmol} / 1(>360 \mathrm{mg} / \mathrm{dl})$ at presentation also being informative. Other features classically associated with type 1 diabetes, such as ketosis without acidosis, osmotic symptoms, family history or a history of autoimmune diseases are weak discriminators. ${ }^{2} \mathrm{GAD}$ should be the primary antibody measured and, if negative, should be followed by islet tyrosine phosphatase 2 (IA2) and/or zinc transporter 8 (ZNT8) where these tests are available. In those diagnosed below the age of 35 years who have no clinical features of type 2 diabetes or monogenic diabetes, a negative result does not change the diagnosis of type 1 diabetes since 5 $10 \%$ of people with type 1 diabetes do not have antibodies. ${ }^{3}$ Monogenic diabetes is suggested by the presence of one or more of the following features: $\mathrm{HbA}_{1 \mathrm{c}}<58 \mathrm{mmol} / \mathrm{mol}(7.5 \%)$ at diagnosis, one parent with diabetes, features of specific monogenic cause (e.g. renal cysts, partial lipodystrophy, maternally inherited deafness, severe insulin resistance in the absence of obesity), and monogenic diabetes prediction model probability $>5 \%$ (www.diabetesgenes.org/exeter-diabetes-app/ ModyCalculator; accessed 20 August 2021). ${ }^{4} \mathrm{~A}$ C-peptide test is only indicated in people receiving insulin treatment. A random sample (with concurrent glucose) within $5 \mathrm{~h}$ of eating can replace a formal C-peptide stimulation test in the context of classification. If the result is $\geq 600 \mathrm{pmol} / \mathrm{l}$, the circumstances of testing do not matter. If the result is $<600 \mathrm{pmol} / \mathrm{l}$ and the concurrent glucose is $<4 \mathrm{mmol} / \mathrm{l}(<72 \mathrm{mg} / \mathrm{dl})$ or the person may have been fasting, consider repeating the test. Results showing very low levels $(<80 \mathrm{pmol} / \mathrm{l})$ do not need to be repeated. Where a person is insulintreated, C-peptide must be measured prior to insulin discontinuation to exclude severe insulin deficiency. Do not test C-peptide within 2 weeks of a hyperglycaemic emergency. ${ }^{5}$ Features of type 2 diabetes include increased BMI $\left(\geq 25 \mathrm{~kg} / \mathrm{m}^{2}\right)$, absence of weight loss, absence of ketoacidosis and less marked hyperglycaemia. Less discriminatory features include non-White ethnicity, family history, longer duration and milder severity of symptoms prior to presentation, features of the metabolic syndrome and absence of a family history of autoimmunity. ${ }^{6}$ If genetic testing does not confirm monogenic diabetes, the classification is unclear and a clinical decision should be made about treatment. ${ }^{7}$ Type 2 diabetes should be strongly considered in older individuals. In some cases, investigation for pancreatic or other types of diabetes may be appropriate. ${ }^{8} \mathrm{~A}$ person with possible type 1 diabetes who is not treated with insulin will require careful monitoring and education so that insulin can be rapidly initiated in the event of glycaemic deterioration. ${ }^{9} \mathrm{C}$-peptide values $200-600 \mathrm{pmol} / \mathrm{l}$ are usually consistent with type 1 diabetes or maturity-onset diabetes of the young (MODY) but may occur in insulin-treated type 2 diabetes, particularly in people with normal or low BMI or after long duration

C-peptide measurement Beyond 3 years after diagnosis where there is uncertainty about diabetes type, a random Cpeptide measurement (with concurrent glucose) within $5 \mathrm{~h}$ of eating is recommended. Where a person is treated with insulin, this test should always be performed prior to insulin discontinuation to exclude severe insulin deficiency.

Persistent C-peptide $>600 \mathrm{pmol} / \mathrm{l}$ (non-fasting) is strongly suggestive of type 2 diabetes and people with C-peptide in this range are often able to replace insulin with other agents [27-30]. Routine C-peptide testing in those with clinically diagnosed type 1 diabetes of at least 3 years duration has led to reclassification in $11 \%$ of those with adult-onset diabetes
[31]. By contrast, low or absent C-peptide confirms the diagnosis of type 1 diabetes. Although low C-peptide concentrations may occur in some types of secondary diabetes and very long-standing type 2 diabetes, these situations are unlikely to be confused for type 1 diabetes; however, in some cases, investigation of other types of diabetes may be appropriate.

Plasma C-peptide is the recommended test where available, with modestly higher performance than urine measurement. The latter may be confounded by impaired renal function. If urinary C-peptide:creatinine ratio is used, a value $<0.2 \mathrm{nmol} /$ mol can be used to define severe insulin deficiency.

Genetic testing As monogenic diabetes was less likely to have been considered in the past, molecular genetic testing for neonatal diabetes should be considered for all people with type 1 diabetes, regardless of current age, who were diagnosed under 6 months of age as more than $80 \%$ have monogenic neonatal diabetes, and the 30-50\% with ATP-sensitive potassium $\left(\mathrm{K}_{\mathrm{ATP}}\right)$ channel mutations can replace insulin with sulfonylureas $[32,33]$.

Monogenic diabetes should be considered in those with one or more of the following features: age at diagnosis of less than 35 years, $\mathrm{HbA}_{1 \mathrm{c}}<58 \mathrm{mmol} / \mathrm{mol}(7.5 \%)$ at diagnosis, one parent with diabetes, and features of specific monogenic cause (e.g. renal cysts, partial lipodystrophy, maternally inherited deafness, severe insulin resistance in the absence of obesity) [34]. A monogenic diabetes prediction model risk calculator (www.diabetesgenes.org/mody-probability-calculator; accessed 20 August 2021) may also be used to identify which individuals diagnosed between 6 months and 35 years are at increased risk of monogenic diabetes [35]. Those at increased risk should have islet autoantibody and C-peptide testing. Molecular genetic testing should only be considered if the antibodies are negative and non-fasting C-peptide is $>200 \mathrm{pmol} / 1$ [36-38]. Molecular genetic testing is not universally available.

\section{Section 3: Aims and goals of management of type 1 diabetes}

The aim of diabetes care and management is to support people with type 1 diabetes to live a long and healthy life. The management strategies to achieve this aim broadly include:

- Effectively delivering exogenous insulin to maintain glucose levels as close to the individual's target range as is safely possible to prevent the development and progression of diabetes complications while:

$\bigcirc$ Minimising episodes of hypoglycaemia, of all levels, including Level $1(<3.9$ to $\geq 3.0 \mathrm{mmol} / 1$ $[<70$ to $\geq 54 \mathrm{mg} / \mathrm{dl}]$ ) but, in particular, Level 2 $(<3.0 \mathrm{mmol} / 1[<54 \mathrm{mg} / \mathrm{dl}])$ and Level 3 (severe 
event characterised by altered mental and/or physical functioning that requires assistance from another person for recovery) hypoglycaemia, and preventing episodes of DKA, while treating these appropriately should they occur.

- Effectively managing cardiovascular risk factors.

- Providing approaches, treatments and devices that minimise the psychosocial burden of living with type 1 diabetes and, consequently, diabetes-related distress, while promoting psychological wellbeing.

Management strategies should adapt to new therapies and technologies as they become available, according to the wishes and desires of the person with diabetes.

The importance of glycaemic management was demonstrated convincingly by the DCCT [39] and the Epidemiology of Diabetes Interventions and Complications (EDIC) follow-up study [40]. With the use of intensive insulin therapy that aimed to achieve blood glucose levels close to the non-diabetes range, $\mathrm{HbA}_{1 \mathrm{c}}$ was lowered by $\sim 2 \%(22 \mathrm{mmol} / \mathrm{mol})$ to a mean $\mathrm{HbA}_{1 \mathrm{c}}$ of $\sim 7.0 \%$ (53 mmol/mol) over a mean of 6.5 years, compared with standard care (mean $\mathrm{HbA}_{1 \mathrm{c}} \sim 9.0 \%$ [75 mmol/mol]) [39]. The risk of primary development of retinopathy was reduced by $75 \%$ and progression of retinopathy slowed by $54 \%$. The development of microalbuminuria was reduced by $39 \%$ and clinical neuropathy by $60 \%$ in those assigned to intensive therapy. These benefits persisted beyond the end of the trial despite equivalent glucose levels in the two groups $\left(\mathrm{HbA}_{1 \mathrm{c}} \sim 8 \%[64 \mathrm{mmol} / \mathrm{mol}]\right)$ in the post-trial period; furthermore, reductions in incident cardiovascular disease and mortality in the intensively-treated group emerged with time [40]. This seminal study has been the basis for glycaemic target recommendations for type 1 diabetes worldwide. The cost of intensive management was, however, a 2-3fold increase in the rates of severe hypoglycaemia, as well as weight gain.

The main results of the DCCT were published in 1993, before any of the current insulin analogues and diabetes technologies, except for insulin pumps, were available. Increasingly, achieving and maintaining glucose levels in the target range have become possible with fewer episodes of hypoglycaemia [41-44]. Although the evidence of $\mathrm{HbA}_{1 \mathrm{c}}$ reduction remains the most robust measure associated with chronic diabetes complications and is the only measure that is prospectively validated, more recent studies have begun to examine the relationship between time that glucose is within the target range and long-term complications and have provided the basis for glycaemic targets with newer glucose monitoring technologies $[45,46]$.

The glycaemic target should be individualised considering factors that include duration of diabetes, age and life expectancy, comorbid conditions, known cardiovascular disease or advanced microvascular complications, impaired awareness of hypoglycaemia (IAH) and other individual considerations, and it may change over time. Goals should be achieved in conjunction with an understanding of the person's psychosocial needs and a reduction in diabetes distress if elevated. An $\mathrm{HbA}_{1 \mathrm{c}}$ goal for most adults of $<53 \mathrm{mmol} / \mathrm{mol}(<7.0 \%)$ without significant hypoglycaemia is appropriate. Following discussion between the person with diabetes and their healthcare team, achievement of lower $\mathrm{HbA}_{1 \mathrm{c}}$ levels than the goal of $53 \mathrm{mmol} / \mathrm{mol}(7 \%)$ may be acceptable, and even beneficial, if these can be achieved safely without adverse effects of treatment. Less-stringent $\mathrm{HbA}_{1 \mathrm{c}}$ goals (such as $<64 \mathrm{mmol} /$ mol $[<8.0 \%])$ may be appropriate for individuals with limited life expectancy or where the harms of treatment are greater than the benefits. It should be recognised that any reduction in $\mathrm{HbA}_{1 \mathrm{c}}$ from high initial levels has significant benefit even if the 'goal' is not reached.

Capillary blood glucose monitoring (BGM) can help people with type 1 diabetes achieve these $\mathrm{HbA}_{1 \mathrm{c}}$ goals. A preprandial capillary plasma glucose target of 4.4-7.2 mmol/1 ( $80-130 \mathrm{mg} /$ $\mathrm{dl}$ ) is appropriate for many people. Postprandial glucose may be targeted if $\mathrm{HbA}_{1 \mathrm{c}}$ goals are not met despite reaching preprandial glucose targets. Postprandial glucose measurements should be made $1-2 \mathrm{~h}$ after the beginning of the meal, which generally corresponds to peak levels in people with diabetes. A peak postprandial capillary plasma glucose of $<10.0 \mathrm{mmol} / 1(<180 \mathrm{mg} / \mathrm{dl})$ is appropriate for most people with diabetes, although an ideal target for normoglycaemia is $<7.8 \mathrm{mmol} / 1(<140 \mathrm{mg} / \mathrm{dl})$. Higher goals in those with limited life expectancy or where the harms of treatment are greater than the benefits are recommended (Table 1).

Further measurements that complement $\mathrm{HbA}_{1 \mathrm{c}}$ and BGM are assessments of the glucose management indicator (GMI) and time in range (TIR) from continuous glucose monitoring (CGM) data. GMI is calculated based on the average sensor glucose over the last 14 days and provides an approximation of a laboratory-measured $\mathrm{HbA}_{1 \mathrm{c}}$ in some individuals, but it may be higher or lower than actual $\mathrm{HbA}_{1 \mathrm{c}}$ in others [45]. GMI and TIR may be more useful than $\mathrm{HbA}_{1 \mathrm{c}}$ for clinical management because they reflect more recent blood glucose levels and provide more detailed clinical information. A typical GMI goal is $<53 \mathrm{mmol} / \mathrm{mol}(<7.0 \%)$. TIR is often taken as $3.9-10 \mathrm{mmol} / 1(70-180 \mathrm{mg} / \mathrm{dl})$ for most adults and time below range (TBR) as below $3.9 \mathrm{mmol} / \mathrm{l}(70 \mathrm{mg} / \mathrm{dl}$ ) (risk alert level), as well as less than $3.0 \mathrm{mmol} / \mathrm{l}(54 \mathrm{mg} / \mathrm{dl})$ (clinically significant). Other metrics are also defined (Fig. 2). TIR is associated with microvascular complications $[45,46]$ and a TIR of $70 \%$ roughly corresponds to an $\mathrm{HbA}_{1 \mathrm{c}}$ of $53 \mathrm{mmol} / \mathrm{mol}(7.0 \%)$. An international consensus conference reported that for most adults with type 1 diabetes, a target TIR should be above $70 \%$, with TBR less than $4 \%$ and less than $1 \%$ for clinically significant hypoglycaemia. The primary target for older people with a long duration of diabetes should be TBR less than $1 \%$ [47]. 
Table 1 Glycaemic targets for most adults with type 1 diabetes

\begin{tabular}{|c|c|}
\hline Variable & Target value \\
\hline $\mathrm{HbA}_{1 \mathrm{c}}$ & $<53 \mathrm{mmol} / \mathrm{mol}(<7.0 \%)$ \\
\hline GMI & $<53 \mathrm{mmol} / \mathrm{mol}(<7.0 \%)$ \\
\hline Preprandial glucose & $\begin{array}{l}4.4-7.2 \mathrm{mmol} / \mathrm{l} \\
\quad(80-130 \mathrm{mg} / \mathrm{dl})\end{array}$ \\
\hline $1-2 \mathrm{~h}$ postprandial glucose $\mathrm{e}^{\mathrm{a}}$ & $\begin{array}{l}<10.0 \mathrm{mmol} / 1 \\
\quad(<180 \mathrm{mg} / \mathrm{dl})\end{array}$ \\
\hline TIR & $>70 \%$ \\
\hline \multicolumn{2}{|l|}{ TBR } \\
\hline 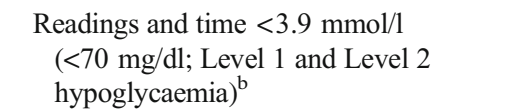 & $<4 \%$ \\
\hline $\begin{array}{l}\text { Readings and time }<3.0 \mathrm{mmol} / \mathrm{l} \\
(<54 \mathrm{mg} / \mathrm{dl} ; \text { Level } 2 \text { hypoglycaemia })^{\mathrm{b}}\end{array}$ & $<1 \%$ \\
\hline \multicolumn{2}{|l|}{ Time above range } \\
\hline $\begin{array}{l}\text { Readings and time }>10.0 \mathrm{mmol} / 1 \\
(>180 \mathrm{mg} / \mathrm{dl} ; \text { Level } 1 \text { and Level } 2 \\
\text { hyperglycaemia })^{\mathrm{c}}\end{array}$ & $<25 \%$ \\
\hline $\begin{array}{l}\text { Readings and time }>13.9 \mathrm{mmol} / \mathrm{l} \\
\quad(>250 \mathrm{mg} / \mathrm{dl} \text {; Level } 2 \text { hyperglycaemia })^{\mathrm{c}}\end{array}$ & $<5 \%$ \\
\hline Glycaemic variability $(\% \mathrm{CV})^{\mathrm{d}}$ & $\leq 36 \%$ \\
\hline
\end{tabular}

All glycaemic targets should be individualised and agreed with the person with diabetes. Lower or higher targets may be appropriate according to individual characteristics

${ }^{a}$ A postprandial glucose target of $<7.8 \mathrm{mmol} / \mathrm{l}(<140 \mathrm{mg} / \mathrm{dl})$ may be recommended if this can be achieved safely. Higher targets in those with limited life expectancy or where the harms of treatment are greater than the benefits are recommended. In some individuals at notably higher risk for Level 3 hypoglycaemia, it may be necessary to increase the glucose target range to decrease the TBR

${ }^{\mathrm{b}}$ Level 1 hypoglycaemia is defined as blood glucose levels $<3.9$ to $\geq 3.0 \mathrm{mmol} / 1(<70$ to $\geq 54 \mathrm{mg} / \mathrm{dl})$; Level 2 hypoglycaemia is defined as blood glucose levels $<3.0 \mathrm{mmol} / 1(<54 \mathrm{mg} / \mathrm{dl})$

${ }^{\mathrm{c}}$ Level 1 hyperglycaemia is defined as blood glucose levels $>10.0$ to $\leq 13.9 \mathrm{mmol} / \mathrm{l}$ (>180 to $\leq 250 \mathrm{mg} / \mathrm{dl}$ ); Level 2 hyperglycaemia is defined as blood glucose levels $>13.9 \mathrm{mmol} / 1$ ( $>250 \mathrm{mg} / \mathrm{dl})$

${ }^{\mathrm{d}}$ Some studies suggest that lower \%CV targets $(<33 \%)$ provide additional protection against hypoglycaemia

The cornerstone of type 1 diabetes therapy is insulin replacement. This is challenging because insulin demands vary widely according to meals, exercise and many other factors. Furthermore, the insulin doses needed to prevent hyperglycaemia are associated with a high risk of hypoglycaemia, leaving people with type 1 diabetes walking a tightrope between high and low glucose levels. Insulin management must be supported by adequate monitoring of glucose and education and training to allow the individual with type 1 diabetes to make the most of their treatment regimen.

The prevention of long-term complications of diabetes, particularly cardiovascular disease, extends beyond glycaemic management to include the optimal management of blood pressure and use of lipid-lowering medication. There is an absence of high-quality data to guide blood pressure targets in type 1 diabetes, but RCTs in other populations have demonstrated that treatment of hypertension to a blood pressure $<140 / 90 \mathrm{mmHg}$ reduces cardiovascular events and microvascular complications. Blood pressure targets should be individualised but a target of $<140 / 90 \mathrm{mmHg}$ is appropriate for those with a lower risk for cardiovascular disease (10 year risk of $<15 \%$ ). A lower target of $<130 / 80 \mathrm{mmHg}$ is recommended for those at higher cardiovascular disease risk or with evidence of microvascular complications, particularly renal disease. ACE inhibitors or angiotensin receptor blockers are recommended first-line therapies.

Similar to the situation for blood pressure, there is a paucity of trials of lipid-lowering therapy in people with type 1 diabetes, but an observational study reported that lipid-lowering therapy is associated with a $22-44 \%$ reduction in the risk of cardiovascular disease and death among individuals with type 1 diabetes without a prior history of cardiovascular disease [48]. Based on type 2 diabetes guidelines, moderateintensity statins should be considered for people aged over 40 years, and in those aged between 20-39 years with additional atherosclerotic cardiovascular disease risk factors or when the 10 year cardiovascular risk estimated by one of the risk calculators suitable for people with type 1 diabetes exceeds 10\% [49-51]. Additional agents, such as ezetimibe or proprotein convertase subtilisin/kexin type 9 (PCSK9) inhibitors, may be needed.

Antiplatelet agents, such as aspirin, should be considered for all people with type 1 diabetes and existing cardiovascular disease. Antiplatelet agents may be indicated for primary prevention but the benefit should be balanced with the increased risk of gastrointestinal bleeding.

In asymptomatic people with type 1 diabetes, routine screening for coronary artery disease is not recommended as it does not improve outcomes as long as atherosclerotic cardiovascular disease risk factors are treated. However, investigations for coronary artery disease should be considered if the person has any of the following: atypical cardiac symptoms, signs or symptoms of associated vascular disease or electrocardiogram abnormalities.

Type 1 diabetes is a demanding condition and requires ongoing professional medical, educational and psychosocial support. Care may differ at particular times of life, such as at the point of diagnosis, during concomitant illness or pregnancy, and later in life. Given the complexity of management, healthcare professionals should have the appropriate skills, training and resources to help people with type 1 diabetes access the education, technology, knowledge and urgent care they require. These issues are discussed in greater detail in the sections that follow. Overall approaches for people with newly diagnosed or established type 1 diabetes are shown in Figs 3 and 4. 
AGP Report: Continuous Glucose Monitoring

Time in Ranges Goals for Type 1 and Type 2 Diabetes

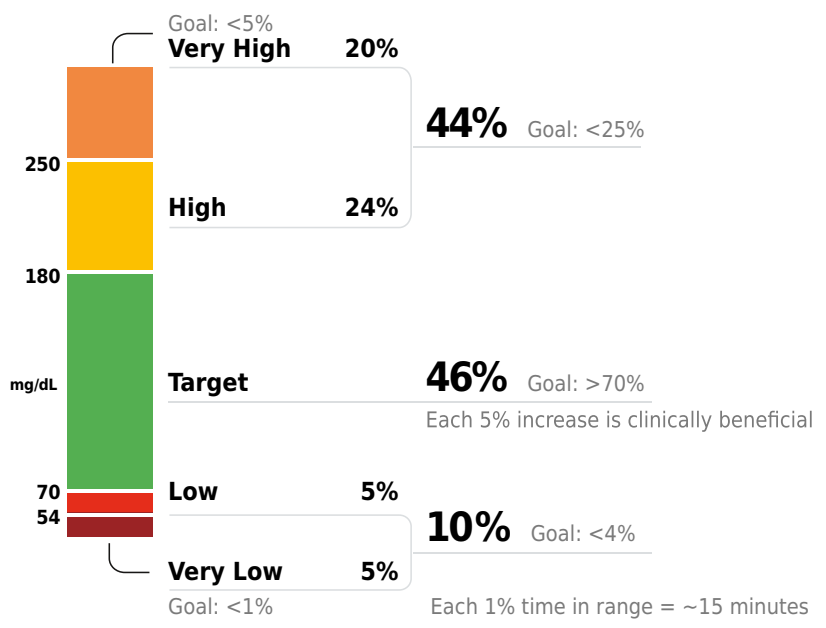

Test Patient DOB: Jan 1, 1970

14 Days: August 8-August 21, 2021

Time CGM Active: $100 \%$

\section{Glucose Metrics}

Average Glucose

$175 \mathrm{mg} / \mathrm{dL}$

Goal: $<154 \mathrm{mg} / \mathrm{dL}$

Glucose Management Indicator (GMI)

$7.5 \%$

Goal: $<7 \%$

\section{Glucose Variability}

$45.5 \%$

Defined as percent coefficient of variation

Goal: $\leq 36 \%$

\section{Ambulatory Glucose Profile (AGP)}

AGP is a summary of glucose values from the report period, with median (50\%) and other percentiles shown as if they occurred in a single day.

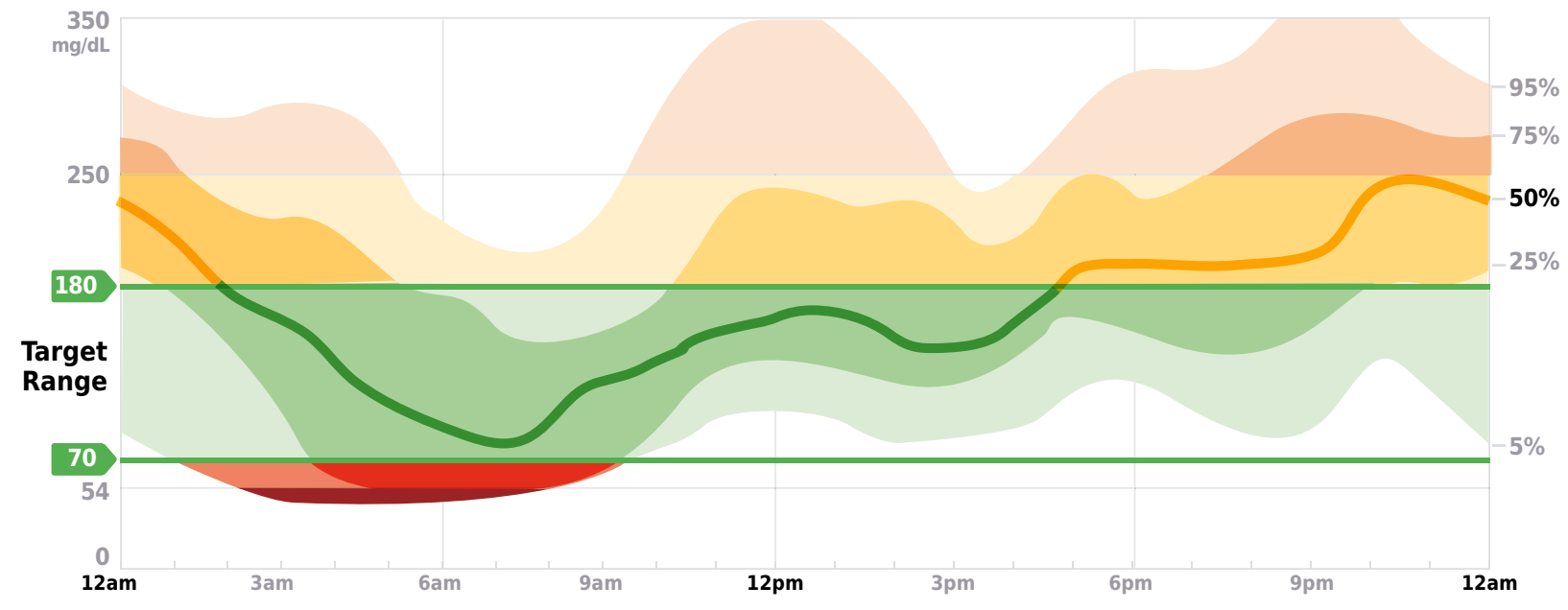

\section{Daily Glucose Profiles}

Each daily profile represents a midnight-to-midnight period.

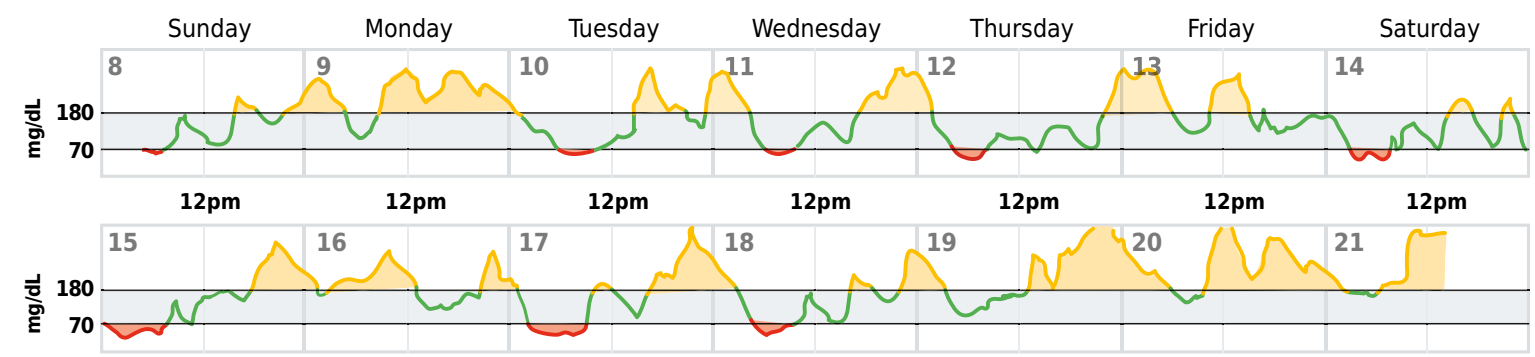


Fig. 2 CGM visualisation in an ambulatory glucose profile (AGP) report. Figure courtesy of R. M. Bergenstal and the International Diabetes Center, Minneapolis, MN, USA. To convert glucose values to $\mathrm{mmol} / \mathrm{l}$, values in $\mathrm{mg} / \mathrm{dl}$ should be divided by 18 . DOB, date of birth

\section{Section 4: Schedule of care}

A detailed evaluation should be obtained at the initial consultation, and more targeted interval care at follow-up visits with a focus on person-centred care (Table 2) [52, 53]. A personalised approach for visit frequency is recommended but visits should occur at least annually. More frequent contact, however, is preferred for most individuals, for example, those who have been recently diagnosed, those who are not meeting their diabetes goals, those who require cardiovascular risk management, and those who would benefit from additional self-management education and psychosocial support. The increased contact will allow additional review of glucose data and other support. Additional visits can also be useful when the therapeutic regimen changes, for example, when the insulin regimen is modified or when a new device is started.

In the past, initial and follow-up visits were primarily conducted face-to-face and telemedicine only used sporadically. With the onset of the coronavirus disease-2019 (COVID19) pandemic, the use of telemedicine became a necessity and there was an abrupt widespread adoption of remote visits (videoconference/telephone call) to deliver diabetes care. Pre COVID-19, results from a limited number of studies using telemedicine in different subgroups of people with type 1 diabetes suggested that remote monitoring, education and provider visits have the potential to: improve outcomes, quality of life and self-management; increase access to care and reduce costs; and are well-accepted with improved treatment satisfaction [54-57].

The use of telemedicine, however, should be individualised and will vary depending upon individual needs, computer literacy and access to care [58]. The healthcare professional and person with diabetes should be in a private space. In advance of the visit, people with diabetes should receive clear instructions on the expectations for the televisit, including how to connect to the consultation and how to upload data from their diabetes devices (glucose meters, data-collecting applications [apps], CGM devices and insulin pumps) prior to the appointment [59]. When clinically indicated and appropriate, people with diabetes should be asked to weigh themselves and perform home blood pressure measurements where possible. A list of all medications and relevant medical reports should be available. Despite the value of telemedicine, people should have the option to schedule an in-person visit, where possible.

\section{Section 5: Diabetes self-management education and support}

DSMES is an essential component of type 1 diabetes care that allows all other diabetes interventions to work optimally. The objective of DSMES is to provide those living with type 1 diabetes (and their caregivers, if applicable) with the knowledge, skills and confidence to successfully self-manage the diabetes on a daily basis and, thereby, reduce the risks of acute and long-term complications while maintaining quality of life [60]. DSMES aims to empower people with type 1 diabetes, with an emphasis on shared decision-making and active collaboration with the healthcare team. Where possible, DSMES programmes should be evidence-based and conform to local and national standards to demonstrate effectiveness.

\section{Levels and content of diabetes self-management education and support}

Three levels of DSMES can be distinguished:

- Level 1 comprises provision of diabetes information and one-to-one advice.

- Level 2 refers to ongoing learning that may be informal, perhaps through a peer group.

- Level 3 DSMES refers to structured education that meets nationally agreed criteria, including an evidence-based curriculum, quality assurance of teaching standards and regular audit. These programmes are guided by learning and behaviour change theories.

Several Level 3 programmes have been developed for adults with type 1 diabetes and have proven to be effective, both in terms of improved glycaemic outcomes and improved psychosocial outcomes [61]. Most programmes use a group format, increasingly supplemented with digital support, including text messaging and cloud-based solutions and telemedicine [62]. Structured DSMES programmes most often include multiple components and cover a broad range of topics, from pathophysiology to medical technology and healthy coping (Table 3).

Specific DSMES should not be confined to one particular moment but offered on a continuous basis and tailored to the ever-evolving individual's educational needs. People with type 1 diabetes may be diagnosed at a young age or during adulthood, and many live with type 1 diabetes throughout different life stages. Four critical times where DSMES is particularly needed can be distinguished: (1) at diagnosis; (2) when not meeting targets; (3) when transitions occur; and (4) when complications develop (Fig. 5) [63]. DSMES should be revisited when a child transitions to adult diabetes services, as there may be significant knowledge gaps in someone diagnosed early in life, when education at the time was directed to the parents and caregivers. DSMES should be tailored towards an individuals' needs, taking 


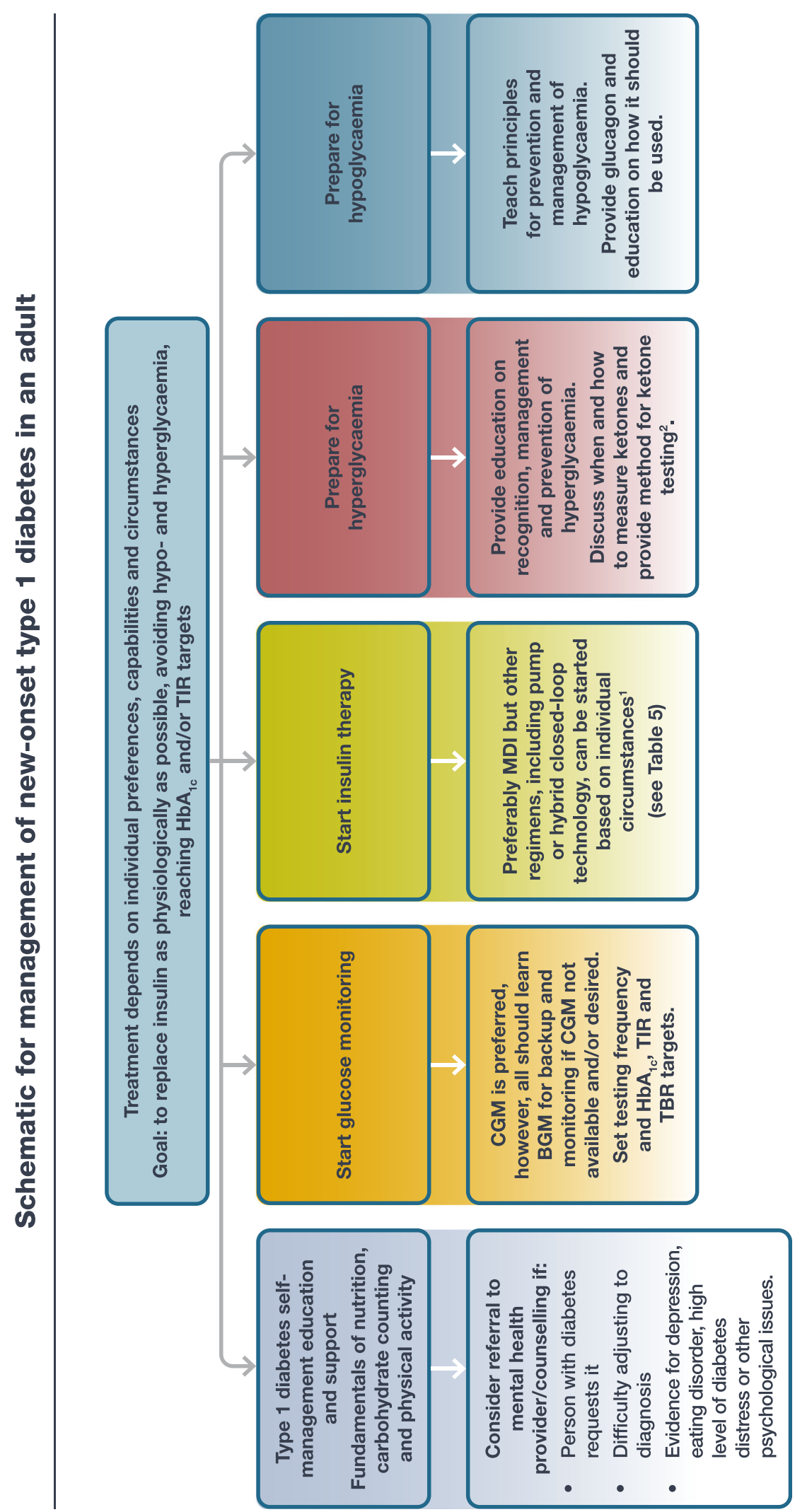

ีำ

客

चु 흉

믈

敢

. $:$

造离

중 옹

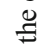

吾

?.

응

은 융

可

政

今

.

官

正

过

बํㅠㅇ

-

용

记

을

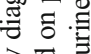

趂

兘응

픙

혼 홍

完 유

등

를

言

든.

흘 휴

흘 훙

峸官

ब

密

홍

훙

들웅

氙

$<$.

为总总 


\section{General principles for management of blood glucose in existing type 1 diabetes in an adult}

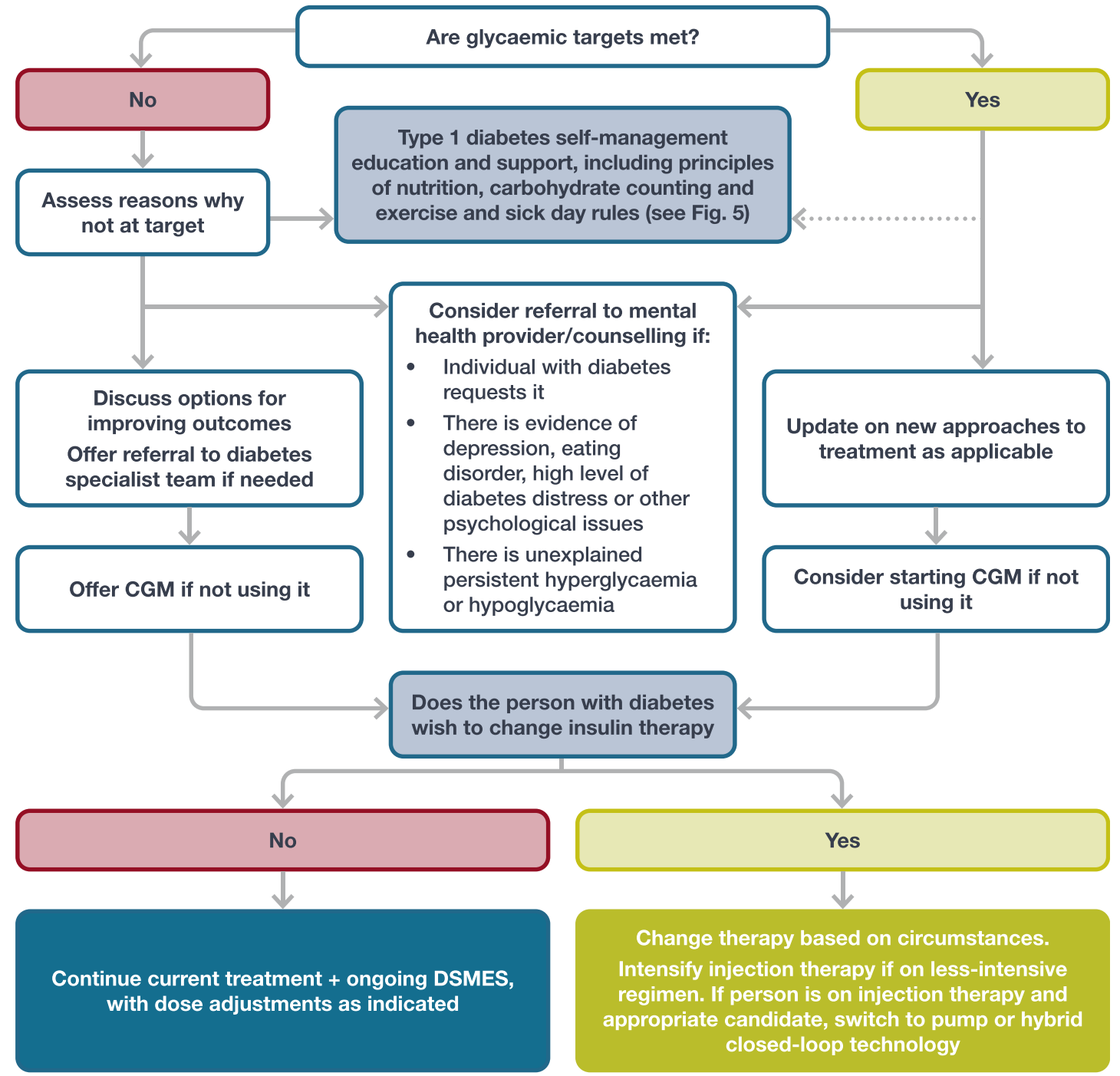

People can switch back and forth between MDI and pump or hybrid closed-loop therapy based on preference and circumstances; however, all people must be prepared to use injected insulin therapy if pump or hybrid closed-loop systems fail or are not available. BGM should be available as a backup to CGM

All treatment depends on patient preferences, capabilities and circumstances.

Confirm person with diabetes has unexpired glucagon and ketone testing supplies available ${ }^{1}$

Fig. 4 A framework for the follow-up treatment of an individual with type 1 diabetes. ${ }^{1}$ The availability of blood and urine ketone measurement varies across healthcare systems

into account cognitive function and literacy, family history and comorbidities, as well as ethnic, socio-cultural, financial, geographical and lifestyle factors [64]. A structured, periodic assessment of educational needs and barriers should be an integral part of ongoing diabetes care (see Text box: Needs assessment for diabetes management, education and support).
There are numerous smartphone and web-based apps that aim to help people with type 1 diabetes navigate the challenges of self-management. Although widely used, the available evidence on the safety and effectiveness of diabetes health apps remains limited, with issues ranging from inadequate evidence on app accuracy and clinical validity to lack of 
Table 2 Schedule of care

\begin{tabular}{|c|c|}
\hline Component of care & Details of evaluation \\
\hline \multicolumn{2}{|l|}{ Medical and family history } \\
\hline \multirow[t]{6}{*}{ Diabetes history } & Date of diagnosis \\
\hline & Presentation at onset \\
\hline & Islet autoantibodies (date) \\
\hline & C-peptide (date) \\
\hline & Episodes of DKA or Level 3 hypoglycaemia \\
\hline & Hypoglycaemia awareness \\
\hline \multirow[t]{2}{*}{ Family history } & Type 1 diabetes or type 2 diabetes in first-degree relatives \\
\hline & Other autoimmune disorders \\
\hline \multirow[t]{3}{*}{$\begin{array}{l}\text { Personal history of chronic } \\
\text { complications }\end{array}$} & $\begin{array}{l}\text { Microvascular: retinopathy, macular oedema, laser/injection therapy, date of last } \\
\text { retinal evaluation (exam or photos); peripheral neuropathy, autonomic } \\
\text { neuropathy; nephropathy }\end{array}$ \\
\hline & Macrovascular: heart, cerebrovascular and peripheral arterial disease \\
\hline & Foot ulcers or amputations \\
\hline \multirow{11}{*}{$\begin{array}{l}\text { Personal history of common } \\
\text { comorbidities }\end{array}$} & Autoimmune disorders: thyroid, coeliac, others ${ }^{\mathrm{a}}$ \\
\hline & Hypertension \\
\hline & Lipid disorder \\
\hline & Overweight and obesity \\
\hline & Eating disorders \\
\hline & Hearing loss \\
\hline & Sleep disorder \\
\hline & Dermopathy \\
\hline & Fractures \\
\hline & $\begin{array}{l}\text { Joint and soft tissue disorders: cheiroarthropathy, trigger finger, capsulitis, carpal } \\
\text { tunnel syndrome }\end{array}$ \\
\hline & $\begin{array}{l}\text { Dental and gum health } \\
\text { Pregnancy and contraception history }\end{array}$ \\
\hline Other & Immunisation history \\
\hline \multirow[t]{4}{*}{ Additional behavioural factors } & Diet and nutrition: use of carbohydrate counting, weight history \\
\hline & Physical activity \\
\hline & Smoking, alcohol, substance use \\
\hline & Sleep \\
\hline \multicolumn{2}{|l|}{ Diabetes management } \\
\hline \multirow[t]{2}{*}{ Current insulin regimen } & MDI: pens, including connected insulin pens; syringes; needles \\
\hline & $\begin{array}{l}\text { Insulin pump (type/model): settings; backup injection plan } \\
\text { Type of meter/strips }\end{array}$ \\
\hline \multirow{3}{*}{ BGM } & Frequency of use \\
\hline & Mean (SD), range \\
\hline & Pattern \\
\hline \multirow[t]{4}{*}{ CGM } & Type/model \\
\hline & Data sharing; if yes, with whom \\
\hline & Glucometrics \\
\hline & Pattern \\
\hline \multirow[t]{4}{*}{ Other } & Other diabetes medications \\
\hline & Glucagon prescribed \\
\hline & Ketone testing supplies prescribed (where available) \\
\hline & Software/app use \\
\hline \multirow[t]{4}{*}{ Psychosocial issues } & $\begin{array}{l}\text { Monitor psychological wellbeing: diabetes-specific distress; depressive symptoms; } \\
\text { anxiety symptoms }\end{array}$ \\
\hline & $\begin{array}{l}\text { Consider, also, the potential presence of fear of hypoglycaemia and disordered } \\
\text { eating }\end{array}$ \\
\hline & Screen for social determinants of health and social support \\
\hline & Assess cognitive status \\
\hline DSMES & Assess and plan for meeting individual needs \\
\hline
\end{tabular}


Table 2 (continued)

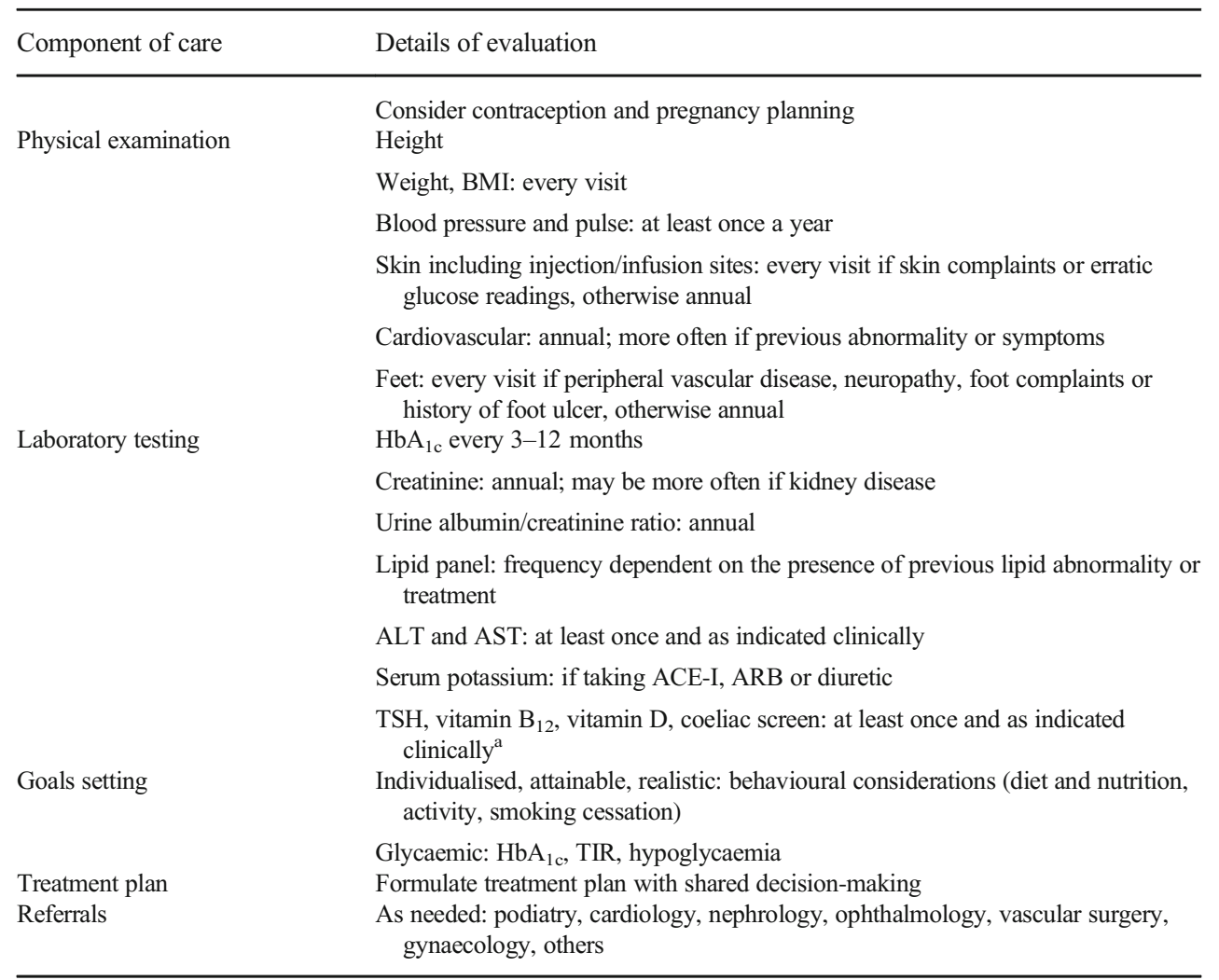

${ }^{a}$ Individuals with type 1 diabetes are also at increased risk for the development of other autoimmune diseases, including autoimmune thyroid disorders, pernicious anaemia, coeliac disease, collagen vascular diseases and Addison's disease [291, 292]. The optimal frequency of screening for these conditions in adults has not been established

ACE-I, ACE inhibitor; ALT, alanine aminotransferase; ARB, angiotensin II receptor blocker; AST, aspartate aminotransferase; TSH, thyroid stimulating hormone

\section{Needs assessment for diabetes management, education and support}

\section{Key assessment features}

- Health history

- Cognition, functional health literacy and numeracy

- Diabetes distress and support systems

- Religious and cultural influences

- Health beliefs and attitudes

- Physical limitations

- Social determinants of health e.g. financial status

- Barriers training provision, poor interoperability and standardisation and insufficient data security [65].

\section{Section 6: Monitoring of glucose levels}

People with type 1 diabetes should have an assessment of their glucose levels with their healthcare professional as often as is clinically indicated, but at least annually. Glycaemic status should be assessed at least every 3 months in those whose therapy has changed or who are not meeting glycaemic goals.

\section{$\mathrm{HbA}_{1 c}$}

Monitoring of blood glucose has traditionally been by $\mathrm{HbA}_{1 \mathrm{c}}$, which has been used in most studies that demonstrate the effects of lowering glucose on the development and progression of diabetes complications [39]. There is a strong correlation $(r=>0.9)$ between $\mathrm{HbA}_{1 \mathrm{c}}$ and mean blood glucose levels during the preceding 3 months when glucose levels are stable [66]. In several conditions, however, $\mathrm{HbA}_{1 \mathrm{c}}$ does not reflect 
Table 3 Key content areas of DSMES

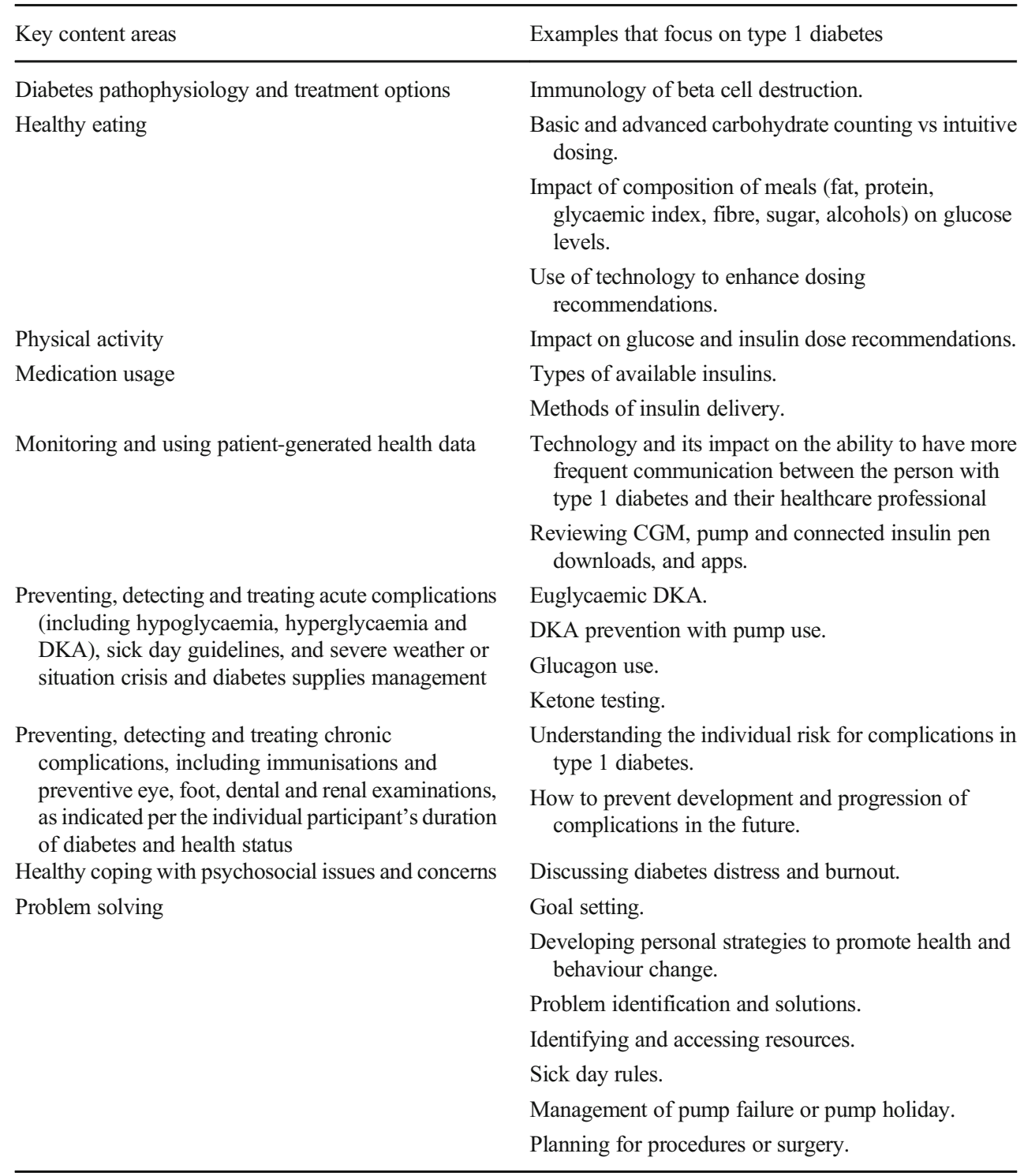

mean glucose; these are mainly situations where erythrocyte turnover is altered or in the presence of haemoglobinopathies (Table 4) [67]. Variability exists between individuals, but the $\mathrm{HbA}_{1 \mathrm{c}}$ and blood glucose within an individual correlate over time [68]. Although $\mathrm{HbA}_{1 \mathrm{c}}$ is an indicator of mean glucose, it does not inform glycaemic variability and hypoglycaemia and, therefore, is inappropriate as the only method of glucose evaluation in type 1 diabetes [68, 69].

Other biomarkers, such as fructosamine, 1,5-anhydroglucitol and glycated albumin, provide measures of mean glucose, albeit with shorter durations than $\mathrm{HbA}_{1 \mathrm{c}}$. None of these are as well associated with diabetes complications as $\mathrm{HbA}_{1 \mathrm{c}}[70]$.

\section{Capillary blood glucose monitoring}

Capillary BGM involves the use of a handheld meter and provides a measurement of capillary plasma glucose.
Frequent BGM measurements are important as an integrated part of diabetes management to guide insulin dosage, food intake and prevention of hypoglycaemia with exercise. Every person with type 1 diabetes should have the equipment to undertake BGM, regardless of whether they are using CGM.

BGM is needed before meals to give the user the chance to adjust the meal insulin dose if the pre-meal glucose is out of range at the time, while measurements over a few days will show whether the doses active before that meal require adjustment. Additionally, BGM is needed to prevent and detect hypoglycaemia in several situations, such as: before bedtime; before driving; before, during, and after exercise; and when hypoglycaemic symptoms occur. The evidence for the optimal number of daily BGM measurements is lacking and may depend on variation in the person's lifestyle. 


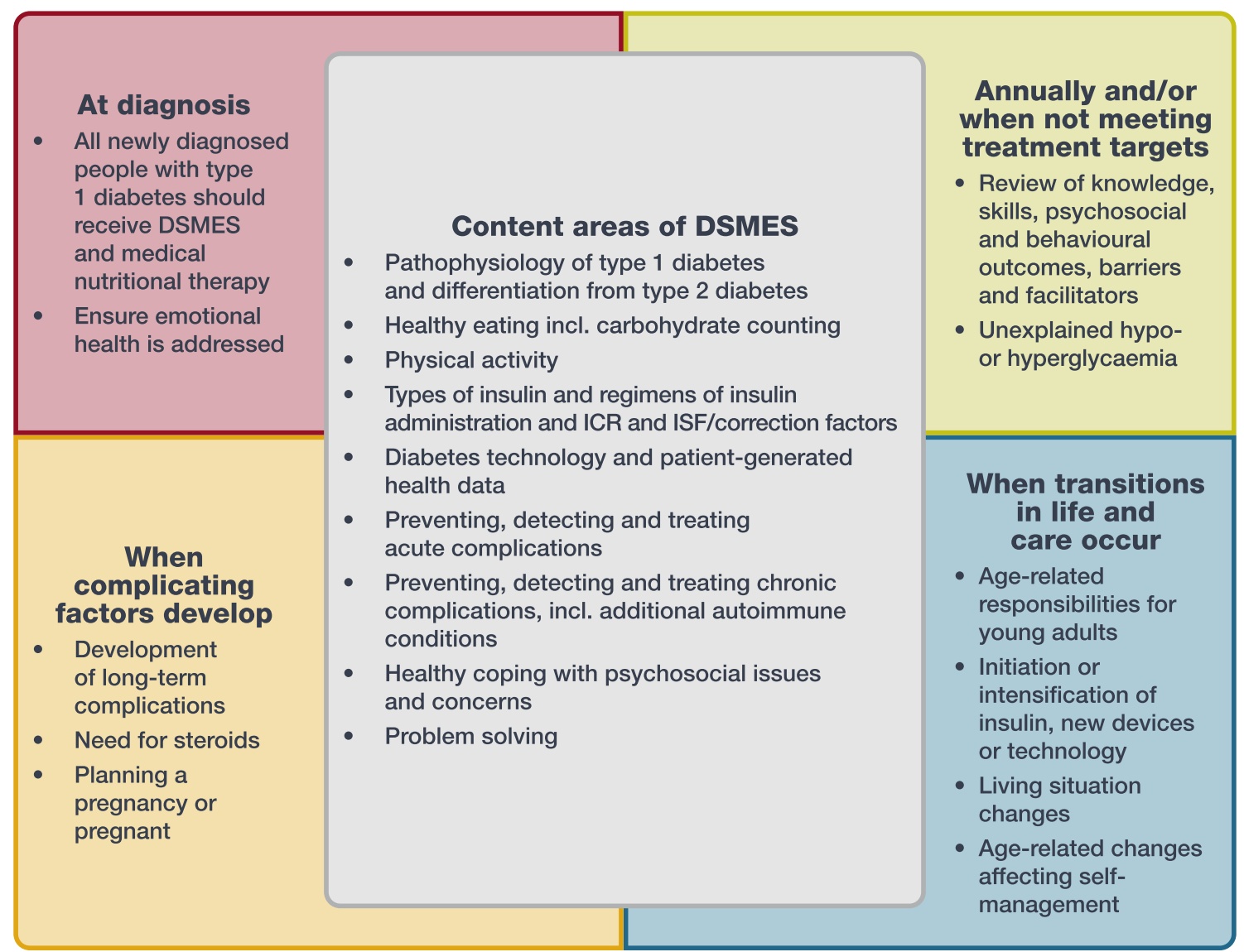

Fig. 5 The four critical times when DSMES is particularly needed for people with diabetes (and their caregivers, when applicable). ICR, insulin:carbohydrate ratio; incl., including; ISF, insulin sensitivity factor

In registry studies, increased testing frequency is associated with lower $\mathrm{HbA}_{1 \mathrm{c}}$ [71]. However, even with frequent $\mathrm{BGM}$, most people with type 1 diabetes will have undetected and an unacceptable high frequency of hyper- and hypoglycaemia [72]. Frequent measurements are often not feasible and can be distressing. Seeing high or low glucose values can evoke feelings of frustration, anxiety and guilt, leading many people with type 1 diabetes to measure less often than needed [73]. Downloading memory-capable glucose meters can be helpful in observing patterns of hyper- or hypoglycaemia and allowing the person with diabetes to reflect on insulin dose adjustment [74]. Most meters meet the accuracy standards established by the International Organization for Standardization and manufacturers need to evaluate each product's clinical performance in a broad population of users over time to ensure that their products continue to meet standards of clinical accuracy [75].

\section{Continuous glucose monitoring}

CGM is the standard for glucose monitoring for most adults with type 1 diabetes. CGM devices, which have been available commercially since 2006 , measure interstitial glucose to provide an estimate of plasma glucose. CGM devices have evolved and improved enough in accuracy to the point where most currently available sensors are 'non-adjunctive', meaning that a check with capillary BGM before a treatment decision is taken is not required. However, BGM may still be required if there are concerns that the CGM readings do not reflect the plasma glucose.

Currently there are two types of CGM devices: one provides a continuous value of current glucose and trends to a receiver, mobile app, smartwatch, or pump (designated as real-time CGM [rt-CGM]), while the other requires the glucose level to be determined by scanning a small reader or smartphone across the transmitter (intermittently scanned CGM [is-CGM]). Historically, rt-CGM has offered a variety of alerts, both in terms 
Table 4 Non-glycaemic factors that alter $\mathrm{HbA}_{1 \mathrm{c}}$ levels [70]

\begin{tabular}{|c|c|}
\hline Effect on $\mathrm{HbA}_{1 \mathrm{c}}$ & Factor \\
\hline Apparent increase & $\begin{array}{l}\text { - Age } \\
\text { - Ethnicity: } \mathrm{HbA}_{1 \mathrm{c}} \text { is slightly higher in African Americans than in people of White } \\
\text { Northern-European ancestry } \\
\text { - Anaemias with decreased erythrocyte turnover: iron, vitamin } \mathrm{B}_{12} \text {, folate } \\
\text { - Severe hypertriglyceridaemia (hypertriacylglycerolaemia) } \\
\text { - Severe hyperbilirubinaemia } \\
\text { - Chronic alcohol consumption } \\
\text { - Chronic salicylate consumption } \\
\text { - Chronic opioid ingestion }\end{array}$ \\
\hline Apparent decrease & $\begin{array}{l}\text { - Pregnancy (second and third trimester) } \\
\text { - Anaemias of chronic disease } \\
\text { - Haemolytic anaemia } \\
\text { - Splenomegaly and splenectomy } \\
\text { - Acute blood loss } \\
\text { - Renal failure } \\
\text { - Advanced liver disease drugs: dapsone; trimethoprim/sulfamethoxazole } \\
\text { - Vitamin E ingestion } \\
\text { - Ribavirin and interferon alpha } \\
\text { - Erythrocyte transfusion }\end{array}$ \\
\hline $\begin{array}{l}\text { Apparent increase or } \\
\text { decrease }\end{array}$ & $\begin{array}{l}\cdot \text { Haemoglobin variants } \\
\cdot \text { Vitamin C ingestion }\end{array}$ \\
\hline
\end{tabular}

${ }^{\text {a }}$ Variability within races is greater than variability between races [293] of indicating when a specific glucose level is reached as well as for trends in glucose levels. Early is-CGM devices did not have these alerts but increasingly include them. In the near future, these sensors and others in development will increasingly connect to other devices, including connected insulin pens. All currently available devices can be uploaded to an internet cloud to allow people with diabetes and healthcare professionals to easily view the data at or between clinic visits. CGMs report a reading every $1-15 \mathrm{~min}$.

rt-CGM is effective for adults with type 1 diabetes in improving $\mathrm{HbA}_{1 \mathrm{c}}$ (particularly when high) and reducing hypoglycaemia for both those using insulin pumps or multiple daily injections (MDI) [42-44, 76]. RCTs of the original isCGM devices are more mixed but observational data are supportive of their use. However, switching from is-CGM without alarms to rt-CGM improved TIR and $\mathrm{HbA}_{1 \mathrm{c}}$ and reduced Level 3 hypoglycaemia [77]. rt-CGM is beneficial in reducing the burden of hypoglycaemia in older adults with type 1 diabetes [78] and those with IAH [44]. Most people with type 1 diabetes can benefit from this technology with appropriate initial and ongoing education, including frequent observation of the glucose trends. The choice of the device should be based on individual preferences and circumstances.

Some people may not find CGM valuable as they may feel that they do not require it or find it stressful because they dislike being 'attached to a device', being constantly reminded of their diabetes or feeling exhausted by alarms (alarm fatigue). Cost considerations can also play a role.

Retrospective analysis of CGM data can guide and enhance therapeutic decision-making, patient understanding and engagement in adjusting behaviours. Standardised glucose reports with visual cues, such as the ambulatory glucose profile (AGP) and daily tracings, should be available for all CGM devices (Text box: Standardised CGM metrics for clinical care; Fig. 2) [79, 80].

Although healthcare professionals should regularly access and review CGM data as part of clinical management, people with type 1 diabetes should be encouraged to review their own reports regularly and follow their progress over time, contacting their healthcare professional as needed for worsening or changing trends.

People with type 1 diabetes should be warned that contact dermatitis (both irritant and allergic) may occur with all CGM devices that attach to the skin [81-83]. In some instances, the use of an implanted sensor can help avoid skin reactions in those who are sensitive to tape $[84,85]$.

\section{Ketone measurement}

Ketone bodies are produced when insulin concentrations are too low to prevent lipolysis. If left untreated, ketosis can lead to progressive dehydration and DKA. Measurement of ketones is 


\section{Standardised CGM metrics for clinical care}

- Number of days CGM device is worn: - recommend 14 days

- Percentage of time CGM device is active: o recommend $70 \%$ of data from 14 days

- Mean glucose

- GMI

- Glycaemic variability (\%CV)

- Time above range

- Per cent of readings and time $>13.9 \mathrm{mmol} / \mathrm{l}$ (>250 mg/dl); Level 2 hyperglycaemia

- Per cent of readings and time $>10.0 \mathrm{mmol} / \mathrm{l}$ (>180 mg/dl); Level 1 and Level 2 hyperglycaemia

- TIR

- Per cent of readings and TIR 3.9-10.0 $\mathrm{mmol} / \mathrm{l}(70-180 \mathrm{mg} / \mathrm{dl})$

- TBR

- Per cent of readings and time $<3.9 \mathrm{mmol} / \mathrm{l}$ ( $<70 \mathrm{mg} / \mathrm{dl}$ ); Level 1 and Level 2 hypoglycaemia

- Per cent of readings and time $<3.0 \mathrm{mmol} / \mathrm{l}$ (<54 mg/dl); Level 2 hypoglycaemia

Copyright: ADA, adapted from [47]. Copyright and all rights reserved. Material from this publication has been used with the permission of American Diabetes Association.

important during periods of illness or hyperglycaemia to facilitate the management of the hyperglycaemia and prevent and/or treat DKA.

Ketone bodies may be measured in blood or urine. Urine testing, the traditional method, detects acetoacetate, but not $\beta$ hydroxybutyrate, which is measured in blood testing. This means that urine testing may give a falsely low estimate of ketosis. Furthermore, after an episode of ketoacidosis, measurement of blood ketones provides a more accurate assessment of adequate treatment as urine tests may continue to be positive for $48 \mathrm{~h}$ as acetone leaks from fat tissue after ketogenesis and lipolysis have stopped. Modern technology allows the rapid and accurate measurement of ketones from a finger prick blood sample using a strip and meter. Blood ketone measurement is the method of choice and so adults with type 1 diabetes should be offered blood ketone testing strips and a meter [86]. Blood and urine ketone testing is not available in all countries and settings.

\section{Section 7: Insulin therapy}

The ideal regimen of insulin replacement maintains blood glucose in the normal physiological range, as far as possible, while allowing flexibility in terms of mealtimes and activity levels. Typical insulin replacement regimens incorporate several components: basal insulin to restrain gluconeogenesis and ketogenesis in the preprandial state; mealtime insulin to cover the intake of carbohydrate and other macronutrients; and correction insulin to treat hyperglycaemia.

\section{Choice of regimen}

Most people with type 1 diabetes should use regimens that mimic physiology as closely as possible, irrespective of the presentation. This is best achieved with either MDI of subcutaneous basal insulin analogues and mealtime rapid-acting or ultra-rapid-acting insulin analogues, or with continuous subcutaneous insulin infusion of a rapid-acting insulin analogue via a pump, delivered as continuous basal insulin combined with manual mealtime boluses. In the USA, inhaled human insulin is an alternative to subcutaneous rapid-acting analogues [3]. Although first-generation basal analogues and NPH insulin are frequently administered once a day, greater flexibility and better coverage of basal insulin needs may be obtained if they are administered twice daily. Trials have demonstrated that the latest basal analogues may cause less hypoglycaemia than first-generation basal analogues and NPH insulin, while rapid-acting analogues achieve better mealtime coverage and less post-meal hypoglycaemia than short-acting (regular) human insulin [87, 88]. Insulin analogues are, therefore, considered the insulins of choice.

Ultra-rapid analogues have a slightly earlier time of onset and peak action than rapid-acting analogues. These insulins reduce postprandial hyperglycaemia but have otherwise not been shown to reduce $\mathrm{HbA}_{1 \mathrm{c}}$ or hypoglycaemia to a greater extent than rapid-acting analogues [3]. Currently, recombinant human insulin or analogues of human insulin account for the vast majority of insulin used worldwide.

$\mathrm{HbA}_{1 \mathrm{c}}$, TIR, and TBR are improved further when physiological MDI or pump regimens are augmented with CGM usage [89], with the greatest benefits seen with algorithmdriven automated basal (and in some systems correction) insulin delivery, which is commonly called hybrid closed-loop therapy [90, 91].

Despite these advantages, the costs of insulin analogues and CGM or pump therapy are barriers for some people, while others do not wish to wear a device or inject multiple times per day. In these cases, subcutaneous regimens of human short- 


\section{Representative relative attributes of insulin delivery approaches in people with type 1 diabetes $^{1}$}

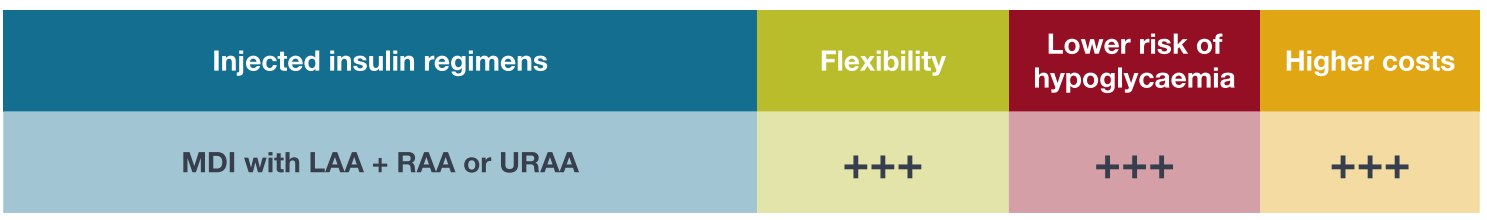

Less-preferred, alternative injected insulin regimens

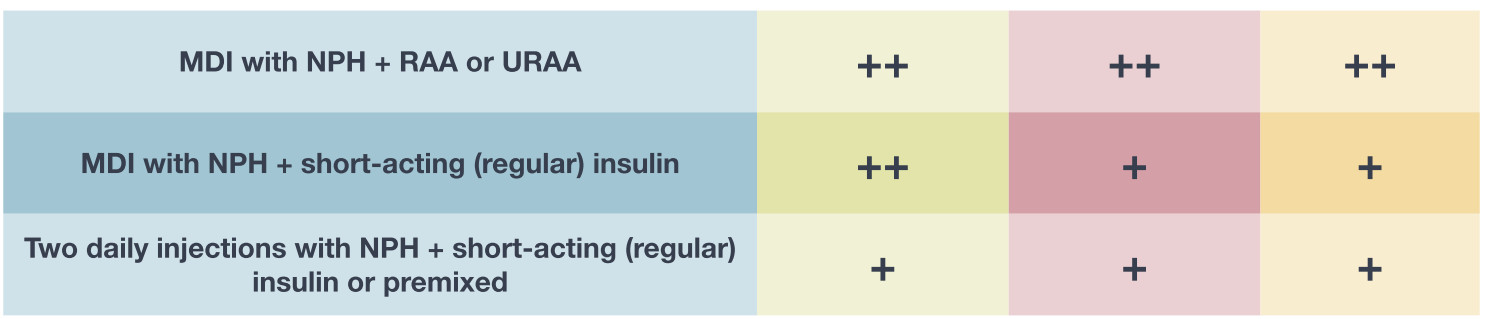

\section{Continuous insulin infusion regimens \\ Hybrid closed-loop technology \\ Insulin pump with threshold/ \\ predictive low-glucose suspend \\ Insulin pump therapy without automation}

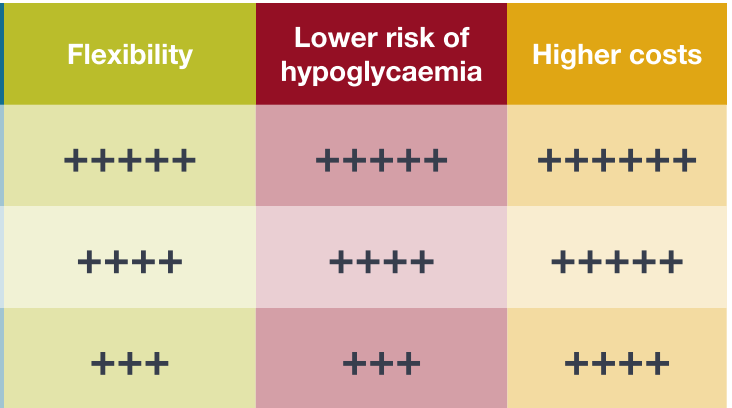

association of the regimen with increased flexibility, lower risk of hypoglycaemia and higher costs between the considered regimens. LAA, long-acting insulin analogue; RAA, rapid-acting insulin analogue; URAA: ultra-rapid-acting insulin analogue

Smaller gauge and shorter needles provide almost painless injections. Contrary to common wisdom, skin thickness is not significantly increased in individuals who have overweight or obesity. Needles as short as $4 \mathrm{~mm}$, injected at a $90^{\circ}$ angle, enter the subcutaneous space with minimal risk of intramuscular injection in most adults [92]. The use of longer needles increases the risk of intramuscular injection. MDI regimens may be enhanced with emerging technology, such as bolus calculators and memory-enabled pens that keep track of insulin doses.

Different insulin pumps for subcutaneous insulin delivery are available in many countries. The primary mechanical differences between pumps are whether they utilise external tubing to connect to an infusion set or a pod directly applied to the skin and controlled via a wireless connection to a controller. Current pumps include bolus calculators programmed with personalised insulin:carbohydrate ratio and correction factors. 


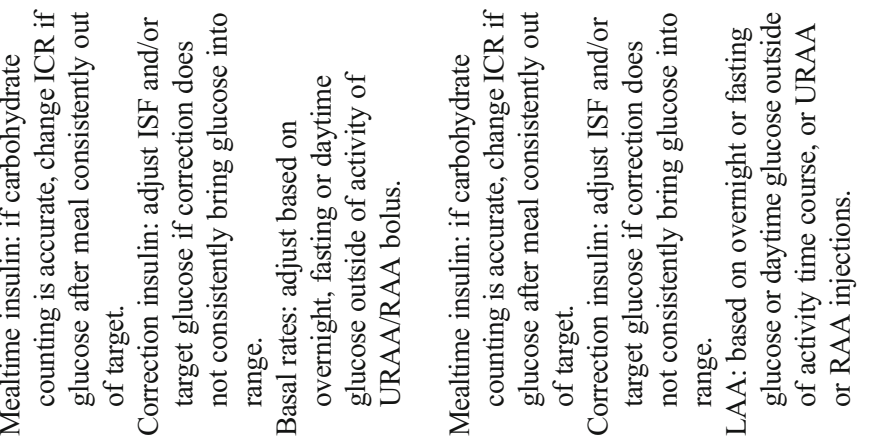

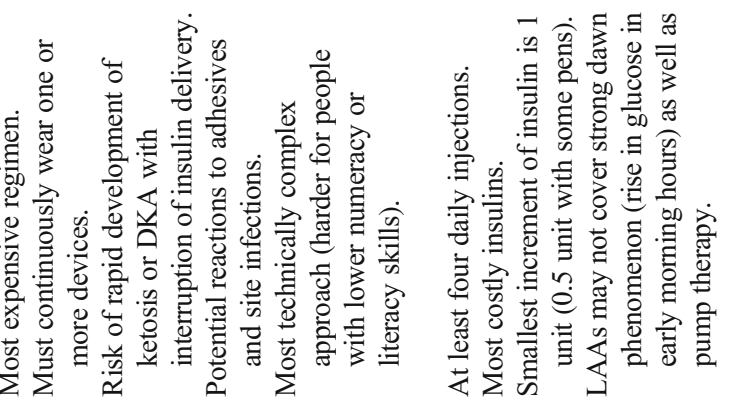

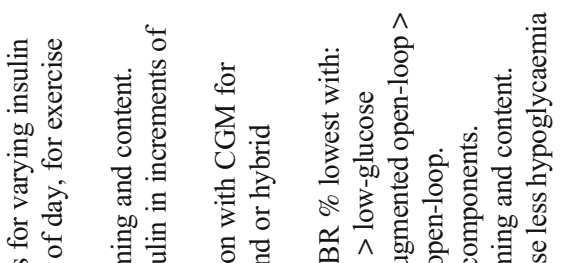

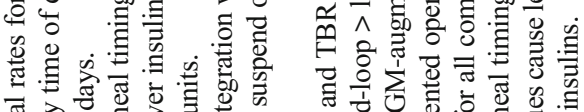

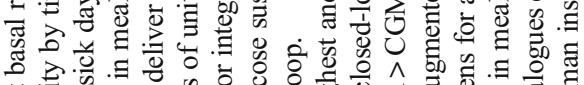

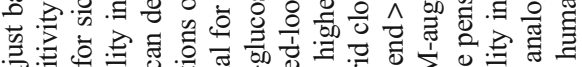

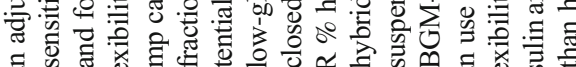

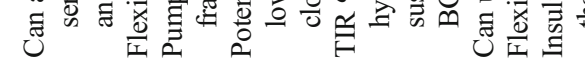

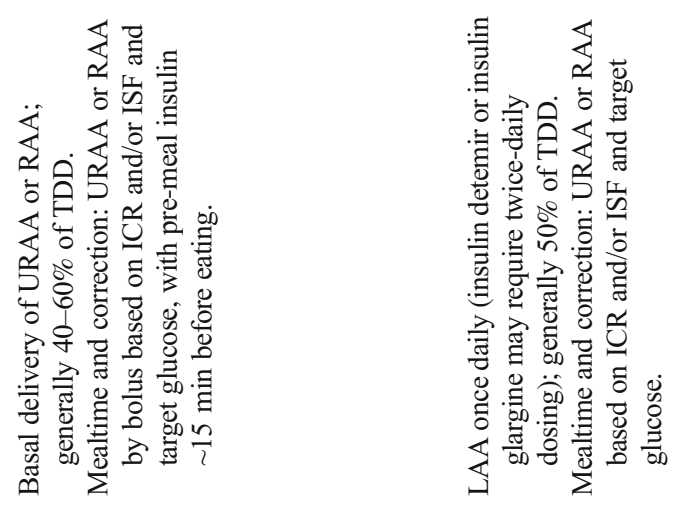

$\frac{0}{\frac{0}{0}}$

要

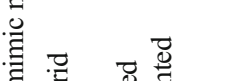

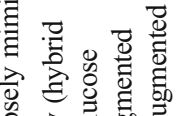

过

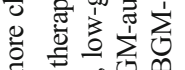

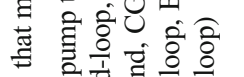

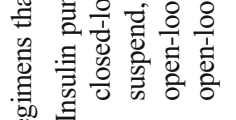

$\stackrel{\infty}{\check{2}} \Xi$

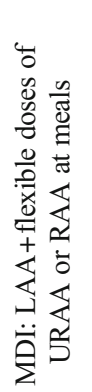

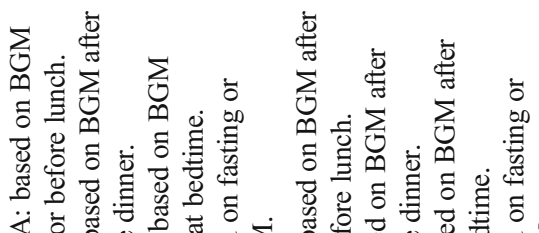

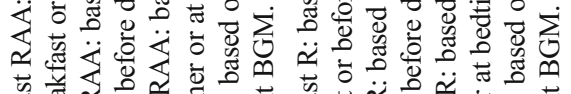

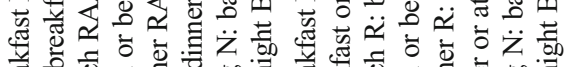

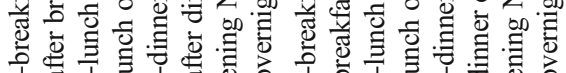

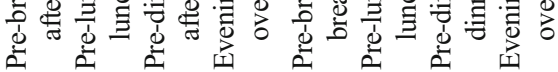

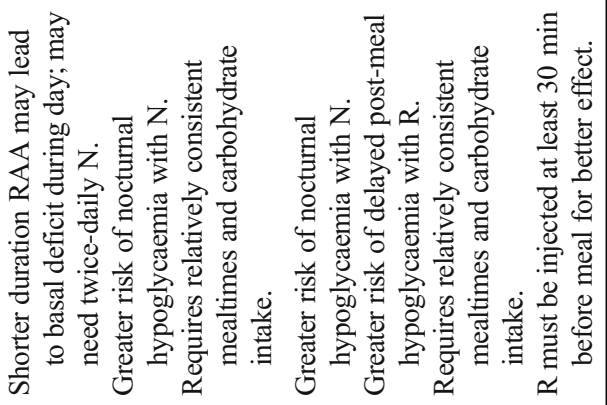
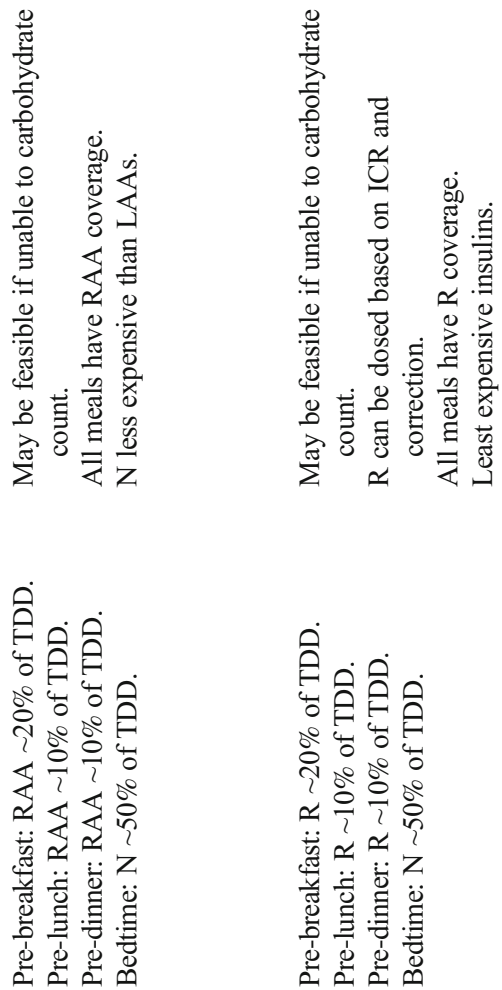


$$
\frac{4}{m}
$$


Hybrid closed-loop systems comprise an insulin pump, continuous glucose sensor and a control algorithm. The algorithm controls basal insulin delivery and, in some cases, correction boluses, based on CGM data, while the user still boluses manually for meals [90, 91].

Some people with type 1 diabetes are using 'do-it-yourself', user-driven, open-source artificial insulin delivery systems, which use commercially available CGM systems and pumps, with software algorithms that communicate with both and can reverse-engineer the pump control of basal and corrective doses [93]. Regulatory bodies do not allow healthcare professionals to prescribe these systems, but healthcare professionals should respect an individual's right to make informed choices about their care and continue to offer support to the people using these systems.

Fully closed-loop automated insulin delivery systems are currently being evaluated in clinical trials being conducted by several collaborative groups in both North America and Europe [94]. The expectation is that some of these will receive regulatory approval in the next few years. This should allow people with type 1 diabetes to achieve better glucose management with minimal risk of hypoglycaemia. Bi-hormonal (insulin and glucagon) automated insulin delivery systems are under investigation and could also contribute to the optimisation of glucose management. This is a rapidly evolving area, and readers may wish to keep abreast by referring to the 'Technology' section of the ADA Standards of Care, which is a living document that is updated frequently [53].

\section{Adverse effects}

The main adverse effect associated with insulin therapy is hypoglycaemia, which is discussed in the next section. The safety and efficacy of insulin therapy is closely related to glucose monitoring and insulin dose adjustments made by the individual with diabetes or, more recently, made automatically through control algorithms. Therefore, education in the management of insulin doses is a crucial component of this therapy, both at initiation and during follow-up. This education includes rescue strategies in case of hyperglycaemic or hypoglycaemic deviations, including the measurement of urine or blood ketone bodies or the prescription of carbohydrate intake and glucagon, respectively.

Insulin causes body weight gain and can lead to some people with type 1 diabetes reducing their insulin doses. Clinicians should review such weight concerns related to insulin and discuss strategies to avoid undesirable weight gain.

Skin reactions to subcutaneous insulin therapy include local inflammation (often due to the $\mathrm{pH}$ of or additives to the insulin), insulin-induced lipoatrophy and insulin-induced lipohypertrophy. Lipoatrophy has become rare as the purity of manufacture of human and analogue insulin has improved.
Lipohypertrophy is common and typically occurs when the same sites are repeatedly used for injections or pump sites; it leads to use of higher insulin doses and is a cause of glycaemic variability, leading to both hyper- and hypoglycaemia [95, 96]. People with type 1 diabetes should receive instructions about proper injection technique, including regular site rotation and skin examination, at the time of insulin initiation, with periodic reminders thereafter. Clinicians should inspect and palpate injection and infusion sites at least annually.

As described above for CGM devices, individuals should be warned about possible skin reactions to pump adhesives.

\section{Alternative routes of administration}

Although subcutaneous insulin therapy has been the mainstay of treatment for almost a century, this mode does not mimic physiological insulin secretion well. Healthy beta cells secrete a burst of insulin into the portal circulation at the onset of glucose intake, with approximately $70 \%$ of the insulin cleared by the liver and not entering the systemic circulation, whereas subcutaneous insulin enters the systemic circulation with some delay and is removed relatively slowly. Inhaled human insulin, available only in the USA, has a very rapid onset of action and short duration compared with subcutaneous rapidacting analogues [3]. Inhaled insulin ameliorates early postprandial hyperglycaemia well, but its short duration of action results in less control of later postprandial hyperglycaemia. Additionally, inhaled insulin can cause cough or sore throat, and therapy must be monitored with periodic spirometry because of possible effects on lung function [97].

Peritoneal delivery of human short-acting (regular) insulin, with rapid transit to the portal system, can be accomplished with implantable insulin pumps or through a port connected to an intraperitoneal catheter (available only in some countries in Europe at considerable cost). Compared with subcutaneous insulin regimens, intraperitoneal insulin infusion reduces $\mathrm{HbA}_{1 \mathrm{c}}$, glycaemic variability and hypoglycaemia $[98,99]$. Insulin aggregation, local infections and catheter occlusions are reported complications of the devices used for this route of insulin delivery. In some individuals, an increased production of anti-insulin antibodies has been observed while using this route of insulin delivery. The effect on glucose levels is variable, ranging from no effect to marked glucose swings according to the binding affinity of the antibodies to insulin.

\section{Section 8: Hypoglycaemia}

Hypoglycaemia is the main limiting factor in the glycaemic management of type 1 diabetes. Hypoglycaemia is classified into three levels: 
- Level 1 corresponds to a glucose value below $3.9 \mathrm{mmol} / 1$ $(70 \mathrm{mg} / \mathrm{dl})$ and greater than or equal to $3.0 \mathrm{mmol} / 1(54 \mathrm{mg} /$ $\mathrm{dl}$ ) and is named as an alert value.

- Level 2 is for glucose values below $3.0 \mathrm{mmol} / \mathrm{l}(54 \mathrm{mg} / \mathrm{dl})$ and considered clinically important hypoglycaemia.

- Level 3 designates any hypoglycaemia characterised by altered mental state and/or physical status needing the intervention of a third party for recovery [100].

Although these were originally developed for clinical trials reporting, they are useful clinical constructs. Particular attention should be made to prevent Level 2 and 3 hypoglycaemia.

Level 1 hypoglycaemia is common, with most people with type 1 diabetes experiencing several episodes per week. Hypoglycaemia with glucose levels below $3.0 \mathrm{mmol} / 1$ $(54 \mathrm{mg} / \mathrm{dl})$ occurs much more often than previously appreciated [46, 101]. Level 3 hypoglycaemia is less common but occurred in $12 \%$ of adults with type 1 diabetes over a 6 month period in a recent global observational analysis [102]. Several studies have shown that rates of hypoglycaemia have not declined, even with more widespread use of insulin analogues and CGM, while other studies have shown benefit with these therapeutic advances [41].

Risks for hypoglycaemia, particularly Level 3 hypoglycaemia, include longer duration of diabetes, older age, history of recent Level 3 hypoglycaemia, alcohol ingestion, exercise, lower education levels, lower household incomes [41], chronic kidney disease and IAH [103-105]. Endocrine conditions, such as hypothyroidism, adrenal and growth hormone deficiency and coeliac disease may precipitate hypoglycaemia. Older diabetes databases consistently documented that people with lower $\mathrm{HbA}_{1 \mathrm{c}}$ levels had 2-3fold higher rates of Level 3 hypoglycaemia. However, in the Type 1 Diabetes Exchange Clinic Registry, the risk of Level 3 hypoglycaemia was increased not only in those whose $\mathrm{HbA}_{1 \mathrm{c}}$ was below $7.0 \%(53 \mathrm{mmol} / \mathrm{mol})$, but also in people with an $\mathrm{HbA}_{1 \mathrm{c}}$ above $7.5 \%$ (58 mmol/mol) [41].

It is possible that the absence of a relationship between $\mathrm{HbA}_{1 \mathrm{c}}$ and Level 3 hypoglycaemia in real-world settings is explained by relaxation of glycaemic targets by those with a history of hypoglycaemia, or confounders, such as inadequate self-management behaviours that contribute to both hyperand hypoglycaemia. A secondary analysis of the IN CONTROL trial, where the primary analysis showed a reduction in Level 3 hypoglycaemia in people using CGM, demonstrated an increase in the rate of Level 3 hypoglycaemia with lower $\mathrm{HbA}_{1 \mathrm{c}}$, similar to what was reported in the DCCT [106]. This implies that lowering $\mathrm{HbA}_{1 \mathrm{c}}$ may still come with a higher risk of Level 3 hypoglycaemia.

Mortality from hypoglycaemia in type 1 diabetes is not trivial. One recent trial noted more than $8 \%$ of deaths for those younger than 56 years were from hypoglycaemia [107]. The mechanism for this is complex, including cardiac arrhythmias, activation of both the coagulation system and inflammation and endothelial dysfunction [108]. What may not be as well recognised is that Level 3 hypoglycaemia is also associated with major microvascular events, non-cardiovascular disease and death from any cause, although much of this evidence is obtained from people with type 2 diabetes [108]. With regard to cognitive function, in the DCCT and EDIC study, after 18 years of follow-up, severe hypoglycaemia in middle-aged adults did not appear to affect neurocognitive function [109]. However, independent of other risk factors and comorbidities, more episodes of severe hypoglycaemia were associated with greater decrements in psychomotor and mental efficiency that were most notable after 32 years of follow-up [110]. It appears that older adults with type 1 diabetes are more prone to mild cognitive impairment associated with hypoglycaemia [110, 111], while hypoglycaemia occurs more frequently in those with cognitive impairment. CGM data were not available in the DCCT era and so the true extent of serious hypoglycaemia over time is not known.

\section{Impaired awareness of hypoglycaemia}

IAH is the reduced ability to recognise low blood glucose levels that would otherwise prompt an appropriate corrective therapy [112]. Its prevalence is estimated to be close to $25 \%$ in people with type 1 diabetes but is likely to be underestimated according to CGM data [113]. IAH increases the risk of Level 3 hypoglycaemia by sixfold [114] and may lead to the person with diabetes omitting insulin injections intentionally or loosening tight glucose management to prevent their occurrence.

The pathophysiology of IAH is still not fully understood but includes a partial or total loss of sympathoadrenal reactions to hypoglycaemia that prevent catecholaminergic stimulation of hepatic glucose output and restraint of muscle glucose uptake [104]. The connections between autonomic neuropathy and IAH are complex since both the defect of sympathoadrenal reaction to hypoglycaemia can be a component of autonomic neuropathy and hypoglycaemia itself can promote neuropathy. Indeed, recurrent hypoglycaemia is a major cause of IAH. Sleep disturbance, psychological stress and alcohol can also induce IAH [112].

In clinical practice, physicians should be proactive in asking people with type 1 diabetes whether, and at which glucose level, they feel hypoglycaemia in order to identify IAH and adjust individual glucose targets to prevent the occurrence of Level 3 hypoglycaemia. The reference method to assess IAH is the hyperinsulinaemic-hypoglycaemic clamp [115], although this is not used out of a research frame due to its invasiveness, cost and time commitment from people with diabetes. Self-reported awareness, however, agrees well with the autonomic glucose threshold [116]. The Gold questionnaire and Clarke questionnaire, showing a score equal or above 4 are indicative of IAH [114, 117], and the PedersenBjergaard et al questionnaire and Hypoglycaemia Awareness 
Questionnaire (HypoA-Q) can also identify IAH [118, 119]. Another good test for hypoglycaemia awareness is to ask, 'Do your symptoms of hypoglycaemia usually occur at a blood glucose level of $\geq 3.0 \mathrm{mmol} / 1(\geq 54 \mathrm{mg} / \mathrm{dl})$ or $<3.0 \mathrm{mmol} / 1$ ( $<54 \mathrm{mg} / \mathrm{dl}$ ) or do you not feel symptoms?' Those responding, 'less than $3.0 \mathrm{mmol} / \mathrm{l}(54 \mathrm{mg} / \mathrm{dl})$ ' or not experiencing symptoms have a $>4$-fold increased risk of Level 3 hypoglycaemia [120]. The UK National Institute for Health and Care Excellence recommended for the first time that an assessment of hypoglycaemia, including awareness, should form part of clinical consultations [86].

\section{Prevention of hypoglycaemia}

Hypoglycaemia is not inevitable and several strategies can be used to reduce the risk [121]. Structured education programmes, such as Dose Adjustment For Normal Eating (DAFNE) and blood glucose awareness training (BGAT), which provide informed support for active insulin dose selfadjustment, are the key to the prevention of hypoglycaemia and lead to sustained falls in Level 3 hypoglycaemia rates in those at high risk $[122,123]$. The use of insulin analogue regimens are associated with less hypoglycaemia, while hybrid closed-loop systems result in both improvement in TIR and reduction in TBR [91].

Strict avoidance of hypoglycaemia can help to restore hypoglycaemia awareness [124]. Structured diabetes education in flexible insulin therapy, which may incorporate psychotherapeutic and behavioural therapies, progressing to diabetes technology, incorporating sensors and insulin pumps, are effective treatments in those with persisting need [125]. CGM use promotes the identification of current or impending low glucose levels that people may not feel. BGAT, education to optimise insulin dosing and type, and hypoglycaemia avoidance motivational programmes all improve hypoglycaemia awareness. In some situations, it may be necessary to increase the glucose target range [124, 126]. Several clinical trials have not shown a reduction of IAH by using CGM despite a reduced incidence of Level 3 hypoglycaemia [101, 112, 124, 126-128].

\section{Treatment of hypoglycaemia}

The recommended correction of hypoglycaemia is the oral intake of approximately $15 \mathrm{~g}$ of glucose or equivalent simple carbohydrate when a capillary blood glucose level is $<3.9 \mathrm{mmol} / 1 \quad(<70 \mathrm{mg} / \mathrm{dl})$ [129]. This should be repeated every $15 \mathrm{~min}$ until any symptoms have resolved and the blood glucose level is above $3.9 \mathrm{mmol} / 1(70 \mathrm{mg} / \mathrm{dl})$. A larger amount of glucose may be needed if glucose levels are below $3.0 \mathrm{mmol} / 1$ $(54 \mathrm{mg} / \mathrm{dl})$. Lower carbohydrate intakes can be used when symptoms are associated with a capillary blood glucose level above $3.9 \mathrm{mmol} / \mathrm{l}(70 \mathrm{mg} / \mathrm{dl})$. As there may be a 5-15 min lag between changes in capillary blood glucose and interstitial glucose, the restoration of normoglycaemia may not be detected by CGM straight away. The use of capillary glucose measurement is recommended to prevent over-treatment of the hypoglycaemia.

The specific recommendations for correction of hypoglycaemia or trends for hypoglycaemia according to CGM in people using automated insulin delivery systems will have to be defined as this mode of therapy expands in forthcoming years. Less carbohydrate (5-15 g) may need to be ingested to correct hypoglycaemia because the automated insulin delivery system should have already reduced or stopped basal insulin delivery [130].

Where there is a reduced level of consciousness, oral glucose intake is contraindicated because of risk for aspiration. Instead, glucagon via subcutaneous or intramuscular injection or nasal delivery should be given by attending people. Intravenous glucose injection is a possible alternative for healthcare professionals in cases of Level 3 hypoglycaemia.

After the acute symptoms have resolved, a further $20 \mathrm{~g}$ of long-acting carbohydrate as part of a snack or meal should be given and the cause of the hypoglycaemic episode sought to prevent further episodes.

\section{Goal of nutrition therapy for} type 1 diabetes

- Promote healthy eating patterns, emphasising a variety of nutrient-dense foods in appropriate sizes to improve overall health and to:

- Improve $\mathrm{HbA}_{1 \mathrm{c}}$, blood pressure and cholesterol and aid in maintaining weight

- Individualise nutrition needs based on personal and cultural preferences, health literacy and access to healthy food choices

- Provide practical tools for day-to-day meal planning

- Focus on matching insulin doses with meal composition through advanced carbohydrate counting

Information from [134]. 


\section{Section 9: Additional behavioural considerations}

\section{Nutrition therapy}

Nutrition, in particular carbohydrate intake, has a major effect on blood glucose levels, and people with type 1 diabetes need to understand the effect of food on their diabetes and plan meals accordingly (see Text box: Goal of nutrition therapy for type 1 diabetes). People with type 1 diabetes should be referred for individualised medical nutrition therapy provided by a registered dietitian who is knowledgeable and skilled in providing diabetes-specific nutritional advice in conjunction with the diabetes technology being used. Medical nutrition therapy delivered by a registered dietitian is associated with a reduction in $\mathrm{HbA}_{1 \mathrm{c}}$ of $1.0-1.9 \%(11-21 \mathrm{mmol} / \mathrm{mol})$ for people with sub-optimally managed type 1 diabetes when integrated into an overall management programme [131].

There is no one eating pattern recommended for people with type 1 diabetes. The nutrition approach should be individualised based on personal preferences, socioeconomic status, cultural backgrounds and comorbidities. Carbohydrate counting is the most common meal planning approach in type 1 diabetes. In conjunction with promoting healthy eating patterns, carbohydrate counting and insulin:carbohydrate ratios can be a useful method for adjusting mealtime insulin dosing for optimal glycaemic outcomes [132, 133]. While low-carbohydrate and verylow-carbohydrate eating patterns have become increasingly popular and reduce $\mathrm{HbA}_{1 \mathrm{c}}$ levels in the short term, it is important to incorporate these in conjunction with healthy eating guidelines. Additional components of the meal, including high fat and/or high protein, may contribute to delayed hyperglycaemia and the need for insulin dose adjustments. Since this is highly variable between individuals, postprandial glucose measurements for up to $3 \mathrm{~h}$ or more may be needed to determine initial dose adjustments [134].

The average BMI of individuals with type 1 diabetes is rising at a faster rate than the general population, partly as a result of insulin intensification and societal factors that also affect the general population, such as physical inactivity. Weight loss and maintenance interventions involving nutritional advice and physical activity should be offered to individuals with type 1 diabetes who have overweight or obesity, in conjunction with other DSMES topics. New interactive technologies using mobile phones to provide information, insulin bolus calculations based on insulin:carbohydrate ratios and telemedicine communications with care providers may be used to aid in reducing both weight gain and the time required for education [65]. In the case of extreme low weight, unhealthy eating habits should be reviewed, including the possibility of insulin omission.

\section{Alcohol and recreational drug use}

Similar to the general population, many individuals with type 1 diabetes consume alcohol, although its effects on glycaemic management are not always adequately considered by those with diabetes and their healthcare professionals. Increased alcohol consumption is associated with a higher risk of DKA and Level 3 hypoglycaemia [135]. Some of this increase may occur through the association with other risk-taking behaviour. However, excessive alcohol consumption impairs cognitive function and symptom awareness, leading to a diminished ability to self-manage the diabetes. Alcohol promotes ketosis, which in the context of consumption of sugary alcoholic beverages, may increase the risk of DKA [136]. Alcohol also inhibits hepatic gluconeogenesis, leading to an increased risk of hypoglycaemia for up to $24 \mathrm{~h}$ after the last drink [137]. Hypoglycaemia is particularly hazardous because of the potential to confuse the symptoms of hypoglycaemia with alcohol intoxication.

Cannabis has been legalised in multiple jurisdictions. An association between recent recreational cannabis consumption and a more than twofold increased risk of DKA has been reported from countries where cannabis has been legalised, possibly related to the emergence of higher potency formulations of cannabis and other synthetic cannabinoids [138]. Use of cocaine and other stimulant-like drugs, such as amfetamine, methamfetamine and ecstasy (or 3,4-methylenedioxymethamfetamine [MDMA]), increase glucose production and inhibit glucose clearance, which increases the risk of DKA. Having a diagnosis of a substance use disorder confers an increased all-cause mortality in populations with diabetes across a range of substances, including cocaine, opioids and cannabis, regardless of consumption.

As many people are unlikely to spontaneously report their alcohol or drug use to clinicians, systematic screening for excess alcohol and/or drug use is recommended [139]. Healthcare professionals have a responsibility to inform people with type 1 diabetes about the effects of drugs and alcohol on diabetes and related risks, otherwise people with diabetes will seek information elsewhere, which is frequently incorrect and misleading [140]. Brief interventions to reduce risky drinking and drug use have been well validated in a variety of populations and offer the potential to improve diabetes medication taking and outcome [141]. In the case of alcohol or drug addiction, referral to a specialised clinic is warranted.

\section{Smoking}

Since smoking increases the risk of macrovascular and microvascular complications in people with diabetes, smoking cessation should be promoted and supported in all individuals with type 1 diabetes. The direct effect of smoking on blood 
glucose levels in people with diabetes needs more research to assess the impact [142, 143].

\section{Physical activity}

People with type 1 diabetes should be encouraged to engage in a combination of aerobic and resistance exercise on most days because exercise is associated with improved fitness, increased insulin sensitivity, leading to reduced insulin requirement, improved cardiovascular health with better lipid profile and endothelial function, and decreased mortality [144-147]. Independent effects on beta cell function and $\mathrm{HbA}_{1 \mathrm{c}}$ have not been established beyond doubt but appear beneficial. In addition, regular physical activity is associated with reduced risk of microvascular complications, osteoporosis and cancer in people with type 1 diabetes [148]. Exercise also helps maintain a healthy BMI and promotes sleep quality and mental wellbeing.

It is important that physical activity is performed safely. The major risks are from the acute effects of exercise on glucose concentrations, which depend on several factors, including: the baseline fitness of the individual and type, intensity and the duration of activity; the amount of insulin in the circulation; the blood glucose concentration before exercise; and the composition of the last meal or snack. People with type 1 diabetes should be taught about the effects of exercise on glucose levels and how to balance exogenous insulin delivery and carbohydrate intake for the different forms and intensities of exercise.

Glycaemic management during exercise should be made safer with CGM systems. The updated consensus statement for management of exercise in type 1 diabetes highlights very detailed suggestions regarding the use of trend arrows and adjustment of insulin doses and carbohydrate intake [149].

When discussing the importance of exercise, consideration of cardiovascular and lower extremity comorbid conditions is critical. Advice should be given about appropriate footwear and foot inspection for those with peripheral neuropathy to avoid the risk of ulceration. However, walking does not increase the risk of ulceration in people with peripheral neuropathy [150]. Weight-bearing exercise should be avoided in active foot disease. If an individual has proliferative diabetic retinopathy or severe non-proliferative diabetic retinopathy, then vigorous activity requiring straining may be contraindicated because of the risk of vitreous haemorrhage or retinal detachment [151]. The individual should be advised to consult an ophthalmologist prior to engaging in an intense exercise regimen.

Additional details regarding the diabetes management during physical activity or exercise have been described elsewhere [152]. When there is excessive physical exercise combined with extreme low weight, an eating disorder should be considered.
Sleep

Proper sleep hygiene is essential for all individuals. Sleep may be disrupted in people with type 1 diabetes as a result of both behavioural and physiological aspects of diabetes and its management [153]. They may include hyper- and hypoglycaemic episodes, blood glucose variability and loss of blood pressure decline. However, studies performed so far have not determined causality. On the other hand, sleep disturbances including poor sleep quality and shorter sleep duration are associated with worsening glycaemic levels in type 1 diabetes [154, 155].

\section{Sick day/illness management}

Stressful events, including illness, may affect glucose levels and increase risk of DKA. More frequent glucose and ketone measurements are necessary to identify insulin adjustments. Individuals should devise a sick day management plan in consultation with their healthcare professional [156]. Examples of sick day protocols are available online [157, 158]. All recommend ingestion of adequate amounts of fluids and carbohydrates, as well as when to monitor glucose and ketone levels, give insulin and under what circumstances a person with diabetes should seek urgent medical care.

\section{Driving}

Unrecognised hypoglycaemia and rapidly dropping glucose levels are the most relevant hazards for drivers with type 1 diabetes. These risks may be reduced by the use of CGM or BGM prior to driving and at 2 hourly intervals. Local regulations and recommendations should be followed for driving with type 1 diabetes [159, 160]. In some countries, glucose meter downloads are essential to support applications for heavy goods and public service vehicle driving licenses. Safe driving practices should be discussed regularly with people who drive.

\section{Employment}

People with type 1 diabetes can successfully undertake a wide range of employment but there remains prejudice against those with diabetes that can limit employment opportunities. The main concerns are associated with the risks of acute hypoglycaemia as well as certain situations in which continued supply of effective insulin is not possible, for example working in very hot climates. Additionally, chronic diabetes complications may affect the ability to work in certain situations. For some occupations, any risk of hypoglycaemia is considered unacceptable, but efforts have been made to address these risks. For example, in some countries, people with type 1 diabetes are now working as commercial 
airline pilots. For this reason, any person with type 1 diabetes should be supported to undertake professional activity, job or employment for which they are otherwise qualified and can do safely [161]. Employment circumstances should allow the safe use and storage of insulin and unrestrained access to glucose monitoring and self-treatment of hyper- or hypoglycaemia.

\section{Travel}

Planning ahead is the key to safe and trouble-free travel for individuals with type 1 diabetes. This includes preparing diabetes-related and emergency supplies, which should be available at hand during the travel. A plan of adjusting insulin doses, especially when travelling across time zones, is essential to reduce glucose fluctuations [162]. In particular, it is important to consider the impact of change in usual schedule, hot weather, reduced stress and relaxation, and changes in exercise patterns on glucose levels while on holiday.

Depending on the locale of travel destinations, it may be advisable to research the estimated carbohydrate content of local foods to aid better insulin adjustment. Frequent glucose measurement with CGM or BGM is advisable for any travel [163]. Additionally, it may be helpful to have note cards written in the local language to communicate that the person has type 1 diabetes and may need urgent glucose administration if hypoglycaemic.

\section{Additional religious and cultural considerations}

Fasting for religious and cultural reasons is a widespread practice globally. Healthcare professionals should ask if the person with type 1 diabetes wishes to partake in fasting and provide guidance and support [164].

\section{Section 10: Psychosocial care}

Type 1 diabetes is a psychologically challenging chronic condition, with treatment outcomes highly dependent on the person's ongoing self-care behaviours. Cognitive, emotional and social factors are critical determinants of self-care behaviours and, consequently, treatment success $[165,166]$. Emotional health is an important focus and outcome of person-centred diabetes care [167].

\section{Psychosocial problems}

Diabetes-specific emotional distress affects $20-40 \%$ of people with type 1 diabetes and can be experienced at any point in time from early adulthood to older age. Two 'critical' times, however, are following the diagnosis and when complications develop [168]. Feeling powerless and overwhelmed by the daily self-care demands, fear of hypoglycaemia and worries about complications are among the most cited sources of distress by people with type 1 diabetes. Prolonged significant diabetes distress is associated with depressed mood and elevated $\mathrm{HbA}_{1 \mathrm{c}}$ levels [169].

Lack of social support or feeling 'policed' by family, friends or co-workers also evokes emotional distress in individuals with type 1 diabetes [170]. Conversely, social support is a protective factor, serving as a buffer against stress. Depression and anxiety symptoms are twice as prevalent among people with type 1 diabetes relative to people without diabetes, negatively impacting quality of life [171-173]. Anxiety and depression often co-exist and may partly overlap with symptoms of diabetes distress [174]. Psychological distress, including mild to major depression, is a risk factor for poor self-care, hyperglycaemia, complications and excess mortality [174-176]. The association between generalised anxiety and sub-optimal blood glucose levels is less clear [177, 178].

Given the high prevalence and impact of psychosocial problems and psychological disorders in diabetes, screening and monitoring should be integral parts of diabetes care, not least because these psychological comorbidities tend to negatively affect diabetes outcomes and vice versa. Validated screening tools that can help to 'flag' psychological problems that may require follow-up or referral to a mental health specialist have been developed for most problem areas and are available in multiple languages. Clinicians engaging in screening need to understand the psychological and social issues that may complicate diabetes management, have good communication skills and be able to refer to specialised mental health services where appropriate. Recently, a working group from the International Consortium for Health Outcomes Measurement (ICHOM) made recommendations for a standard set of practical and validated psychosocial measures [179], including the WHO-5 Wellbeing Index (WHO-5) [180], Problem Areas in Diabetes (PAID) scale [181], and Patient Health Questionnaire (PHQ-9) [182]. Completion of these three questionnaires takes approximately $7 \mathrm{~min}$ and can be scheduled prior to the visit, either online or in the waiting room. For generalised anxiety, the Generalized Anxiety Disorder 7-item (GAD-7) is recommended [183]. Brief screeners for depression (two items) [184], depression and anxiety (four items) [185] and diabetes distress (five or two items) $[186,187]$ are also available.

Fig. 7 Simplified overview of indications for beta cell replacement therapy in people with type 1 diabetes. The two main forms of beta cell replacement therapy are whole-pancreas transplantation or islet cell transplantation. Beta cell replacement therapy can be combined with kidney transplantation if the individual has end-stage renal disease, which may be performed simultaneously or after kidney transplantation. All decisions about transplantation must balance the surgical risk, metabolic need and the choice of the individual with diabetes 


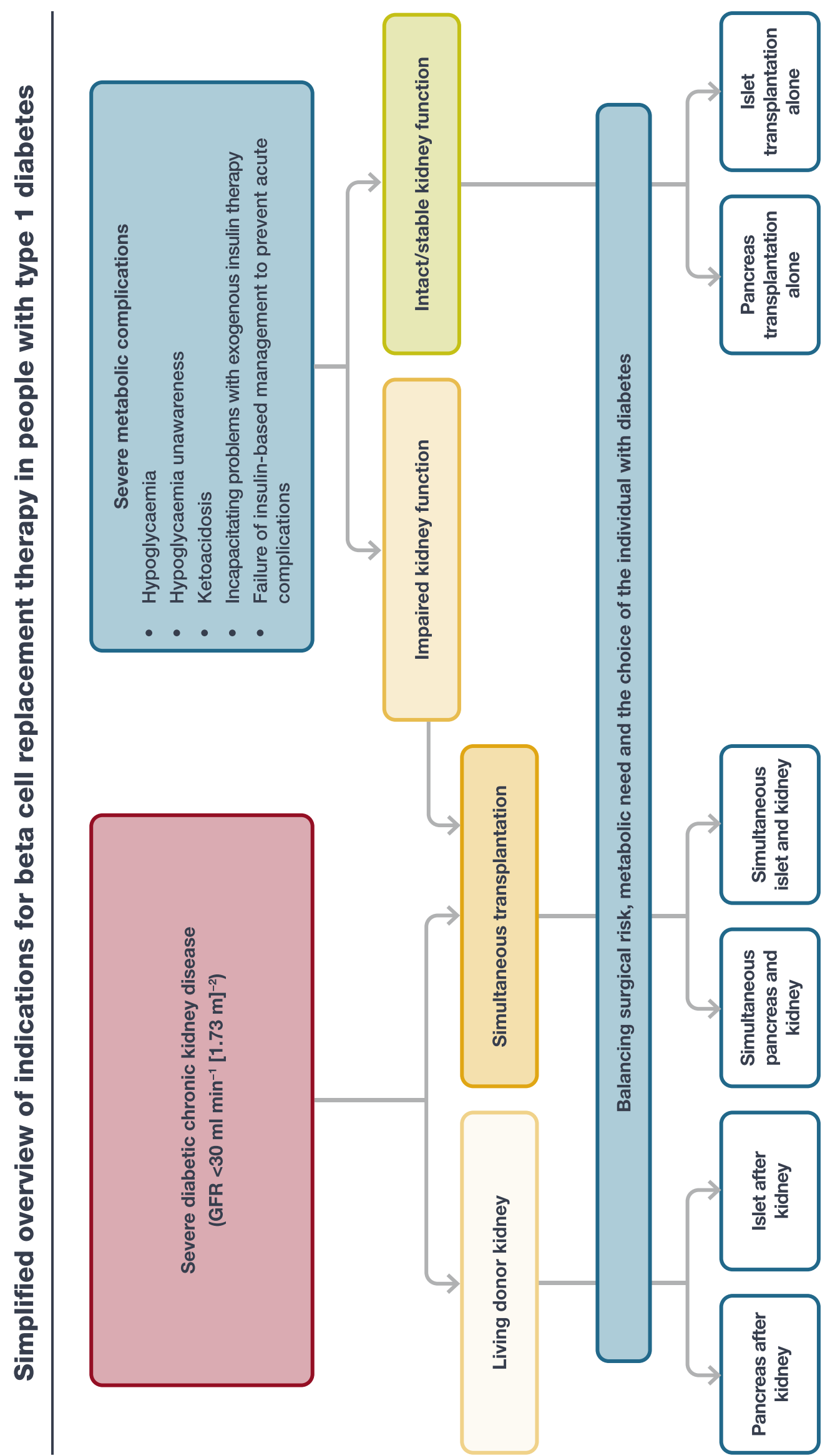


Assessment and periodic monitoring of emotional health, at least on an annual basis, is recommended to promote casefinding, emotional wellbeing and patient satisfaction with care $[188,189]$. This may require changes to current service provision, for example, inviting people with diabetes to complete standardised questionnaires prior to their consultation.

Fear of hypoglycaemia affects up to $10 \%$ of adults with type 1 diabetes, particularly among those experiencing repeated episodes of Level 3 hypoglycaemia [190]. Fear of hypoglycaemia may translate into avoidance behaviours aimed at keeping blood glucose at a 'safe' level, resulting in persistent hyperglycaemia [191]. In cases of problematic fear of hypoglycaemia, administering the Hypoglycemia Fear Survey (HFS) can help to identify specific worries and level of severity [192]. Both disproportional high and low fear of hypoglycaemia warrant attention.

Eating disorders, including anorexia nervosa, bulimia nervosa and binge eating, are over-represented in type 1 diabetes populations, particularly in young women [193, 194] but may also occur in men. Insulin omission as a weight-loss strategy ('diabulimia') often starting in teenage years warrants special attention [195, 196]. If indicated, screening for eating disorders is advised, using a validated instrument suited for use in people with type 1 diabetes, for example, the Diabetes Eating Problems Survey-Revised (DEPS-R) or Eating Disorders Inventory-3 Risk Composite (EDI-3RC) [197].

In case of a positive screen, offering a referral to specialised mental health services is recommended.

\section{Social determinants of health}

Social and financial hardships can negatively impact an individual's mental health, motivation, and capacity to engage in self-management practices, increasing the risk for elevated $\mathrm{HbA}_{1 \mathrm{c}}$ and complications. In a review of social determinants of health and diabetes [198], the importance of the following domains is discussed: (1) neighbourhood and physical environment (e.g. housing stability); (2) built environment (e.g. walkability, access to green spaces); (3) environmental exposures (e.g. pollution); (4) food access, availability and affordability; and (5) healthcare access, affordability and quality.

Socioeconomic challenges, particularly the inability to pay for food, insulin, other medications and supplies, need to be recognised and addressed. Several screening tools are available [199-204]. Sample questions that have been used include: How hard is it for you to pay for the very basics like food, housing, medical care, and heating? At any time since the last interview or in the last 2 years have you ended up taking less insulin than was prescribed for you because of cost? In the past 12 months has lack of transportation kept you from attending medical appointments or from getting insulin? The diabetes team should have access to a social worker and/or links to community resources to help those with these needs.

\section{Psychosocial interventions}

All members of the diabetes care team have a responsibility for providing psychosocial care as an integral component of diabetes care. Preferably, the diabetes care team should include a mental health professional (psychiatrist, psychologist and/or social worker) to advise the team and consult with people with diabetes in need of psychosocial support [205]. Three levels of psychosocial support can be distinguished and diabetes teams have an important role in all three levels.

At the first level, people living with type 1 diabetes do not require professional mental health care. They may engage in self-help programmes and/or receive informal coaching, as well as family, peer and community support to assist them in coping with the psychological demands of self-managing type 1 diabetes as well as socioeconomic challenges. At the second level, which concerns approximately one-quarter of individuals with type 1 diabetes, some degree of professional psychosocial support is warranted. Support for social needs can be provided by a social worker and/or community organisation. It is important that therapists have a good understanding of diabetes treatments and integrate diabetes management in the psychological treatment. Psychological therapies, including time-limited (online) cognitive behavioural therapy (CBT), mindfulness and interpersonal therapies are effective with regard to a range of psychological outcomes, including diabetes distress and depression. The effects of psychotherapy on glycaemic levels are generally small but tend to increase when diabetes self-management education is incorporated in the treatment [206]. Approximately 5\% of the adults with type 1 diabetes are in need of psychiatric treatment, the third level, which may involve psychotropic medication that can have an impact on glycaemic management. Psychiatric comorbidities, such as anorexia nervosa and schizophrenia, require close collaboration between the mental health specialist and diabetes care team [207, 208].

\section{Section 11: Diabetic ketoacidosis}

DKA is a life-threatening but preventable acute complication of type 1 diabetes, characterised by hyperglycaemia, metabolic acidosis and ketosis. There are times when the glucose levels are normal or only minimally elevated. The underlying cause is insulin deficiency, either absolute (new diagnosis of type 1 diabetes or omission of insulin in those with diagnosed disease) or relative (increased counter-regulatory hormones due to infection or other stressors without an adequate increase in insulin doses). 
The prevalence of DKA and risk factors for the complication have been less-well studied in adults with type 1 diabetes than in children. In the USA, national surveillance of emergency department visits and hospital admissions suggests a rate of 28 cases per 1000 adults with diabetes per year, with a worrisome increase in emergency department visits and admissions for DKA seen since 2009 [209]. The US Type 1 Diabetes Exchange Clinic Network reported that $4.8 \%$ of participants (age 26 to 93 years) had been hospitalised for DKA in the prior year [41]. In a European (predominantly Germany and Austria) registry, adults with type 1 diabetes had DKA at a rate of 2.5 per 100 patient years [210].

As DKA occurs repeatedly in some people with diabetes, risk factors should be identified and approached in a prevention strategy. Some known risk factors are non-modifiable, such as low socioeconomic status, younger age, female sex and ethnicity [41, 210], whereas other factors associated with increased risk of DKA are potentially modifiable. These include having had one previous episode of DKA, high $\mathrm{HbA}_{1 \mathrm{c}}$, low self-management skills (including omission of insulin therapy), psychiatric disorders, infections, somatic comorbidity, alcohol and drug abuse and less interaction with the healthcare team [211-213]. Older studies demonstrated a higher risk of DKA in those using insulin pumps, likely due to the lack of depot insulin when continuous delivery of insulin is disrupted [214]. However, more recent studies have not found this to be the case [41, 210, 215]. Adjunctive use of sodium-glucose cotransporter (SGLT) inhibitors (see below) in adults with type 1 diabetes increases the risk of DKA by an absolute rate of about $4 \%$ per year, suggesting the need for intensive diabetes self-management education and monitoring [216, 217]. DKA in the setting of SGLT inhibitor use is often so-called euglycaemic DKA, with initial case reports describing admission glucose levels of 5.3-12.4 mmol/1 (96$224 \mathrm{mg} / \mathrm{dl})$ [218].

Diabetes self-management education is an effective tool in reducing DKA risk. Additional medical, behavioural health interventions, including home ketone testing, and psychosocial support are often needed. Telemedicine offers the potential to reach populations with decreased access to care, and $24 \mathrm{~h}$ access to advice about managing hyperglycaemia and ketosis/ketonaemia at home can reduce the risk of hospital admission [211].

A detailed description of the management of DKA is beyond the scope of this report but the general principles of treatment are replacement of fluid, insulin and potassium. Different protocols for DKA treatment exist in different parts of the world [219, 220]. For further information regarding treatment, refer to previous reviews [221, 222].

\section{Section 12: Pancreas and islet transplantation}

Whole organ pancreas and pancreatic islet transplantation are currently the only means of clinical beta cell replacement (Fig.
7). Both therapeutic options can effectively prevent hypoglycaemia, restore normoglycaemia and possibly stabilise the progression of complications of type 1 diabetes [223-227]. However, chronic systemic immunosuppression is needed in both forms to prevent allogeneic rejection. Therefore, the indication must thoroughly balance risk and benefit, taking into consideration psychological factors as well [228]. In the USA, islet transplantation is not yet approved for clinical use and reimbursement.

Most whole-pancreas transplants are performed simultaneously with a kidney transplant (simultaneous pancreas and kidney [SPK] transplant). This is the 'gold-standard' therapy for people with type 1 diabetes and pre-final or end-stage renal disease if no contraindications (malignancies, chronic infections, insufficient self-management and severe cardiovascular conditions) are present. SPK transplants show a 5 year pancreas graft survival of $83 \%$ and are superior to pancreas transplants alone (PTA) or pancreas after a kidney transplant $(55 \%$ and 70\%, respectively) [229]. With an SPK transplant, most recipients can expect amelioration of problematic hypoglycaemia for more than a decade [229-231].

PTA are usually performed in people who are relatively young $\left(<50\right.$ years) and do not have obesity $\left(<30 \mathrm{~kg} / \mathrm{m}^{2}\right)$ or coronary artery disease. These selection criteria minimise operative mortality $(<1 \%)$ and reduce early technical pancreas graft loss $(<10 \%)$ [229, 232]. The main indications are a history of frequent, acute and severe metabolic complications (hypoglycaemia, hyperglycaemia, ketoacidosis), clinical and emotional problems with exogenous insulin therapy that are incapacitating, or consistent failure of insulin-based management, including technological aids [233].

Islet transplantation, a less invasive procedure, is indicated in people with excessive glycaemic lability and frequent Level 3 hypoglycaemia despite optimal medical therapy, and allows for inclusion of older people and those with coronary artery disease who would not be eligible for a whole-pancreas transplant [224, 234, 235]. Careful patient selection and protocol optimisation have led to substantial clinical improvements [224]. Insulin independence can be maintained for 5 years in $50 \%$ of recipients $[236,237]$. Although achievement of insulin independence remains an important objective, several multi-centre clinical trials of islet transplants in people with type 1 diabetes and problematic hypoglycaemia have adopted a combination of near-normal glycaemic levels $\left(\mathrm{HbA}_{1 \mathrm{c}}\right.$ $<7.0 \%$ [ $<53 \mathrm{mmol} / \mathrm{mol}]$ ) together with the elimination of Level 3 hypoglycaemia as the primary endpoint and the clinically relevant dual goal of intervention [238-240]. These outcomes can translate into improved patient-reported outcomes, but research in this area is limited [241].

Regardless of the beta cell replacement approach (pancreas or islets), the majority of recipients experience reliable prevention of problematic hypoglycaemia with near-normal glycaemic levels. Islet and pancreas transplants are the only approaches to date that 
Table 6 Adjunctive therapies for type 1 diabetes

\begin{tabular}{|c|c|c|c|c|}
\hline Variable & Metformin & Pramlintide & GLP-1 RA & $\begin{array}{l}\text { SGLT- } 2 \text { or SGLT-1/2 } \\
\text { inhibitors }\end{array}$ \\
\hline $\mathrm{HbA}_{1 \mathrm{c}}$ reduction & $\begin{array}{l}\sim 1 \mathrm{mmol} / \mathrm{mol} \\
\quad(\sim 0.1 \%)\end{array}$ & $3-4 \mathrm{mmol} / \mathrm{mol}(0.3-0.4 \%)$ & $2-4 \mathrm{mmol} / \mathrm{mol}(0.2-0.4 \%)$ & $\begin{array}{c}2-4 \mathrm{mmol} / \mathrm{mol} \\
(0.2-0.4 \%)\end{array}$ \\
\hline Fasting glucose & Minimal effect & No effect & Minimal effect & $\begin{array}{l}\text { Modest decrease } \\
(0.8 \mathrm{mmol} / 1 \\
[15 \mathrm{mg} / \mathrm{dl}])\end{array}$ \\
\hline Postprandial glucose & Minimal effect & Significant decrease & Modest decrease & Modest decrease \\
\hline TIR & No data & No data & No data & $\begin{array}{l}\text { Increased }(\sim 12 \% \text { at } \\
\text { higher doses })\end{array}$ \\
\hline Insulin dose & Unchanged & Mealtime reductions & Predominantly mealtime reductions & $\begin{array}{l}\text { Mealtime and basal } \\
\text { reductions }(\sim 10 \% \\
\text { total reduction })\end{array}$ \\
\hline Body weight & Modest $(\sim 1 \mathrm{~kg})$ & Modest ( 1 kg) & Significant $(\sim 5 \mathrm{~kg})$ & Moderate $(2-3 \mathrm{~kg})$ \\
\hline Systolic blood pressure & No change & No change & $\begin{array}{l}4 \mathrm{mmHg} \text { decrease (with increase in } \\
\text { heart rate) }\end{array}$ & 3-4 mmHg decrease \\
\hline Hypoglycaemia & Low risk & $\begin{array}{l}\text { Potential increase in Level } 3 \\
\text { hypoglycaemia if prandial insulin } \\
\text { doses are not decreased }\end{array}$ & Increase in hypoglycaemia & Low risk \\
\hline Side effects & GI side effects & GI side effects & GI side effects; increase in ketosis & $\begin{array}{l}\text { Genital mycotic } \\
\text { infections; increased } \\
\text { risk of DKA }\end{array}$ \\
\hline $\begin{array}{l}\text { Approval status for type } \\
1 \text { diabetes in EU/US }\end{array}$ & $\begin{array}{l}\text { Not currently } \\
\text { approved }\end{array}$ & US approved & Not currently approved & $\begin{array}{l}\text { EU approved low dose } \\
\text { when BMI } \\
\geq 27 \mathrm{~kg} / \mathrm{m}^{2}\end{array}$ \\
\hline $\begin{array}{l}\text { Specific groups for } \\
\text { whom treatment may } \\
\text { be of benefit }\end{array}$ & $\begin{array}{l}\text { Women with } \\
\text { polycystic } \\
\text { ovary } \\
\text { syndrome }\end{array}$ & No specific groups & $\begin{array}{l}\text { Overweight and obese; high insulin } \\
\text { dose; risk of cardiovascular and } \\
\text { renal disease }\end{array}$ & $\begin{array}{l}\text { Risk of cardiovascular } \\
\text { and renal disease }\end{array}$ \\
\hline
\end{tabular}

EU, European Union; GI, gastrointestinal

confer both sustained recovery from IAH and restoration of glucose counter-regulation and, thereby, reliable protection from Level 3 hypoglycaemia in people with long-standing type 1 diabetes [242]. However, these approaches have not been compared with the newer systems of hybrid closed-loop technology, which might render immunosuppression requiring therapies less necessary, in large long-term studies [243].

\section{Section 13: Adjunctive therapies}

While insulin therapy is essential for people with type 1 diabetes, obtaining glycaemic goals with insulin alone is difficult because of the risks of hypoglycaemia. Furthermore, insulin therapy is often associated with undesirable weight gain, which may worsen insulin resistance, does not address other pathophysiological abnormalities, such as alpha cell dysfunction, and does not wholly protect individuals from an increased risk of cardiovascular disease or other complications. Adjunctive therapies aim to augment insulin therapy by addressing some of these critical unmet needs.
To date, although several drugs have been licensed as adjunctive therapies, the evidence of their effectiveness on clinically relevant outcomes other than blood glucose levels, such as cardiovascular and renal disease, is limited. It is not possible to make a general recommendation about their use but they can be considered in individual cases (Table 6). However, before these drugs are prescribed, insulin therapy should be optimised.

\section{Metformin}

Metformin has been evaluated in numerous small trials in people with type 1 diabetes with hopes that its insulinsensitising properties would improve glycaemic management and/or reduce cardiovascular risk [244, 245]. The largest study to date assessed the use of metformin $1 \mathrm{~g}$, twice daily, in 428 people with type 1 diabetes who were treated for 3 years, with a primary endpoint of changes in mean carotid intima-media thickness, a marker of cardiovascular disease risk. The study ultimately found no difference in the primary endpoint, minimal and non-sustained effects on $\mathrm{HbA}_{1 \mathrm{c}}$, minimal effects on weight ( $\sim 1 \mathrm{~kg}$ reduction) and no change in total daily insulin dose [246]. 


\section{Pramlintide}

Pramlintide, an amylin analogue, is approved for therapeutic use as an adjunctive therapy to insulin in the USA, but not in Europe. It remains the only US Food and Drug Administration (FDA)approved adjunctive therapy for type 1 diabetes. Injection prior to meals acts to suppress glucagon secretion, delay gastric emptying and promote satiety [247-250]. Clinical trials have shown a reduction in $\mathrm{HbA}_{1 \mathrm{c}}(0.3-0.4 \%$ [3-4 mmol/mol]) and modest $(\sim 1 \mathrm{~kg})$ weight loss [251-254]. As a result of its adverse effects and need for additional injections, clinical uptake of pramlintide has been limited. However, co-formulations of amylin with insulin are currently in development, as is the possibility of use of pramlintide in pumps or artificial pancreas systems.

\section{Glucagon like peptide-1 receptor agonists}

Glucagon like peptide-1 receptor agonists (GLP-1 RA) have been explored in people with type 1 diabetes for two indications; the first aimed to ameliorate beta cell decline at the time of diagnosis and there are ongoing trials of this approach. In one study of 308 people with recently diagnosed type 1 diabetes, liraglutide, when used in combination with anti-IL-21, preserved beta cell function [255]. The second indication is as an adjunctive therapy in established type 1 diabetes by blunting glucagon secretion, decreasing gastric emptying, and promoting satiety and weight loss [256]. The largest clinical trials in people with type 1 diabetes were conducted with liraglutide and showed decreases in $\mathrm{HbA}_{1 \mathrm{c}}$ at daily doses of $1.8 \mathrm{mg}(0.2-0.4 \%$ [2- $4 \mathrm{mmol} / \mathrm{mol}])$, decreases in weight $(\sim 5 \mathrm{~kg})$ and reductions in insulin doses [257, 258]. However, increased rates of hypoglycaemia and ketosis were shown. Subgroup analysis in people with residual C-peptide production suggests greater $\mathrm{HbA}_{1 \mathrm{c}}$ reduction and improved safety, with lower risk of ketosis. Trials in people with type 2 diabetes have shown convincing reductions in cardiovascular events with some GLP-1 RA [259]; whether these benefits would also be seen in people with type 1 diabetes is unknown. GLP-1 RA have been approved for management of obesity, but not in people with type 1 diabetes. However, given the clinical trial results in people without type 1 diabetes [260], these agents may have a role for those with type 1 diabetes who have concomitant obesity.

\section{SGLT inhibitors}

In several Phase III programmes in people with type 1 diabetes, the use of SGLT-1 or SGLT-1/2 inhibitors reduced $\mathrm{HbA}_{1 \mathrm{c}}$, improved TIR, reduced body weight and improved blood pressure [244]. However, an increased rate of DKA led to rejection of market authorisation for type 1 diabetes by the FDA, whereas the European Medicines Agency has approved low-dose dapagliflozin $(5 \mathrm{mg})$ and sotagliflozin (200 mg) for those with a BMI $\geq 27 \mathrm{~kg} / \mathrm{m}^{2}$ [261]. While no risk mitigation strategies have been proven to lower the risk of
DKA, a consensus statement on SGLT2 inhibitors and DKA suggested careful patient selection, appropriate insulin dose adjustment to avoid insulinopaenia, starting with a low dose of SGLT2 inhibitors, and regular ketone measurements with prompt action to address elevated values as sensible precautions aimed at preventing DKA [216].

In people with type 2 diabetes, improved cardiovascular outcomes, mainly due to a reduction in congestive heart failure, and improved renal outcomes have been established, but there are only limited data on the applicability of these findings to people with type 1 diabetes [262, 263]. However, increasingly, data on SGLT2 inhibitors have shown renal and heart failure benefits in people without diabetes, suggesting that people with type 1 diabetes and these comorbidities may also benefit.

\section{Section 14: Special populations}

\section{Pregnancy including preconception and postnatal care}

Both maternal and fetal pregnancy outcomes are worse in women with type 1 diabetes compared with women without diabetes. Hyperglycaemia before and during pregnancy increases the risk of complications in the pregnant woman and developing fetus and, also, affects further child development. Thus, women should be supported to achieve blood glucose ranges close to those seen in pregnant women without diabetes, with an $\mathrm{HbA}_{1 \mathrm{c}}$ target of $48 \mathrm{mmol} / \mathrm{mol}(\leq 6.5 \%)$ [264, 265]. Women should aim for fasting and pre-meal glucose concentrations below $5.3 \mathrm{mmol} / \mathrm{l}(95 \mathrm{mg} / \mathrm{dl})$, and postprandial values of below $7.8 \mathrm{mmol} / \mathrm{l}(140 \mathrm{mg} / \mathrm{dl}) 1 \mathrm{~h}$ after a meal and below $6.7 \mathrm{mmol} / 1$ $(120 \mathrm{mg} / \mathrm{dl}) 2 \mathrm{~h}$ after a meal. Although CGM is not approved in the USA for use in pregnancy and no studies in pregnancy have used CGM alone, the Continuous Glucose Monitoring in Women With Type 1 Diabetes in Pregnancy Trial (CONCEPTT) showed that when CGM was used in conjunction with BGM, CGM was associated with better pregnancy outcomes [266] and is widely recommended in Europe. Many women rely on CGM during pregnancy and its use should be encouraged with the caveat that BGM should be performed if there are concerns that the CGM reading is inaccurate. When CGM is used in pregnancy, the target range is lower than outside of pregnancy (3.5-7.8 mmol/1 [63-140 mg/dl]).

The major limiting step to achieving normoglycaemia is hypoglycaemia, which occurs more frequently in the first half of pregnancy, in part because of diminished awareness of hypoglycaemia and pregnancy-associated nausea and vomiting [267]. Pregnant women with type 1 diabetes are at risk of DKA at lower blood glucose levels than in the nonpregnant state and should receive education on DKA prevention and detection [268]. Postpartum breastfeeding, erratic sleep and eating schedules may increase the risk of 
hypoglycaemia and insulin dosing may require adjustment $[269,270]$.

The management of pregnancy begins before conception as a planned pregnancy is associated with improved outcomes for both the women and offspring. Effective contraception should be used until the woman is ready for pregnancy. Choice of a safe and reliable method of contraception should be based on the preference of the woman, her individual risk factors, such as the presence of micro- or macrovascular complications, and the WHO Medical Eligibility Criteria for Contraceptive Use [271].

All women of childbearing age with type 1 diabetes should be informed about the importance of seeking professional help prior to trying to conceive; this provides an opportunity not only to improve glycaemic management but to offer folic acid to prevent neural tube defects, screen for diabetes-related complications and stop potentially teratogenic medications.

Diabetes in pregnancy is best managed by a multidisciplinary team, including a diabetologist/endocrinologist, obstetrician, dietitian, diabetes nurse/educator and diabetes midwife. A detailed description of the management of pregnancy in women with type 1 diabetes is beyond the scope of this report but is available elsewhere $[272,273]$.

\section{Older people with type 1 diabetes}

Insulin regimens in older adults should be individualised and patient safety is a key priority. Glycaemic targets should be based on functional status and life expectancy, rather than chronological age. As older adults with type 1 diabetes are especially vulnerable to hypoglycaemia, target glucose values should be adjusted to minimise the occurrence of hypoglycaemic events. Since, in some older adults with type 1 diabetes, administration of insulin may become more difficult, simplification of insulin management may be justified in cases of individuals with complications or functional or cognitive impairment. The use of advanced technologies in older individuals is useful and should not be discontinued or a priori excluded because of the older age $[78,274]$.

\section{People with late complications of type 1 diabetes}

As there is no evidence that intensive glycaemic management slows the progression of late microvascular complications of diabetes, glycaemic targets in individuals with advanced complications should be individualised and based on the balance of risks and benefits [39, 275]. Diabetes management may be particularly challenging in individuals with chronic kidney disease who may be at an increased risk of hypoglycaemia and in whom $\mathrm{HbA}_{1 \mathrm{c}}$ can be falsely low [276] and in people with gastroparesis and unpredictable rates of food absorption [277]. The rate of optimising blood glucose levels in this group of people should also be individualised as rapid improvement may be associated with transient early worsening of retinopathy or the development of acute painful neuropathy [278, 279]. In people with cardiovascular complications, hypoglycaemia avoidance should be one of the management priorities [280].

\section{Section 15: Inpatient management of type 1 diabetes}

There have been no large RCTs specifically assessing glycaemic targets for inpatients with type 1 diabetes. Therefore, type 2 diabetes guidelines should be followed, which recommend target glucose ranges of $7.8-10.0 \mathrm{mmol} / 1$ $(140-180 \mathrm{mg} / \mathrm{dl})$ for the majority of non-critically and critically ill patients [281]. However, it is important that the healthcare team recognises key differences between type 1 diabetes and type 2 diabetes. People with type 1 diabetes, particularly those with concomitant chronic kidney disease, are at higher risk of hypoglycaemia, which should be avoided by careful insulin and carbohydrate matching [129]. Furthermore, people with type 1 diabetes are at high risk of developing ketosis if insulin is withheld [282]. People with type 1 diabetes often find the inpatient care of their diabetes stressful and disempowering. A major issue for some inpatients with type 1 diabetes care is coping with fixed meal timings. Therefore, inpatients with type 1 diabetes should be clearly identified to avoid common errors, such as omission of mealtime insulin or withholding of basal insulin for procedures or surgery.

Inpatient services should have protocols to allow people who can monitor their glucose and self-administer insulin safely to do so. Similarly, patients using diabetes devices should be allowed to use them in an inpatient setting or during outpatient procedures when proper supervision is available and the patient/caregiver is capable of managing the device(s) [283]. Whenever a dedicated inpatient diabetes service is available, they should be consulted for glycaemic management, DSMES and discharge planning [284]. Finally, the use of diabetes technology (CGM and insulin pumps) can be continued in selected, non-critically ill patients with clear mentation and previous training and education [285, 286]. Institutions should develop clear guidelines to manage inpatient type 1 diabetes safely.

\section{Section 16: Emergent and future perspectives}

Both xenotransplantation with porcine islets and human stem cells are under investigation to solve the problem of limited availability of donors for pancreas or islet transplantation [287]. 
Stem cell strategies have used either patient-specific stem cells or universal allogeneic cells. In the former, the patient's own stem cells are reprogrammed or transdifferentiated to become beta cells. By contrast, generic allogeneic cells may be used for multiple patients and centrally produced from a bank of human embryonic stem cells (hESCs) or of induced pluripotent stem cells (iPSCs). One of the key issues is protecting the cells from immune attack, both rejection and recurrent autoimmunity. Three general strategies are being investigated: (1) use of immunosuppressive or immunomodulatory drugs; (2) use of a physical barrier (e.g. encapsulation) [288]; and (3) gene editing for immune evasion and/or immune protection [289]. Both academic and commercial groups are pursuing these approaches and some are already in clinical trials.

Immunotherapy approaches are being evaluated for their potential use in Stage 1 ( $\geq 2$ islet autoantibodies but normoglycaemia) or Stage 2 (autoantibodies and dysglycaemia) type 1 diabetes to prevent Stage 3 clinical type 1 diabetes, and for the preservation of beta cell function before and shortly after onset of Stage 3 clinical type 1 diabetes [290]. Many interventions have been tested in clinical trials but, to date, the most promising results have been from the anti-CD3 monoclonal antibody teplizumab, low-dose anti-thymocyte globulin (ATG), and the anti-TNF drug, golimumab. These have been shown to preserve beta cell function in recent-onset type 1 diabetes, and teplizumab also has delayed the clinical onset of type 1 diabetes. Several other trials are underway with the hope of not only preserving but even improving beta cell function and being able to interdict the type 1 diabetes disease process sufficiently to prevent the development of the disease.

\section{Section 17: Conclusion}

This report has covered many areas of the management of type 1 diabetes, however, the writing group recognises that huge gaps exist in our knowledge in the prevention, diagnosis and treatment of the disease. People with type 1 diabetes deserve better, higher quality research evidence on which to determine their optimal care. We are also aware of the inequalities in treatment experienced by many people with type 1 diabetes and we must advocate for better services to ensure that all individuals with type 1 diabetes have access to the care they need.

Acknowledgements We acknowledge the support of M. I. Hill, M. Saraco and R. A. Gabbay (all ADA, Arlington, VA, USA), and P. Niemann, N. Buckley-Mühge and M. Gruesser (all EASD, Dusseldorf, Germany), the Committee for Clinical Affairs of the EASD and the Professional Practice Committee of the ADA. We acknowledge A. Jones (University of Exeter, Exeter, UK) for his invaluable help with the 'Diagnosis of type 1 diabetes' section. We also acknowledge D. F. Kruger (Henry Ford Health System, Detroit, MI, USA), G. Aleppo (Northwestern University, Chicago, IL, USA), D. Schatz (University of Florida, Gainesville, FL, USA), J. Speight (Australian Centre for
Behavioural Research in Diabetes, Melbourne, VIC, Australia), A.-G. Ziegler (Technical University of Munich, Munich, Germany) and C. Mathieu (Katholieke Universiteit Leuven, Leuven, Belgium) for serving as internal peer reviewers for the EASD and ADA. We would like to thank C. Franklin and M. Bonar of the Leicester Diabetes Centre (Leicester, UK) for the graphic design of the figures and R. M. Bergenstal and the International Diabetes Center, Minneapolis (MN, USA) for the ambulatory glucose profile (AGP) figure (Fig. 2).

Funding The report was jointly commissioned and funded by the ADA and EASD. The authors did not receive any payment for their involvement in the writing group.

Authors' relationships and activities RIGH serves on the speakers' bureau for and receives research support from Novo Nordisk. He serves on the speakers' bureau for Abbott, Eli Lilly, Otsuka and Roche. He also served as the Editor-in-Chief of Diabetic Medicine until December 2020. JHD received research funding from Afon, Eli Lilly and Novo Nordisk. He served on advisory boards for Adocia, Novo Nordisk and Zealand Pharma and was on a speaker's bureau for Novo Nordisk. AH-F is an auditor for the ADA's Education Recognition Program. She is a participant in a speaker's bureau for Abbott Diabetes Care and Xeris. She is also a member of Xeris' advisory board. IBH receives industry research funding from Medtronic Diabetes, Insulet and Beta Bionics. He is a consultant for Bigfoot, Roche and Abbott Diabetes Care. MSK receives research funding from Novo Nordisk and Bayer. TK has served on advisory boards for Abbott, Ascensia, Bioton, Boehringer Ingelheim, Dexcom, Eli Lilly, Medtronic, Roche, Sanofi and Ypsomed. He has received research funding from Medtronic and is a participant in a speakers' bureau for Abbott, Ascensia, Bioton, Boehringer Ingelheim, Eli Lilly, Medtronic, Novo Nordisk, Roche, Sanofi and Servier. BL declares that there are no relationships or activities that might bias, or be perceived to bias, their work. $\mathrm{KN}$ receives research funding from, is a member of the advisory board for, and is a stockholder in Novo Nordisk. She is an advisory board member for Medtronic and Abbott Diabetes Care and receives research funding from Dexcom, Medtronic and Zealand Pharma. JP is a consultant to Sanofi, Novo Nordisk, Eli Lilly, Zealand, Mannkind and Diasome. ER serves on the advisory board for Abbott, Air Liquide SI, Dexcom, Insulet, Sanofi, Roche, Novo Nordisk and Eli Lilly, and received research support from Dexcom and Tandem. JSS is a member of the board of directors for Applied Therapeutics and Dexcom. He serves on the scientific advisory board for Abvance, ActoBiotics, Adocia, Avotres, Oramed, Orgenesis, Sanofi Diabetes, Tolerion and Viacyte. He received research support from Tolerion. He is an advisor and consultant to Boehringer Ingelheim, Dance Biopharm/Aerami Therapeutics, Enthera, Ideal Life, Imcyse, Immnomolecular Therapeutics, Novo Nordisk, Provention Bio, Sanofi Diabetes, Signos, Tolerion and VielaBio. He is a shareholder or option holder in Abvance, Avotres, Dance Biopharm/Aerami Therapeutics, Dexcom, Ideal Life, Immnomolecular Therapeutics, Oramed and Orgenesis. FJS is consultant to Abbott, Eli Lilly, Sanofi and Novo Nordisk, and serves on the speakers' bureau for Abbott, Eli Lilly, Sanofi and Novo Nordisk. He has received research funding from Sanofi and Novo Nordisk. RSW receives research funding from Eli Lilly, Medtronic, Insulet, Diasome, Kowa, Tolerion, Novo Nordisk and Boehringer Ingelheim. ALP serves on the advisory board for Abbott Diabetes Care, Eli Lilly, Novo Nordisk, Medscape and Zealand Pharmaceuticals. She has received research support from Dexcom and Insulet and has received donated devices from Abbott Diabetes Care. She also has stock options from Omada Health and Livongo and is a special government employee of the FDA. 
Contribution statement RIGH and ALP were co-chairs for the consensus statement writing group. AH-F, IBH, MSK, JP, JSS and RSW were the writing group members for the ADA. JHD, TK, BL, KN, ER and FJS were the writing group members for the EASD. All authors were responsible for drafting the article and revising it critically for important intellectual content. All authors approved the version to be published.

\section{References}

1. Miller RG, Secrest AM, Sharma RK, Songer TJ, Orchard TJ (2012) Improvements in the life expectancy of type 1 diabetes: the Pittsburgh Epidemiology of Diabetes Complications study cohort. Diabetes. 61(11):2987-2992. https://doi.org/10.2337/ db11-1625

2. Mobasseri M, Shirmohammadi M, Amiri T, Vahed N, Hosseini Fard H, Ghojazadeh M (2020) Prevalence and incidence of type 1 diabetes in the world: a systematic review and meta-analysis. Health Promot Perspect 10(2):98-115. https://doi.org/10.34172/ hpp. 2020.18

3. Hirsch IB, Juneja R, Beals JM, Antalis CJ, Wright EE (2020) The evolution of insulin and how it informs therapy and treatment choices. Endocr Rev 41(5):733-755. https://doi.org/10.1210/ endrev/bnaa015

4. Stamatouli AM, Quandt Z, Perdigoto AL et al (2018) Collateral damage: insulin-dependent diabetes induced with checkpoint inhibitors. Diabetes. 67(8):1471-1480. https://doi.org/10.2337/ dbi18-0002

5. Davis AK, DuBose SN, Haller MJ et al (2015) Prevalence of detectable C-peptide according to age at diagnosis and duration of type 1 diabetes. Diabetes Care 38(3):476-481. https://doi.org/ $10.2337 / \mathrm{dc} 14-1952$

6. Thomas NJ, Lynam AL, Hill AV et al (2019) Type 1 diabetes defined by severe insulin deficiency occurs after 30 years of age and is commonly treated as type 2 diabetes. Diabetologia. 62(7): 1167-1172. https://doi.org/10.1007/s00125-019-4863-8

7. Muñoz C, Floreen A, Garey C et al (2019) Misdiagnosis and diabetic ketoacidosis at diagnosis of type 1 diabetes: patient and caregiver perspectives. Clin Diabetes 37(3):276-281. https://doi. org/10.2337/cd18-0088

8. Hope SV, Wienand-Barnett S, Shepherd M et al (2016) Practical classification guidelines for diabetes in patients treated with insulin: a cross-sectional study of the accuracy of diabetes diagnosis. Br J Gen Pract 66(646):e315-e322. https://doi.org/10.3399/ bjgp16X684961

9. Shields BM, Peters JL, Cooper C et al (2015) Can clinical features be used to differentiate type 1 from type 2 diabetes? A systematic review of the literature. BMJ Open 5(11):e009088. https://doi.org/ 10.1136/bmjopen-2015-009088

10. Jones AG, Hill AV, Trippett PW, Hattersley AT, McDonald TJ, Shields BM (2019). The utility of clinical features and glycaemia at diagnosis in classifying young adult onset diabetes (Abstract). Available from: www.easd.org/virtualmeeting/home.html\# !resources/the-utility-of-clinical-features-and-glycaemia-atdiagnosis-in-classifying-young-adult-onset-diabetes. Accessed 23 August 2021

11. Thomas NJ, Jones SE, Weedon MN, Shields BM, Oram RA, Hattersley AT (2018) Frequency and phenotype of type 1 diabetes in the first six decades of life: a cross-sectional, genetically stratified survival analysis from UK Biobank. Lancet Diabetes Endocrinol 6(2):122-129. https://doi.org/10.1016/S2213$8587(17) 30362-5$
12. Hillier TA, Pedula KL (2001) Characteristics of an adult population with newly diagnosed type 2 diabetes: the relation of obesity and age of onset. Diabetes Care 24(9):1522-1527. https://doi.org/ 10.2337/diacare.24.9.1522

13. Westphal SA (1996) The occurrence of diabetic ketoacidosis in non-insulin-dependent diabetes and newly diagnosed diabetic adults. Am J Med 101(1):19-24. https://doi.org/10.1016/S00029343(96)00076-9

14. Nakagami T, Qiao Q, Carstensen B et al (2003) Age, body mass index and type 2 diabetes-associations modified by ethnicity. Diabetologia. 46(8):1063-1070. https://doi.org/10.1007/s00125003-1158-9

15. Prior MJ, Prout T, Miller D, Ewart R, Kumar D (1993) The ETDRS Research Group. C-peptide and the classification of diabetes mellitus patients in the Early Treatment Diabetic Retinopathy Study. Report number 6. Ann Epidemiol 3(1):9-17. https://doi.org/10.1016/1047-2797(93)90004-N

16. Chung WK, Erion K, Florez JC et al (2020) Precision medicine in diabetes: a consensus report from the American Diabetes Association (ADA) and the European Association for the Study of Diabetes (EASD). Diabetologia. 63:1671-1693. https://doi.org/ 10.1007/s00125-020-05181-w

17. Buzzetti R, Tuomi T, Mauricio D et al (2020) Management of latent autoimmune diabetes in adults: a consensus statement from an international expert panel. Diabetes. 69(10):2037-2047. https:// doi.org/10.2337/dbi20-0017

18. Shields BM, Shepherd M, Hudson M et al (2017) Populationbased assessment of a biomarker-based screening pathway to aid diagnosis of monogenic diabetes in young-onset patients. Diabetes Care 40(8):1017-1025. https://doi.org/10.2337/dc170224

19. Pearson ER, Starkey BJ, Powell RJ, Gribble FM, Clark PM, Hattersley AT (2003) Genetic cause of hyperglycaemia and response to treatment in diabetes. Lancet. 362(9392):1275-1281. https://doi.org/10.1016/S0140-6736(03)14571-0

20. Hattersley AT, Greeley SAW, Polak M et al (2018) ISPAD clinical practice consensus guidelines 2018: the diagnosis and management of monogenic diabetes in children and adolescents. Pediatr Diabetes 19(S27):47-63

21. Bingley PJ (2010) Clinical applications of diabetes antibody testing. J Clin Endocrinol Metab 95(1):25-33. https://doi.org/10. 1210/jc.2009-1365

22. Sabbah E, Savola K, Ebeling T et al (2000) Genetic, autoimmune, and clinical characteristics of childhood- and adult-onset type 1 diabetes. Diabetes Care 23(9):1326-1332. https://doi.org/10. 2337/diacare.23.9.1326

23. Littorin B, Sundkvist G, Hagopian W et al (1999) Islet cell and glutamic acid decarboxylase antibodies present at diagnosis of diabetes predict the need for insulin treatment. A cohort study in young adults whose disease was initially labeled as type 2 or unclassifiable diabetes. Diabetes Care 22(3):409-412. https://doi. org/10.2337/diacare.22.3.409

24. Lynam A, McDonald T, Hill A et al (2019) Development and validation of multivariable clinical diagnostic models to identify type 1 diabetes requiring rapid insulin therapy in adults aged 18-50 years. BMJ Open 9(9):e031586. https://doi.org/10.1136/bmjopen2019-031586

25. Thomas NJ, Walkey HC, Kaur A et al (2021) The absence of islet autoantibodies in clinically diagnosed older-adult onset type 1 diabetes suggests an alternative pathology, advocating for routine testing in this age group. medRxiv 2021.03.22.21252507 (Preprint). 24 Mar 2021. Available from: https://doi.org/10.1101/ 2021.03.22.21252507. Accessed 23 August 2021

26. Tridgell DM, Spiekerman C, Wang RS, Greenbaum CJ (2011) Interaction of onset and duration of diabetes on the percent of GAD and IA-2 antibody-positive subjects in the type 1 diabetes 
genetics consortium database. Diabetes Care 34(4):988-993. https://doi.org/10.2337/dc10-1903

27. Balasubramanyam A, Garza G, Rodriguez L et al (2006) Accuracy and predictive value of classification schemes for ketosis-prone diabetes. Diabetes Care 29(12):2575-2579. https:// doi.org/10.2337/dc06-0749

28. Hohberg C, Pfützner A, Forst T et al (2009) Successful switch from insulin therapy to treatment with pioglitazone in type 2 diabetes patients with residual beta-cell function: results from the PioSwitch study. Diabetes Obes Metab 11(5):464-471. https:// doi.org/10.1111/j.1463-1326.2008.00975.x

29. Lee A, Morley J (1999) Classification of type 2 diabetes by clinical response to metformin-troglitazone combination and Cpeptide criteria. Endocr Pract 5(6):305-313. https://doi.org/10. 4158/EP.5.6.305

30. Bell DS, Mayo MS (1998) Improved glycemic control with use of oral hypoglycemic therapy with or without insulin. Endocr Pract 4(2):82-85. https://doi.org/10.4158/EP.4.2.82

31. Foteinopoulou E, Clarke CAL, Pattenden RJ et al (2020) Impact of routine clinic measurement of serum C-peptide in people with a clinician-diagnosis of type 1 diabetes. Diabet Med 38:e14449

32. De Franco E, Flanagan SE, Houghton JAL et al (2015) The effect of early, comprehensive genomic testing on clinical care in neonatal diabetes: an international cohort study. Lancet. 386(9997):957963. https://doi.org/10.1016/S0140-6736(15)60098-8

33. Pearson ER, Flechtner I, Njølstad PR et al (2006) Switching from insulin to oral sulfonylureas in patients with diabetes due to Kir6.2 mutations. N Engl J Med 355(5):467-477. https://doi.org/10. 1056/NEJMoa061759

34. Carlsson A, Shepherd M, Ellard S et al (2020) Absence of islet autoantibodies and modestly raised glucose values at diabetes diagnosis should lead to testing for MODY: lessons from a 5year pediatric Swedish National Cohort Study. Diabetes Care 43(1):82-89

35. Shields BM, McDonald TJ, Ellard S, Campbell MJ, Hyde C, Hattersley AT (2012) The development and validation of a clinical prediction model to determine the probability of MODY in patients with young-onset diabetes. Diabetologia. 55(5):12651272. https://doi.org/10.1007/s00125-011-2418-8

36. Besser REJ, Shepherd MH, McDonald TJ et al (2011) Urinary Cpeptide creatinine ratio is a practical outpatient tool for identifying hepatocyte nuclear factor $1-\alpha /$ hepatocyte nuclear factor $4-\alpha$ maturity-onset diabetes of the young from long-duration type 1 diabetes. Diabetes Care 34(2):286-291. https://doi.org/10.2337/dc101293

37. McDonald TJ, Colclough K, Brown R et al (2011) Islet autoantibodies can discriminate maturity-onset diabetes of the young (MODY) from type 1 diabetes. Diabet Med 28(9):1028-1033. https://doi.org/10.1111/j.1464-5491.2011.03287.x

38. Thanabalasingham G, Pal A, Selwood MP et al (2012) Systematic assessment of etiology in adults with a clinical diagnosis of youngonset type 2 diabetes is a successful strategy for identifying maturity-onset diabetes of the young. Diabetes Care 35(6):12061212. https://doi.org/10.2337/dc11-1243

39. The Diabetes Control and Complications Trial Research Group (1993) The effect of intensive treatment of diabetes on the development and progression of long-term complications in insulindependent diabetes mellitus. N Engl J Med 329(14):977-986. https://doi.org/10.1056/NEJM199309303291401

40. The Diabetes Control and Complications Trial (DCCT)/ Epidemiology of Diabetes Interventions and Complications (EDIC) Study Research Group (2016) Intensive diabetes treatment and cardiovascular outcomes in type 1 diabetes: the DCCT/EDIC study 30-year follow-up. Diabetes Care 39(5): 686-693. https://doi.org/10.2337/dc15-1990
41. Weinstock RS, Xing D, Maahs DM et al (2013) Severe hypoglycemia and diabetic ketoacidosis in adults with type 1 diabetes: results from the T1D Exchange clinic registry. J Clin Endocrinol Metab 98(8):3411-3419. https://doi.org/10.1210/jc.2013-1589

42. The Juvenile Diabetes Research Foundation Continuous Glucose Monitoring Study Group (2008) Continuous glucose monitoring and intensive treatment of type 1 diabetes. N Engl J Med 359(14): 1464-1476. https://doi.org/10.1056/NEJMoa0805017

43. Bolinder J, Antuna R, Geelhoed-Duijvestijn P, Kröger J, Weitgasser R (2016) Novel glucose-sensing technology and hypoglycaemia in type 1 diabetes: a multicentre, non-masked, randomised controlled trial. Lancet. 388(10057):2254-2263. https://doi.org/10.1016/S0140-6736(16)31535-5

44. van Beers CAJ, DeVries JH, Kleijer SJ et al (2016) Continuous glucose monitoring for patients with type 1 diabetes and impaired awareness of hypoglycaemia (IN CONTROL): a randomised, open-label, crossover trial. Lancet Diabetes Endocrinol 4(11): 893-902. https://doi.org/10.1016/S2213-8587(16)30193-0

45. Beck RW, Bergenstal RM, Riddlesworth TD et al (2019) Validation of time in range as an outcome measure for diabetes clinical trials. Diabetes Care 42(3):400-405. https://doi.org/10. 2337/dc18-1444

46. Ranjan AG, Rosenlund SV, Hansen TW, Rossing P, Andersen S, Nørgaard K (2020) Improved time in range over 1 year is associated with reduced albuminuria in individuals with sensoraugmented insulin pump-treated type 1 diabetes. Diabetes Care 43(11):2882-2885. https://doi.org/10.2337/dc20-0909

47. Battelino T, Danne T, Bergenstal RM et al (2019) Clinical targets for continuous glucose monitoring data interpretation: recommendations from the international consensus on time in range. Diabetes Care 42(8):1593-1603. https://doi.org/10.2337/dci190028

48. Hero C, Rawshani A, Svensson A-M et al (2016) Association between use of lipid-lowering therapy and cardiovascular diseases and death in individuals with type 1 diabetes. Diabetes Care 39(6): 996-1003. https://doi.org/10.2337/dc15-2450

49. Vistisen D, Andersen GS, Hansen CS et al (2016) Prediction of first cardiovascular disease event in type 1 Diabetes mellitus: the Steno type 1 risk engine. Circulation. 133(11):1058-1066. https:// doi.org/10.1161/CIRCULATIONAHA.115.018844

50. ClinRisk (2018) Welcome to the QRISK®3-2018 risk calculator https://qrisk.org/three. Available from: https://qrisk.org/three/ index.php. Accessed 16 July 2021

51. McGurnaghan SJ, McKeigue PM, Read SH et al (2021) CVD risk prediction T1D. Available from: https://diabepi.shinyapps.io/ cvdrisk/. Accessed 16 July 2021

52. American Diabetes Association (2021) 4. Comprehensive medical evaluation and assessment of comorbidities: standards of medical care in diabetes - 2021. Diabetes Care 44(Supp 1):S40-S52

53. American Diabetes Association (2021) 7. Diabetes technology: standards of medical care in diabetes-2021. Diabetes Care 44(Suppl 1):S85-S99. https://doi.org/10.2337/dc21-S007

54. Borries TM, Dunbar A, Bhukhen A et al (2019) The impact of telemedicine on patient self-management processes and clinical outcomes for patients with types I or II diabetes mellitus in the United States: a scoping review. Diabetes Metab Syndr 13(2): 1353-1357

55. Lee JY, Lee SWH (2018) Telemedicine cost-effectiveness for diabetes management: a systematic review. Diabetes Technol Ther 20(7):492-500. https://doi.org/10.1089/dia.2018.0098

56. Tchero H, Kangambega P, Briatte C, Brunet-Houdard S, Retali G$R$, Rusch E (2019) Clinical effectiveness of telemedicine in diabetes mellitus: a meta-analysis of 42 randomized controlled trials. Telemed J E Health 25(7):569-583. https://doi.org/10.1089/tmj. 2018.0128 
57. Timpel P, Oswald S, Schwarz PEH, Harst L (2020) Mapping the evidence on the effectiveness of telemedicine interventions in diabetes, dyslipidemia, and hypertension: an umbrella review of systematic reviews and meta-analyses. J Med Internet Res 22(3): e16791. https://doi.org/10.2196/16791

58. Duke DC, Barry S, Wagner DV, Speight J, Choudhary P, Harris MA (2018) Distal technologies and type 1 diabetes management. Lancet Diabetes Endocrinol 6(2):143-156. https://doi.org/10. 1016/S2213-8587(17)30260-7

59. Crossen S, Raymond J, Neinstein A (2020) Top 10 tips for successfully implementing a diabetes telehealth program. Diabetes Technol Ther 22(12):920-928. https://doi.org/10.1089/ dia.2020.0042

60. Beck J, Greenwood DA, Blanton L et al (2017) 2017 national standards for diabetes self-management education and support. Diabetes Care 40(10):1409-1419. https://doi.org/10.2337/dci170025

61. Diabetes UK (2021). Diabetes self-management education. Available from: www.diabetes.org.uk/professionals/resources/ resources-to-improve-your-clinical-practice/diabetes-selfmanagement-education. Accessed 11 February 2021

62. Joubert M, Benhamou P-Y, Schaepelynck P et al (2019) Remote monitoring of diabetes: a cloud-connected digital system for individuals with diabetes and their health care providers. J Diabetes Sci Technol 13(6):1161-1168. https://doi.org/10.1177/ 1932296819834054

63. Powers MA, Bardsley JK, Cypress M et al (2020) Diabetes selfmanagement education and support in adults with type 2 diabetes: a consensus report of the American Diabetes Association, the Association of Diabetes Care \& Education Specialists, the Academy of Nutrition and Dietetics, the American Academy of Family Physicians, the American Academy of PAs, the American Association of Nurse Practitioners, and the American Pharmacists Association. Diabetes Care 43(7):1636-1649

64. Chatterjee S, Davies MJ, Heller S, Speight J, Snoek FJ, Khunti K (2018) Diabetes structured self-management education programmes: a narrative review and current innovations. Lancet Diabetes Endocrinol 6(2):130-142. https://doi.org/10.1016/ S2213-8587(17)30239-5

65. Fleming GA, Petrie JR, Bergenstal RM, Holl RW, Peters AL, Heinemann L (2020) Diabetes digital app technology: benefits, challenges, and recommendations. A consensus report by the European Association for the Study of Diabetes (EASD) and the American Diabetes Association (ADA) Diabetes Technology Working Group. Diabetologia. 63(2):229-241. https://doi.org/ 10.1007/s00125-019-05034-1

66. Nathan DM, Kuenen J, Borg R et al (2008) Translating the A1C assay into estimated average glucose values. Diabetes Care 31(8): 1473-1478. https://doi.org/10.2337/dc08-0545

67. Radin MS (2014) Pitfalls in hemoglobin A1c measurement: when results may be misleading. J Gen Intern Med 29(2):388-394. https://doi.org/10.1007/s11606-013-2595-x

68. Beck RW, Connor CG, Mullen DM, Wesley DM, Bergenstal RM (2017) The fallacy of average: how using HbA1c alone to assess glycemic control can be misleading. Diabetes Care 40(8):994 999. https://doi.org/10.2337/dc17-0636

69. Beck RW, Bergenstal RM, Cheng P et al (2019) The relationships between time in range, hyperglycemia metrics, and HbAlc. J Diabetes Sci Technol 13(4):614-626. https://doi.org/10.1177/ 1932296818822496

70. Krhač M, Lovrenčić MV (2019) Update on biomarkers of glycemic control. World J Diabetes 10(1):1-15. https://doi.org/10. 4239/wjd.v10.i1.1

71. Miller KM, Beck RW, Bergenstal RM et al (2013) Evidence of a strong association between frequency of self-monitoring of blood glucose and hemoglobin A1c levels in T1D exchange clinic registry participants. Diabetes Care 36(7):2009-2014. https://doi. org/10.2337/dc12-1770

72. Bode BW, Schwartz S, Stubbs HA, Block JE (2005) Glycemic characteristics in continuously monitored patients with type 1 and type 2 diabetes: normative values. Diabetes Care 28(10):23612366. https://doi.org/10.2337/diacare.28.10.2361

73. Moreland EC, Volkening LK, Lawlor MT, Chalmers KA, Anderson BJ, Laffel LMB (2006) Use of a blood glucose monitoring manual to enhance monitoring adherence in adults with diabetes: a randomized controlled trial. Arch Intern Med 166(6): 689-695. https://doi.org/10.1001/archinte.166.6.689

74. Draznin B (2019) Diabetes technology: science and practice. American Diabetes Association, Alexandria, VA

75. Klonoff DC, Parkes JL, Kovatchev BP et al (2018) Investigation of the accuracy of 18 marketed blood glucose monitors. Diabetes Care 41(8):1681-1688. https://doi.org/10.2337/dc17-1960

76. Beck RW, Riddlesworth T, Ruedy K et al (2017) Effect of continuous glucose monitoring on glycemic control in adults with type 1 diabetes using insulin injections: the DIAMOND randomized clinical trial. JAMA 317(4):371-378. https://doi.org/10.1001/ jama.2016.19975

77. Visser MM, Charleer S, Fieuws S et al (2021) Comparing realtime and intermittently scanned continuous glucose monitoring in adults with type 1 diabetes (ALERTT1): a 6-month, prospective, multicentre, randomised controlled trial. Lancet. 397(10291): 2275-2283. https://doi.org/10.1016/S0140-6736(21)00789-3

78. Pratley RE, Kanapka LG, Rickels MR, Ahmann A, Aleppo G, Beck R et al (2020) Effect of continuous glucose monitoring on hypoglycemia in older adults with type 1 diabetes: a randomized clinical trial. JAMA 323(23):2397-2406. https://doi.org/10.1001/ jama.2020.6928

79. Bergenstal RM, Ahmann AJ, Bailey T et al (2013) Recommendations for standardizing glucose reporting and analysis to optimize clinical decision making in diabetes: the Ambulatory Glucose Profile (AGP). Diabetes Technol Ther 15(3):198-211. https://doi.org/10.1089/dia.2013.0051

80. Beck RW, Bergenstal RM (2021) Beyond A1C-standardization of continuous glucose monitoring reporting: why it is needed and how it continues to evolve. Diabetes Spectr 34(2):102-108. https://doi.org/10.2337/ds20-0090

81. Pleus S, Ulbrich S, Zschornack E, Kamann S, Haug C, Freckmann G (2019) Documentation of skin-related issues associated with continuous glucose monitoring use in the scientific literature. Diabetes Technol Ther 21(10):538-545. https://doi.org/10.1089/ dia.2019.0171

82. Herman A, de Montjoye L, Baeck M (2020) Adverse cutaneous reaction to diabetic glucose sensors and insulin pumps: irritant contact dermatitis or allergic contact dermatitis? Contact Dermatitis 83(1):25-30. https://doi.org/10.1111/cod.13529

83. Rigo RS, Levin LE, Belsito DV, Garzon MC, Gandica R, Williams KM (2020) Cutaneous reactions to continuous glucose monitoring and continuous subcutaneous insulin infusion devices in type 1 diabetes mellitus. J Diabetes Sci Technol 15(4):786-791

84. Deiss D, Irace C, Carlson G, Tweden KS, Kaufman FR (2020) Real-world safety of an implantable continuous glucose sensor over multiple cycles of use: a post-market registry study. Diabetes Technol Ther 22(1):48-52. https://doi.org/10.1089/dia. 2019.0159

85. Sanchez P, Ghosh-Dastidar S, Tweden KS, Kaufman FR (2019) Real-world data from the first U.S. commercial users of an implantable continuous glucose sensor. Diabetes Technol Ther 21(12):677-681. https://doi.org/10.1089/dia.2019.0234

86. National Institute for Health and Care Excellence (2021) Type 1 diabetes in adults: diagnosis and management. Available from: www.nice.org.uk/guidance/ng17. Accessed 10 June 2021 
87. Danne T, Matsuhisa M, Sussebach C et al (2020) Lower risk of severe hypoglycaemia with insulin glargine $300 \mathrm{U} / \mathrm{mL}$ versus glargine $100 \mathrm{U} / \mathrm{mL}$ in participants with type 1 diabetes: a metaanalysis of 6-month phase 3 clinical trials. Diabetes Obes Metab 22(10):1880-1885. https://doi.org/10.1111/dom.14109

88. Lane W, Bailey TS, Gerety G et al (2017) Effect of insulin degludec vs insulin glargine U100 on hypoglycemia in patients with type 1 diabetes: the SWITCH 1 randomized clinical trial. JAMA 318(1):33-44. https://doi.org/10.1001/jama.2017.7115

89. Šoupal J, Petruželková L, Grunberger G et al (2020) Glycemic outcomes in adults with T1D are impacted more by continuous glucose monitoring than by insulin delivery method: 3 years of follow-up from the COMISAIR study. Diabetes Care 43(1):37-43

90. Bergenstal RM, Garg S, Weinzimer SA, Buckingham BA, Bode BW, Tamborlane WV et al (2016) Safety of a hybrid closed-loop insulin delivery system in patients with type 1 diabetes. JAMA 316(13):1407-1408. https://doi.org/10.1001/jama.2016.11708

91. Brown SA, Kovatchev BP, Raghinaru D et al (2019) Six-month randomized, multicenter trial of closed-loop control in type 1 diabetes. N Engl J Med 381(18):1707-1717. https://doi.org/10. 1056/NEJMoa1907863

92. Gibney MA, Arce CH, Byron KJ, Hirsch LJ (2010) Skin and subcutaneous adipose layer thickness in adults with diabetes at sites used for insulin injections: implications for needle length recommendations. Curr Med Res Opin 26(6):1519-1530. https:// doi.org/10.1185/03007995.2010.481203

93. Kesavadev J, Srinivasan S, Saboo B, Krishna BM, Krishnan G (2020) The do-it-yourself artificial pancreas: a comprehensive review. Diabetes Ther 11(6):1217-1235. https://doi.org/10.1007/ s13300-020-00823-Z

94. Boughton CK, Hovorka R (2020) The artificial pancreas. Curr Opin Organ Transplant 25(4):336-342. https://doi.org/10.1097/ MOT.0000000000000786

95. Famulla S, Hövelmann U, Fischer A et al (2016) Insulin injection into lipohypertrophic tissue: blunted and more variable insulin absorption and action and impaired postprandial glucose control. Diabetes Care 39(9):1486-1492. https://doi.org/10.2337/dc160610

96. Blanco M, Hernández MT, Strauss KW, Amaya M (2013) Prevalence and risk factors of lipohypertrophy in insulininjecting patients with diabetes. Diabetes Metab 39(5):445-453. https://doi.org/10.1016/j.diabet.2013.05.006

97. McGill JB, Peters A, Buse JB et al (2020) Comprehensive pulmonary safety review of inhaled Technosphere ${ }^{\circledR}$ insulin in patients with diabetes mellitus. Clin Drug Investig 40(10):973-983. https://doi.org/10.1007/s40261-020-00958-8

98. Spaan N, Teplova A, Stam G, Spaan J, Lucas C (2014) Systematic review: continuous intraperitoneal insulin infusion with implantable insulin pumps for diabetes mellitus. Acta Diabetol 51(3):339351. https://doi.org/10.1007/s00592-014-0557-3

99. Renard E, Schaepelynck-Bélicar P (2007) Implantable insulin pumps. A position statement about their clinical use. Diabetes Metab 33(2):158-166. https://doi.org/10.1016/j.diabet.2006.10. 004

100. The International Hypoglycaemia Study Group (2017) Glucose concentrations of less than $3.0 \mathrm{mmol} / \mathrm{L}(54 \mathrm{mg} / \mathrm{dL})$ should be reported in clinical trials: a joint position statement of the American Diabetes Association and the European Association for the Study of Diabetes. Diabetologia 60:3-6. https://doi.org/ 10.1007/s00125-016-4146-6

101. Heinemann L, Freckmann G, Ehrmann D et al (2018) Real-time continuous glucose monitoring in adults with type 1 diabetes and impaired hypoglycaemia awareness or severe hypoglycaemia treated with multiple daily insulin injections (HypoDE): a multicentre, randomised controlled trial. Lancet. 391(10128): 1367-1377. https://doi.org/10.1016/S0140-6736(18)30297-6
102. Renard E, Ikegami H, Daher Vianna AG et al (2020) The SAGE study: global observational analysis of glycaemic control, hypoglycaemia and diabetes management in T1DM. Diabetes Metab Res Rev. https://doi.org/10.1002/dmrr.3430

103. Seaquist ER, Anderson J, Childs B et al (2013) Hypoglycemia and diabetes: a report of a workgroup of the American Diabetes Association and the Endocrine Society. Diabetes Care 36(5): 1384-1395. https://doi.org/10.2337/dc12-2480

104. Cryer PE (2013) Mechanisms of hypoglycemia-associated autonomic failure in diabetes. N Engl J Med 369(4):362-372. https:// doi.org/10.1056/NEJMra1215228

105. Henriksen MM, Andersen HU, Thorsteinsson B, PedersenBjergaard U (2018) Hypoglycemic exposure and risk of asymptomatic hypoglycemia in type 1 diabetes assessed by continuous glucose monitoring. J Clin Endocrinol Metab 103(6):2329-2335. https://doi.org/10.1210/jc.2018-00142

106. van Beers CAJ, Caris MG, DeVries JH, Serné EH (2018) The relation between $\mathrm{HbA} 1 \mathrm{c}$ and hypoglycemia revisited; a secondary analysis from an intervention trial in patients with type 1 diabetes and impaired awareness of hypoglycemia. J Diabetes Complicat 32(1):100-103. https://doi.org/10.1016/j.jdiacomp.2017.09.005

107. Gagnum V, Stene LC, Jenssen TG et al (2017) Causes of death in childhood-onset type 1 diabetes: long-term follow-up. Diabet Med 34(1):56-63. https://doi.org/10.1111/dme.13114

108. The International Hypoglycaemia Study Group (2019) Hypoglycaemia, cardiovascular disease, and mortality in diabetes: epidemiology, pathogenesis, and management. Lancet Diabetes Endocrinol 7(5):385-396. https://doi.org/10.1016/ S2213-8587(18)30315-2

109. The Diabetes Control and Complications Trial/Epidemiology of Diabetes Interventions and Complications (DCCT/EDIC) Study Research Group (2007) Long-term effect of diabetes and its treatment on cognitive function. N Engl J Med 356(18):1842-1852. https://doi.org/10.1056/NEJMoa066397

110. Jacobson AM, Ryan CM, Braffett BH et al (2021) Cognitive performance declines in older adults with type 1 diabetes: results from 32 years of follow-up in the DCCT and EDIC study. Lancet Diabetes Endocrinol 9(7):436-445. https://doi.org/10.1016/ S2213-8587(21)00086-3

111. Chaytor NS, Barbosa-Leiker C, Ryan CM, Germine LT, Hirsch IB, Weinstock RS (2019) Clinically significant cognitive impairment in older adults with type 1 diabetes. J Diabetes Complicat 33(1):91-97. https://doi.org/10.1016/j.jdiacomp.2018.04.003

112. Lin YK, Fisher SJ, Pop-Busui R (2020) Hypoglycemia unawareness and autonomic dysfunction in diabetes: lessons learned and roles of diabetes technologies. J Diabetes Investig 11(6):13881402. https://doi.org/10.1111/jdi.13290

113. Geddes J, Schopman JE, Zammitt NN, Frier BM (2008) Prevalence of impaired awareness of hypoglycaemia in adults with type 1 diabetes. Diabet Med 25(4):501-504. https://doi.org/ 10.1111/j.1464-5491.2008.02413.x

114. Gold AE, MacLeod KM, Frier BM (1994) Frequency of severe hypoglycemia in patients with type I diabetes with impaired awareness of hypoglycemia. Diabetes Care 17(7):697-703. https://doi.org/10.2337/diacare.17.7.697

115. Mitrakou A, Ryan C, Veneman T et al (1991) Hierarchy of glycemic thresholds for counterregulatory hormone secretion, symptoms, and cerebral dysfunction. Am J Phys 260(1 Pt 1):E67-E74

116. Janssen MM, Snoek FJ, Heine RJ (2000) Assessing impaired hypoglycemia awareness in type 1 diabetes: agreement of selfreport but not of field study data with the autonomic symptom threshold during experimental hypoglycemia. Diabetes Care 23(4):529-532. https://doi.org/10.2337/diacare.23.4.529

117. Clarke WL, Cox DJ, Gonder-Frederick LA, Julian D, Schlundt D, Polonsky W (1995) Reduced awareness of hypoglycemia in adults with IDDM. A prospective study of hypoglycemic frequency and 
associated symptoms. Diabetes Care 18(4):517-522. https://oi. org/10.2337/diacare.18.4.517

118. Pedersen-Bjergaard U, Pramming S, Thorsteinsson B (2003) Recall of severe hypoglycaemia and self-estimated state of awareness in type 1 diabetes. Diabetes Metab Res Rev 19(3):232-240. https://doi.org/10.1002/dmrr.377

119. Speight J, Barendse SM, Singh H et al (2016) Characterizing problematic hypoglycaemia: iterative design and preliminary psychometric validation of the Hypoglycaemia Awareness Questionnaire (HypoA-Q). Diabet Med 33(3):376-385. https:// doi.org/10.1111/dme.12824

120. Hopkins D, Lawrence I, Mansell P et al (2012) Improved biomedical and psychological outcomes 1 year after structured education in flexible insulin therapy for people with type 1 diabetes: the U.K. DAFNE experience. Diabetes Care 35(8):1638-1642. https://doi. org/10.2337/dc11-1579

121. Little SA, Leelarathna L, Barendse SM et al (2014) Severe hypoglycaemia in type 1 diabetes mellitus: underlying drivers and potential strategies for successful prevention. Diabetes Metab Res Rev 30(3):175-190. https://doi.org/10.1002/dmrr. 2492

122. Little SA, Speight J, Leelarathna L et al (2018) Sustained reduction in severe hypoglycemia in adults with type 1 diabetes complicated by impaired awareness of hypoglycemia: two-year followup in the HypoCOMPaSS randomized clinical trial. Diabetes Care 41(8):1600-1607. https://doi.org/10.2337/dc17-2682

123. Iqbal A, Heller SR (2018) The role of structured education in the management of hypoglycaemia. Diabetologia. 61(4):751-760. https://doi.org/10.1007/s00125-017-4334-z

124. Cranston I, Lomas J, Maran A, Macdonald I, Amiel SA (1994) Restoration of hypoglycaemia awareness in patients with longduration insulin-dependent diabetes. Lancet. 344(8918):283287. https://doi.org/10.1016/S0140-6736(94)91336-6

125. Yeoh E, Choudhary P, Nwokolo M, Ayis S, Amiel SA (2015) Interventions that restore awareness of hypoglycemia in adults with type 1 diabetes: a systematic review and meta-analysis. Diabetes Care 38(8):1592-1609. https://doi.org/10.2337/dc150102

126. Cox DJ, Gonder-Frederick L, Ritterband L et al (2006) Blood glucose awareness training: what is it, where is it, and where is it going? Diabetes Spectrum 19(1):43-49. https://doi.org/10.2337/ diaspect.19.1.43

127. Rondags SMPA, de Wit M, Twisk JW, Snoek FJ (2016) Effectiveness of HypoAware, a brief partly web-based psychoeducational intervention for adults with type 1 and insulin-treated type 2 diabetes and problematic hypoglycemia: a cluster randomized controlled trial. Diabetes Care 39(12):2190 2196. https://doi.org/10.2337/dc16-1614

128. Hermanns N, Kulzer B, Krichbaum M, Kubiak T, Haak T (2010) Long-term effect of an education program (HyPOS) on the incidence of severe hypoglycemia in patients with type 1 diabetes. Diabetes Care 33(3):e36-e36. https://doi.org/10.2337/dc09-1656

129. Cryer PE (2010) Hypoglycemia in type 1 diabetes mellitus. Endocrinol Metab Clin N Am 39(3):641-654. https://doi.org/10. 1016/j.ecl.2010.05.003

130. Pinsker JE, Bartee A, Katz M et al (2021) Predictive low-glucose suspend necessitates less carbohydrate supplementation to rescue hypoglycemia: need to revisit current hypoglycemia treatment guidelines. Diabetes Technol Ther 23(7):512-516. https://doi. org/10.1089/dia.2020.0619

131. American Diabetes Association (2019) 5. Lifestyle management: standards of medical care in diabetes-2019. Diabetes Care 42(Suppl 1):S46-S60. https://doi.org/10.2337/dc19-S005

132. Bell KJ, Barclay AW, Petocz P, Colagiuri S, Brand-Miller JC (2014) Efficacy of carbohydrate counting in type 1 diabetes: a systematic review and meta-analysis. Lancet Diabetes
Endocrinol 2(2):133-140. https://doi.org/10.1016/S22138587(13)70144-X

133. Schmidt S, Schelde B, Nørgaard K (2014) Effects of advanced carbohydrate counting in patients with type 1 diabetes: a systematic review. Diabet Med 31(8):886-896. https://doi.org/10.1111/ dme. 12446

134. Evert AB, Dennison M, Gardner CD et al (2019) Nutrition therapy for adults with diabetes or prediabetes: a consensus report. Diabetes Care 42(5):731-754. https://doi.org/10.2337/dci19-0014

135. Hermann JM, Meusers M, Bachran R et al (2017) Self-reported regular alcohol consumption in adolescents and emerging adults with type 1 diabetes: a neglected risk factor for diabetic ketoacidosis? Multicenter analysis of 29630 patients from the DPV registry. Pediatr Diabetes 18(8):817-823. https://doi.org/ 10.1111/pedi. 12496

136. Kerr D, Penfold S, Zouwail S, Thomas P, Begley J (2009) The influence of liberal alcohol consumption on glucose metabolism in patients with type 1 diabetes: a pilot study. QJM 102(3):169-174. https://doi.org/10.1093/qjmed/hen163

137. Turner BC, Jenkins E, Kerr D, Sherwin RS, Cavan DA (2001) The effect of evening alcohol consumption on next-morning glucose control in type 1 diabetes. Diabetes Care 24(11):1888-1893. https://doi.org/10.2337/diacare.24.11.1888

138. Pastor A, Conn J, MacIsaac RJ, Bonomo Y (2020) Alcohol and illicit drug use in people with diabetes. Lancet Diabetes Endocrinol 8(3):239-248. https://doi.org/10.1016/S22138587(19)30410-3

139. Barnard K, Sinclair JMA, Lawton J, Young AJ, Holt RIG (2012) Alcohol-associated risks for young adults with type 1 diabetes: a narrative review. Diabet Med 29(4):434-440. https://doi.org/10. 1111/j.1464-5491.2012.03579.x

140. Barnard KD, Dyson P, Sinclair JMA et al (2014) Alcohol health literacy in young adults with type 1 diabetes and its impact on diabetes management. Diabet Med 31(12):1625-1630. https:// doi.org/10.1111/dme. 12491

141. Engler PA, Ramsey SE, Smith RJ (2013) Alcohol use of diabetes patients: the need for assessment and intervention. Acta Diabetol 50(2):93-99. https://doi.org/10.1007/s00592-010-0200-x

142. Pan A, Wang Y, Talaei M, Hu FB (2015) Relation of smoking with total mortality and cardiovascular events among patients with diabetes mellitus: a meta-analysis and systematic review. Circulation. 132(19):1795-1804. https://doi.org/10.1161/ CIRCULATIONAHA.115.017926

143. Uruska A, Araszkiewicz A, Uruski P, Zozulinska-Ziolkiewicz D (2014) Higher risk of microvascular complications in smokers with type 1 diabetes despite intensive insulin therapy. Microvasc Res 92:79-84. https://doi.org/10.1016/j.mvr.2014.01.002

144. Tikkanen-Dolenc H, Wadén J, Forsblom C et al (2017) Physical activity reduces risk of premature mortality in patients with type 1 diabetes with and without kidney disease. Diabetes Care 40(12): 1727-1732. https://doi.org/10.2337/dc17-0615

145. Bohn B, Herbst A, Pfeifer M et al (2015) Impact of physical activity on glycemic control and prevalence of cardiovascular risk factors in adults with type 1 diabetes: a cross-sectional multicenter study of 18,028 patients. Diabetes Care 38(8):1536-1543. https:// doi.org/10.2337/dc15-0030

146. Wu N, Bredin SSD, Guan Y et al (2019) Cardiovascular health benefits of exercise training in persons living with type 1 diabetes: a systematic review and meta-analysis. J Clin Med 8(2):253. https://doi.org/10.3390/jcm8020253

147. Chimen M, Kennedy A, Nirantharakumar K, Pang TT, Andrews R, Narendran P (2012) What are the health benefits of physical activity in type 1 diabetes mellitus? A literature review. Diabetologia. 55(3):542-551. https://doi.org/10.1007/s00125011-2403-2 
148. Wadén J, Forsblom C, Thorn LM et al (2008) Physical activity and diabetes complications in patients with type 1 diabetes: the Finnish Diabetic Nephropathy (FinnDiane) Study. Diabetes Care 31(2): 230-232. https://doi.org/10.2337/dc07-1238

149. Moser O, Riddell MC, Eckstein ML et al (2020) Glucose management for exercise using continuous glucose monitoring (CGM) and intermittently scanned CGM (isCGM) systems in type 1 diabetes: position statement of the European Association for the Study of Diabetes (EASD) and of the International Society for Pediatric and Adolescent Diabetes (ISPAD) endorsed by JDRF and supported by the American Diabetes Association (ADA). Diabetologia. 63(12):2501-2520

150. Lemaster JW, Reiber GE, Smith DG, Heagerty PJ, Wallace C (2003) Daily weight-bearing activity does not increase the risk of diabetic foot ulcers. Med Sci Sports Exerc 35(7):1093-1099. https://doi.org/10.1249/01.MSS.0000074459.41029.75

151. Riddell MC, Gallen IW, Smart CE et al (2017) Exercise management in type 1 diabetes: a consensus statement. Lancet Diabetes Endocrinol 5(5):377-390. https://doi.org/10.1016/S22138587(17)30014-1

152. Colberg SR (2013) Older Adults. In: Colberg SR (ed) Exercise and diabetes: a clinician's guide to prescribing physical activity, 1st edn. American Diabetes Association, Alexandria, VA, pp 424

153. Reutrakul S, Thakkinstian A, Anothaisintawee T, Chontong S, Borel A-L, Perfect MM et al (2016) Sleep characteristics in type 1 diabetes and associations with glycemic control: systematic review and meta-analysis. Sleep Med 23:26-45. https://doi.org/ 10.1016/j.sleep.2016.03.019

154. Denic-Roberts H, Costacou T, Orchard TJ (2016) Subjective sleep disturbances and glycemic control in adults with long-standing type 1 diabetes: the Pittsburgh's Epidemiology of Diabetes Complications study. Diabetes Res Clin Pract 119:1-12. https:// doi.org/10.1016/j.diabres.2016.06.013

155. van Dijk M, Donga E, van Dijk JG et al (2011) Disturbed subjective sleep characteristics in adult patients with long-standing type 1 diabetes mellitus. Diabetologia. 54(8):1967-1976. https://doi. org/10.1007/s00125-011-2184-7

156. American Diabetes Association (2020) 6. Glycemic targets: standards of medical care in diabetes-2020. Diabetes Care 43(Suppl 1):S66-S76. https://doi.org/10.2337/dc20-S006

157. Centers for Disease Control and Prevention (2020) Managing sick days. Available from: www.cdc.gov/diabetes/managing/flu-sickdays.html. Accessed 16 July 2021

158. Diabetes UK (2021) Diabetes when you're unwell. Available from: www.diabetes.org.uk/guide-to-diabetes/life-with-diabetes/ illness. Accessed 16 July 2021

159. Graveling AJ, Frier BM (2015) Driving and diabetes: problems, licensing restrictions and recommendations for safe driving. Clin Diabetes Endocrinol 1:8

160. American Diabetes Association (2014) Diabetes and driving. Diabetes Care 37(Supp 1):S97-S103. https://doi.org/10.2337/ dc14-S097

161. American Diabetes Association (2014) Diabetes and employment. Diabetes Care 37(Suppl 1):S112-S117

162. Sansum Diabetes Research Institute (2019) Time zones. Available from: https://diabetestravel.sansum.org/time-zones/. Accessed 19 February 2021

163. Charlton AR, Charlton JR (2019) World travel with type 1 diabetes using continuous subcutaneous insulin infusion. Br J Diabetes 19(2):141-146. https://doi.org/10.15277/bjd.2019.224

164. IDF and the Diabetes \& Ramadan International Alliance. Diabetes and Ramadan: Practical Guidelines 2021 (2021). Available from: https://idf.org/e-library/guidelines/165-idf-dar-practicalguidelines-2021.html. Accessed 16 July 2021
165. de Groot M, Golden SH, Wagner J (2016) Psychological conditions in adults with diabetes. Am Psychol 71(7):552-562. https:// doi.org/10.1037/a0040408

166. van Duinkerken E, Snoek FJ, de Wit M (2020) The cognitive and psychological effects of living with type 1 diabetes: a narrative review. Diabet Med 37(4):555-563. https://doi.org/10.1111/dme. 14216

167. Speight J, Hendrieckx C, Pouwer F, Skinner TC, Snoek FJ (2020) Back to the future: 25 years of "Guidelines for encouraging psychological well-being" among people affected by diabetes. Diabet Med 37(8):1225-1229. https://doi.org/10.1111/dme.14165

168. Fisher L, Polonsky WH, Hessler DM et al (2015) Understanding the sources of diabetes distress in adults with type 1 diabetes. J Diabetes Complicat 29(4):572-577. https://doi.org/10.1016/j. jdiacomp.2015.01.012

169. Hessler DM, Fisher L, Polonsky WH et al (2017) Diabetes distress is linked with worsening diabetes management over time in adults with type 1 diabetes. Diabet Med 34(9):1228-1234. https://doi. org/10.1111/dme.13381

170. de Wit M, Trief PM, Huber JW, Willaing I (2020) State of the art: understanding and integration of the social context in diabetes care. Diabet Med 37(3):473-482. https://doi.org/10.1111/dme. 14226

171. Barnard KD, Skinner TC, Peveler R (2006) The prevalence of comorbid depression in adults with type 1 diabetes: systematic literature review. Diabet Med 23(4):445-448. https://doi.org/10.1111/ j.1464-5491.2006.01814.x

172. Hermanns N, Kulzer B, Krichbaum M, Kubiak T, Haak T (2005) Affective and anxiety disorders in a German sample of diabetic patients: prevalence, comorbidity and risk factors. Diabet Med 22(3):293-300. https://doi.org/10.1111/j.1464-5491.2005.01414. $\mathrm{x}$

173. Smith KJ, Béland M, Clyde M et al (2013) Association of diabetes with anxiety: a systematic review and meta-analysis. J Psychosom Res 74(2):89-99. https://doi.org/10.1016/j.jpsychores.2012.11. 013

174. Snoek FJ, Bremmer MA, Hermanns N (2015) Constructs of depression and distress in diabetes: time for an appraisal. Lancet Diabetes Endocrinol 3(6):450-460. https://doi.org/10.1016/ S2213-8587(15)00135-7

175. Pouwer F, Schram MT, Iversen MM, Nouwen A, Holt RIG (2020) How 25 years of psychosocial research has contributed to a better understanding of the links between depression and diabetes. Diabet Med 37(3):383-392. https://doi.org/10.1111/dme.14227

176. Fisher L, Hessler DM, Polonsky WH et al (2016) Prevalence of depression in type 1 diabetes and the problem of over-diagnosis. Diabet Med 33(11):1590-1597. https://doi.org/10.1111/dme. 12973

177. Sultan S, Epel E, Sachon C, Vaillant G, Hartemann-Heurtier A (2008) A longitudinal study of coping, anxiety and glycemic control in adults with type 1 diabetes. Psychol Health 23(1):73-89

178. Nefs G, Hendrieckx C, Reddy P et al (2019) Comorbid elevated symptoms of anxiety and depression in adults with type 1 or type 2 diabetes: results from the International Diabetes MILES study. J Diabetes Complicat 33(8):523-529. https://doi.org/10.1016/j. jdiacomp.2019.04.013

179. Nano J, Carinci F, Okunade O et al (2020) A standard set of person-centred outcomes for diabetes mellitus: results of an international and unified approach. Diabet Med 37(12):2009-2018. https://doi.org/10.1111/dme.14286

180. Krieger T, Zimmermann J, Huffziger S et al (2014) Measuring depression with a well-being index: further evidence for the validity of the WHO Well-Being Index (WHO-5) as a measure of the severity of depression. J Affect Disord 156:240-244. https://doi. org/10.1016/j.jad.2013.12.015 
181. Polonsky WH, Anderson BJ, Lohrer PA et al (1995) Assessment of diabetes-related distress. Diabetes Care 18(6):754-760. https:// doi.org/10.2337/diacare.18.6.754

182. Kroenke K, Spitzer RL, Williams JB (2001) The PHQ-9: validity of a brief depression severity measure. J Gen Intern Med 16(9): 606-613. https://doi.org/10.1046/j.1525-1497.2001.016009606.x

183. Spitzer RL, Kroenke K, Williams JBW, Löwe B (2006) A brief measure for assessing generalized anxiety disorder: the GAD-7. Arch Intern Med 166(10):1092-1097. https://doi.org/10.1001/ archinte.166.10.1092

184. Kroenke K, Spitzer RL, Williams JBW (2003) The Patient Health Questionnaire-2: validity of a two-item depression screener. Med Care 41(11):1284-1292. https://doi.org/10.1097/01.MLR. $0000093487.78664 .3 \mathrm{C}$

185. Kroenke K, Spitzer RL, Williams JBW, Löwe B (2009) An ultrabrief screening scale for anxiety and depression: the PHQ-4. Psychosomatics. 50(6):613-621. https://doi.org/10.1176/appi. psy.50.6.613

186. McGuire BE, Morrison TG, Hermanns N et al (2010) Short-form measures of diabetes-related emotional distress: the Problem Areas in Diabetes Scale (PAID)-5 and PAID-1. Diabetologia. 53(1):66-69. https://doi.org/10.1007/s00125-009-1559-5

187. Fisher L, Glasgow RE, Mullan JT, Skaff MM, Polonsky WH (2008) Development of a brief diabetes distress screening instrument. Ann Fam Med 6(3):246-252. https://doi.org/10.1370/afm. 842

188. Pouwer F, Snoek FJ, van der Ploeg HM, Adèr HJ, Heine RJ (2001) Monitoring of psychological well-being in outpatients with diabetes: effects on mood, $\mathrm{HbA}_{1 \mathrm{c}}$, and the patient's evaluation of the quality of diabetes care: a randomized controlled trial. Diabetes Care 24(11):1929-1935. https://doi.org/10.2337/ diacare.24.11.1929

189. Snoek FJ, Kersch NYA, Eldrup E et al (2012) Monitoring of Individual Needs in Diabetes (MIND)-2: follow-up data from the cross-national Diabetes Attitudes, Wishes, and Needs (DAWN) MIND study. Diabetes Care 35(11):2128-2132. https://doi.org/10.2337/dc11-1326

190. Wild D, von Maltzahn R, Brohan E, Christensen T, Clauson P, Gonder-Frederick L (2007) A critical review of the literature on fear of hypoglycemia in diabetes: implications for diabetes management and patient education. Patient Educ Couns 68(1): 10-15. https://doi.org/10.1016/j.pec.2007.05.003

191. Snoek FJ, Hajos TRS, Rondags SMPA (2014) Psychological effects of hypoglycaemia. In: Frier BM, Heller SR, McCrimmon RJ (eds) Hypoglycaemia in clinical diabetes. John Wiley \& Sons, Chichester, pp 323-333

192. Gonder-Frederick LA, Schmidt KM, Vajda KA et al (2011) Psychometric properties of the hypoglycemia fear survey-ii for adults with type 1 diabetes. Diabetes Care 34(4):801-806. https://doi.org/10.2337/dc10-1343

193. Jones JM, Lawson ML, Daneman D, Olmsted MP, Rodin G (2000) Eating disorders in adolescent females with and without type 1 diabetes: cross sectional study. BMJ 320(7249):15631566. https://doi.org/10.1136/bmj.320.7249.1563

194. Colton PA, Olmsted MP, Daneman D et al (2015) Eating disorders in girls and women with type 1 diabetes: a longitudinal study of prevalence, onset, remission, and recurrence. Diabetes Care 38(7): 1212-1217. https://doi.org/10.2337/dc14-2646

195. Luyckx K, Verschueren M, Palmeroni N, Goethals ER, Weets I, Claes L (2019) Disturbed eating behaviors in adolescents and emerging adults with type 1 diabetes: a one-year prospective study. Diabetes Care 42(9):1637-1644. https://doi.org/10.2337/ dc19-0445

196. Wisting L, Reas DL, Bang L, Skrivarhaug T, Dahl-Jørgensen K, Rø Ø (2017) Eating patterns in adolescents with type 1 diabetes: associations with metabolic control, insulin omission, and eating disorder pathology. Appetite. 114:226-231. https://doi.org/10. 1016/j.appet.2017.03.035

197. d'Emden H, Holden L, McDermott B et al (2013) Disturbed eating behaviours and thoughts in Australian adolescents with type 1 diabetes. J Paediatr Child Health 49(4):E317-E323. https://doi. org/10.1111/jpc. 12014

198. Hill-Briggs F, Adler NE, Berkowitz SA et al (2020) Social determinants of health and diabetes: a scientific review. Diabetes Care. https://doi.org/10.2337/dci20-0053

199. Centers for Disease Control and Prevention (2021) Tools for Putting Social Determinants of Health into Action. Available from: www.cdc.gov/socialdeterminants/tools/index.htm. Accessed 18 February 2021

200. Institute of Medicine (2014) Capturing social and behavioral domains and measures in electronic health records: phase 2 . The National Academies Press, Washington, DC. https://doi.org/10. 4172/2157-7013.1000190

201. American Academy of Family Physicians (2018) Social Needs Screening Tool. Available from: www.aafp.org/dam/AAFP/ documents/patient_care/everyone_project/hops19-physicianform-sdoh.pdf. Accessed 23 August 2021

202. Giuse NB, Koonce TY, Kusnoor SV et al (2017) Institute of medicine measures of social and behavioral determinants of health: a feasibility study. Am J Prev Med 52(2):199-206. https://doi.org/10.1016/j.amepre.2016.07.033

203. Walker RJ, Garacci E, Palatnik A, Ozieh MN, Egede LE (2020) The longitudinal influence of social determinants of health on glycemic control in elderly adults with Diabetes. Diabetes Care 43(4):759-766. https://doi.org/10.2337/dc19-1586

204. Heller CG, Parsons AS, Chambers EC, Fiori KP, Rehm CD (2020) Social risks among primary care patients in a large urban health system. Am J Prev Med 58(4):514-525. https://doi.org/10. 1016/j.amepre.2019.11.011

205. Young-Hyman D, de Groot M, Hill-Briggs F, Gonzalez JS, Hood K, Peyrot M (2016) Psychosocial care for people with diabetes: a position statement of the American Diabetes Association. Diabetes Care 39(12):2126-2140. https://doi.org/10.2337/dc162053

206. van der Feltz-Cornelis CM, Nuyen J, Stoop C et al (2010) Effect of interventions for major depressive disorder and significant depressive symptoms in patients with diabetes mellitus: a systematic review and meta-analysis. Gen Hosp Psychiatry 32(4):380-395. https://doi.org/10.1016/j.genhosppsych.2010.03.011

207. De Hert M, Dekker JM, Wood D, Kahl KG, Holt RIG, Möller H-J (2009) Cardiovascular disease and diabetes in people with severe mental illness position statement from the European Psychiatric Association (EPA), supported by the European Association for the Study of Diabetes (EASD) and the European Society of Cardiology (ESC). Eur Psychiatry 24(6):412-424. https://doi. org/10.1016/j.eurpsy.2009.01.005

208. Stenov V, Joensen LE, Knudsen L, Lindqvist Hansen D, Willaing Tapager I (2020) "Mental health professionals have never mentioned my diabetes, they don't get into that": a qualitative study of support needs in adults with type 1 and type 2 diabetes and severe mental illness. Can J Diabetes 44(6):494-500. https:// doi.org/10.1016/j.jcjd.2020.02.006

209. Benoit SR, Hora I, Pasquel FJ, Gregg EW, Albright AL, Imperatore G (2020) Trends in emergency department visits and inpatient admissions for hyperglycemic crises in adults with diabetes in the U.S., 2006-2015. Diabetes Care 43(5):10571064. https://doi.org/10.2337/dc19-2449

210. Kalscheuer H, Seufert J, Lanzinger S et al (2019) Event rates and risk factors for the development of diabetic ketoacidosis in adult patients with type 1 diabetes: analysis from the DPV registry based on 46,966 patients. Diabetes Care 42(3):e34-e36. https://doi.org/ $10.2337 / \mathrm{dc} 18-1160$ 
211. Ehrmann D, Kulzer B, Roos T, Haak T, Al-Khatib M, Hermanns N (2020) Risk factors and prevention strategies for diabetic ketoacidosis in people with established type 1 diabetes. Lancet Diabetes Endocrinol 8(5):436-446. https://doi.org/10.1016/ S2213-8587(20)30042-5

212. Kinney GL, Akturk HK, Taylor DD, Foster NC, Shah VN (2020) Cannabis use is associated with increased risk for diabetic ketoacidosis in adults with type 1 diabetes: findings from the T1D exchange clinic registry. Diabetes Care 43(1):247-249

213. Hare MJL, Deitch JM, Kang MJY, Bach LA (2020) Clinical, psychological and demographic factors in a contemporary adult cohort with diabetic ketoacidosis and type 1 diabetes. Intern Med J. https://doi.org/10.1111/imj.14877

214. Garg SK, Walker AJ, Hoff HK, D'Souza AO, Gottlieb PA, Chase HP (2004) Glycemic parameters with multiple daily injections using insulin glargine versus insulin pump. Diabetes Technol Ther 6(1):9-15. https://doi.org/10.1089/152091504322783350

215. Hoshina S, Andersen GS, Jørgensen ME, Ridderstråle M, Vistisen D, Andersen HU (2018) Treatment modality-dependent risk of diabetic ketoacidosis in patients with type 1 diabetes: Danish Adult Diabetes Database Study. Diabetes Technol Ther 20(3): 229-234. https://doi.org/10.1089/dia.2017.0231

216. Danne T, Garg S, Peters AL et al (2019) International consensus on risk management of diabetic ketoacidosis in patients with type 1 diabetes treated with sodium-glucose cotransporter (SGLT) inhibitors. Diabetes Care 42(6):1147-1154. https://doi.org/10. 2337/dc18-2316

217. Goldenberg RM, Gilbert JD, Hramiak IM, Woo VC, Zinman B (2019) Sodium-glucose co-transporter inhibitors, their role in type 1 diabetes treatment and a risk mitigation strategy for preventing diabetic ketoacidosis: the STOP DKA protocol. Diabetes Obes Metab 21(10):2192-2202. https://doi.org/10.1111/dom.13811

218. Peters AL, Buschur EO, Buse JB, Cohan P, Diner JC, Hirsch IB (2015) Euglycemic diabetic ketoacidosis: a potential complication of treatment with sodium-glucose cotransporter 2 inhibition. Diabetes Care 38(9):1687-1693. https://doi.org/10.2337/dc150843

219. Dhatariya KK, Vellanki P (2017) Treatment of diabetic ketoacidosis (DKA)/hyperglycemic hyperosmolar state (HHS): novel advances in the management of hyperglycemic crises (UK versus USA). Curr Diab Rep 17(5):33

220. Kitabchi AE, Umpierrez GE, Fisher JN, Murphy MB, Stentz FB (2008) Thirty years of personal experience in hyperglycemic crises: diabetic ketoacidosis and hyperglycemic hyperosmolar state. J Clin Endocrinol Metab 93(5):1541-1552. https://doi.org/ $10.1210 /$ jc. $2007-2577$

221. Savage MW, Dhatariya KK, Kilvert A et al (2011) Joint British Diabetes Societies guideline for the management of diabetic ketoacidosis. Diabet Med 28(5):508-515. https://doi.org/10. 1111/j.1464-5491.2011.03246.x

222. Umpierrez G, Korytkowski M (2016) Diabetic emergencies ketoacidosis, hyperglycaemic hyperosmolar state and hypoglycaemia. Nat Rev Endocrinol 12(4):222-232. https://doi. org/10.1038/nrendo.2016.15

223. Gruessner RWG, Gruessner AC (2013) The current state of pancreas transplantation. Nat Rev Endocrinol 9(9):555-562. https://doi.org/10.1038/nrendo.2013.138

224. Barton FB, Rickels MR, Alejandro R et al (2012) Improvement in outcomes of clinical islet transplantation: 1999-2010. Diabetes Care 35(7):1436-1445. https://doi.org/10.2337/dc12-0063
225. Niclauss N, Morel P, Berney T (2014) Has the gap between pancreas and islet transplantation closed? Transplantation. 98(6): 593-599. https://doi.org/10.1097/TP.0000000000000288

226. Bassi R, Fiorina P (2011) Impact of islet transplantation on diabetes complications and quality of life. Curr Diab Rep 11(5):355363. https://doi.org/10.1007/s11892-011-0211-1

227. Thompson DM, Meloche M, Ao Z et al (2011) Reduced progression of diabetic microvascular complications with islet cell transplantation compared with intensive medical therapy. Transplantation. 91(3):373-378. https://doi.org/10.1097/TP. 0b013e31820437f3

228. Speight J, Woodcock AJ, Reaney MD et al (2016) Well, I wouldn't be any worse off, would I, than I am now? A qualitative study of decision-making, hopes, and realities of adults with type 1 diabetes undergoing islet cell transplantation. Transplant Direct 2(5):e72. https://doi.org/10.1097/TXD.0000000000000581

229. Gruessner AC, Sutherland DER, Gruessner RWG (2012) Longterm outcome after pancreas transplantation. Curr Opin Organ Transplant 17(1):100-105. https://doi.org/10.1097/MOT. 0b013e32834ee700

230. Sollinger HW, Odorico JS, Becker YT, D’Alessandro AM, Pirsch JD (2009) One thousand simultaneous pancreas-kidney transplants at a single center with 22 -year follow-up. Ann Surg 250(4):618-630. https://doi.org/10.1097/SLA. 0b013e3181b76d2b

231. Lehmann R, Graziano J, Brockmann J et al (2015) Glycemic control in simultaneous islet-kidney versus pancreas-kidney transplantation in type 1 diabetes: a prospective 13-year follow-up. Diabetes Care 38(5):752-759. https://doi.org/10.2337/dc14-1686

232. Kandaswamy R, Sutherland DER (2006) Pancreas versus islet transplantation in diabetes mellitus: how to allocate deceased donor pancreata? Transplant Proc 38(2):365-367. https://doi.org/ 10.1016/j.transproceed.2006.01.005

233. American Diabetes Association (2004) Pancreas transplantation in type 1 diabetes. Diabetes Care 27(Suppl 1):S105

234. Ryan EA, Shandro T, Green K et al (2004) Assessment of the severity of hypoglycemia and glycemic lability in type 1 diabetic subjects undergoing islet transplantation. Diabetes. 53(4):955962. https://doi.org/10.2337/diabetes.53.4.955

235. Senior PA, Bellin MD, Alejandro R et al (2015) Consistency of quantitative scores of hypoglycemia severity and glycemic lability and comparison with continuous glucose monitoring system measures in long-standing type 1 diabetes. Diabetes Technol Ther 17(4):235-242. https://doi.org/10.1089/dia.2014.0289

236. Bellin MD, Barton FB, Heitman A et al (2012) Potent induction immunotherapy promotes long-term insulin independence after islet transplantation in type 1 diabetes. Am J Transplant 12(6): 1576-1583. https://doi.org/10.1111/j.1600-6143.2011.03977.x

237. Qi M, Kinzer K, Danielson KK et al (2014) Five-year follow-up of patients with type 1 diabetes transplanted with allogeneic islets: the UIC experience. Acta Diabetol 51(5):833-843. https://doi.org/ 10.1007/s00592-014-0627-6

238. Clinical Islet Transplantation Consortium (2015) Clinical Islet Transplantation Study. Available from: www.isletstudy.org/. Accessed 11 February 2021

239. O'Connell PJ, Holmes-Walker DJ, Goodman D et al (2013) Multicenter Australian trial of islet transplantation: improving accessibility and outcomes. Am J Transplant 13(7):1850-1858. https://doi.org/10.1111/ajt.12250

240. Brooks AM, Walker N, Aldibbiat A et al (2013) Attainment of metabolic goals in the integrated UK islet transplant program with 
locally isolated and transported preparations. Am J Transplant 13(12):3236-3243. https://doi.org/10.1111/ajt.12469

241. Speight J, Reaney MD, Woodcock AJ, Smith RM, Shaw JAM (2010) Patient-reported outcomes following islet cell or pancreas transplantation (alone or after kidney) in type 1 diabetes: a systematic review. Diabet Med 27(7):812-822. https://doi.org/10.1111/j. 1464-5491.2010.03029.x

242. Choudhary P, Rickels MR, Senior PA et al (2015) Evidenceinformed clinical practice recommendations for treatment of type 1 diabetes complicated by problematic hypoglycemia. Diabetes Care 38(6):1016-1029. https://doi.org/10.2337/dc15-0090

243. Lablanche S, Vantyghem M-C, Kessler L et al (2018) Islet transplantation versus insulin therapy in patients with type 1 diabetes with severe hypoglycaemia or poorly controlled glycaemia after kidney transplantation (TRIMECO): a multicentre, randomised controlled trial. Lancet Diabetes Endocrinol 6(7):527-537. https://doi.org/10.1016/S2213-8587(18)30078-0

244. Snaith JR, Holmes-Walker DJ, Greenfield JR (2020) Reducing type 1 diabetes mortality: role for adjunctive therapies? Trends Endocrinol Metab 31(2):150-164. https://doi.org/10.1016/j.tem. 2019.11.007

245. Liu Y-S, Chen C-N, Chen Z-G, Peng Y, Lin X-P, Xu L-L (2020) Vascular and metabolic effects of metformin added to insulin therapy in patients with type 1 diabetes: a systematic review and metaanalysis. Diabetes Metab Res Rev 36(6):e3334. https://doi.org/10. 1002/dmrr.3334

246. Petrie JR, Chaturvedi N, Ford I et al (2017) Cardiovascular and metabolic effects of metformin in patients with type 1 diabetes (REMOVAL): a double-blind, randomised, placebo-controlled trial. Lancet Diabetes Endocrinol 5(8):597-609. https://doi.org/ 10.1016/S2213-8587(17)30194-8

247. Kong MF, King P, Macdonald IA et al (1997) Infusion of pramlintide, a human amylin analogue, delays gastric emptying in men with IDDM. Diabetologia. 40(1):82-88. https://doi.org/10. 1007/s001250050646

248. Kong MF, Stubbs TA, King P et al (1998) The effect of single doses of pramlintide on gastric emptying of two meals in men with IDDM. Diabetologia. 41(5):577-583. https://doi.org/10.1007/ s001250050949

249. Fineman MS, Koda JE, Shen LZ et al (2002) The human amylin analog, pramlintide, corrects postprandial hyperglucagonemia in patients with type 1 diabetes. Metabolism. 51(5):636-641. https:// doi.org/10.1053/meta.2002.32022

250. Chapman I, Parker B, Doran S et al (2005) Effect of pramlintide on satiety and food intake in obese subjects and subjects with type 2 diabetes. Diabetologia. 48(5):838-848. https://doi.org/10.1007/ s00125-005-1732-4

251. Whitehouse F, Kruger DF, Fineman M et al (2002) A randomized study and open-label extension evaluating the long-term efficacy of pramlintide as an adjunct to insulin therapy in type 1 diabetes. Diabetes Care 25(4):724-730. https://doi.org/10.2337/diacare.25. 4.724

252. Ratner RE, Want LL, Fineman MS et al (2002) Adjunctive therapy with the amylin analogue pramlintide leads to a combined improvement in glycemic and weight control in insulin-treated subjects with type 2 diabetes. Diabetes Technol Ther 4(1):5161. https://doi.org/10.1089/15209150252924094

253. Hollander PA, Levy P, Fineman MS et al (2003) Pramlintide as an adjunct to insulin therapy improves long-term glycemic and weight control in patients with type 2 diabetes: a 1-year randomized controlled trial. Diabetes Care 26(3):784-790. https://doi.org/ 10.2337/diacare.26.3.784

254. Ratner RE, Dickey R, Fineman M et al (2004) Amylin replacement with pramlintide as an adjunct to insulin therapy improves long-term glycaemic and weight control in type 1 diabetes mellitus: a 1-year, randomized controlled trial. Diabet Med
21(11):1204-1212. https://doi.org/10.1111/j.1464-5491.2004. 01319.x

255. von Herrath M, Bain SC, Bode B et al (2021) Anti-interleukin-21 antibody and liraglutide for the preservation of $\beta$-cell function in adults with recent-onset type 1 diabetes: a randomised, doubleblind, placebo-controlled, phase 2 trial. Lancet Diabetes Endocrinol 9(4):212-224. https://doi.org/10.1016/S22138587(21)00019-X

256. Nauck MA, Meier JJ (2020) GLP-1 receptor agonists in type 1 diabetes: a MAG1C bullet? Lancet Diabetes Endocrinol 8(4):262264. https://doi.org/10.1016/S2213-8587(20)30043-7

257. Mathieu C, Zinman B, Hemmingsson JU et al (2016) Efficacy and safety of liraglutide added to insulin treatment in type 1 diabetes: the ADJUNCT ONE treat-to-target randomized trial. Diabetes Care 39(10):1702-1710. https://doi.org/10.2337/dc16-0691

258. Ahrén B, Hirsch IB, Pieber TR et al (2016) Efficacy and safety of liraglutide added to capped insulin treatment in subjects with type 1 diabetes: the ADJUNCT TWO randomized trial. Diabetes Care 39(10):1693-1701. https://doi.org/10.2337/dc16-0690

259. Sheahan KH, Wahlberg EA, Gilbert MP (2020) An overview of GLP-1 agonists and recent cardiovascular outcomes trials. Postgrad Med J 96(1133):156-161. https://doi.org/10.1136/ postgradmedj-2019-137186

260. Wilding JPH, Batterham RL, Calanna S et al (2021) Once-weekly semaglutide in adults with overweight or obesity. N Engl J Med 384(11):989. https://doi.org/10.1056/NEJMoa2032183

261. Taylor SI, Blau JE, Rother KI, Beitelshees AL (2019) SGLT2 inhibitors as adjunctive therapy for type 1 diabetes: balancing benefits and risks. Lancet Diabetes Endocrinol 7(12):949-958. https://doi.org/10.1016/S2213-8587(19)30154-8

262. Zelniker TA, Wiviott SD, Raz I et al (2019) SGLT2 inhibitors for primary and secondary prevention of cardiovascular and renal outcomes in type 2 diabetes: a systematic review and metaanalysis of cardiovascular outcome trials. Lancet 393(10166): 31-39. https://doi.org/10.1016/S0140-6736(18)32590-X

263. Groop P-H, Dandona P, Phillip M et al (2020) Effect of dapagliflozin as an adjunct to insulin over 52 weeks in individuals with type 1 diabetes: post-hoc renal analysis of the DEPICT randomised controlled trials. Lancet Diabetes Endocrinol 8(10): 845-854. https://doi.org/10.1016/S2213-8587(20)30280-1

264. Jensen DM, Korsholm L, Ovesen P, Beck-Nielsen H, MoelstedPedersen L, Westergaard JG et al (2009) Peri-conceptional A1C and risk of serious adverse pregnancy outcome in 933 women with type 1 diabetes. Diabetes Care 32(6):1046-1048. https://doi.org/ $10.2337 / \mathrm{dc} 08-2061$

265. Abell SK, Boyle JA, de Courten B et al (2016) Contemporary type 1 diabetes pregnancy outcomes: impact of obesity and glycaemic control. Med J Aust 205(4):162-167. https://doi.org/10.5694/ mja16.00443

266. Feig DS, Donovan LE, Corcoy R et al (2017) Continuous glucose monitoring in pregnant women with type 1 diabetes (CONCEPTT): a multicentre international randomised controlled trial. Lancet. 390(10110):2347-2359. https://doi.org/10.1016/ S0140-6736(17)32400-5

267. Nielsen LR, Pedersen-Bjergaard U, Thorsteinsson B, Johansen M, Damm P, Mathiesen ER (2008) Hypoglycemia in pregnant women with type 1 diabetes: predictors and role of metabolic control. Diabetes Care 31(1):9-14

268. Sibai BM, Viteri OA (2014) Diabetic ketoacidosis in pregnancy. Obstet Gynecol 123(1):167-178. https://doi.org/10.1097/AOG. 0000000000000060

269. Roeder HA, Moore TR, Ramos GA (2016) Changes in postpartum insulin requirements for patients with well-controlled type 1 diabetes. Am J Perinatol 33(7):683-687. https://doi.org/10.1055/s0036-1571323 
270. Davies HA, Clark JD, Dalton KJ, Edwards OM (1989) Insulin requirements of diabetic women who breast feed. BMJ. 298(6684):1357-1358. https://doi.org/10.1136/bmj.298.6684. 1357

271. WHO (2015) Medical eligibility criteria wheel for contraceptive use. Available from: www.who.int/reproductivehealth/ publications/family_planning/mec-wheel-5th/en/. Accessed 16 July 2021

272. American Diabetes Association (2021) 14. Management of diabetes in pregnancy: standards of medical care in diabetes - 2021 . Diabetes Care 44(Suppl 1):S200-S210. https://doi.org/10.2337/ dc21-S014

273. National Institute for Health and Care Excellence (2020) Diabetes in pregnancy: management from preconception to the postnatal period. Available from: www.nice.org.uk/guidance/ng3. Accessed 18 February 2021

274. Leung E, Wongrakpanich S, Munshi MN (2018) Diabetes management in the elderly. Diabetes Spectrum 31(3):245-253. https://doi.org/10.2337/ds18-0033

275. Wang PH, Lau J, Chalmers TC (1993) Meta-analysis of effects of intensive blood-glucose control on late complications of type I diabetes. Lancet. 341(8856):1306-1309. https://doi.org/10.1016/ 0140-6736(93)90816-Y

276. Molitch ME, Adler AI, Flyvbjerg A et al (2015) Diabetic kidney disease: a clinical update from kidney disease: improving global outcomes. Kidney Int 87(1):20-30. https://doi.org/10.1038/ki. 2014.128

277. Aleppo G, Calhoun P, Foster NC et al (2017) Reported gastroparesis in adults with type 1 diabetes (T1D) from the T1D Exchange clinic registry. J Diabetes Complicat 31(12):16691673. https://doi.org/10.1016/j.jdiacomp.2017.08.014

278. The Diabetes Control and Complications Trial Research Group (1998) Early worsening of diabetic retinopathy in the diabetes control and complications trial. Arch Ophthalmol 116(7):874 886. https://doi.org/10.1001/archopht.116.7.874

279. Llewelyn JG, Thomas PK, Fonseca V, King RH, Dandona P (1986) Acute painful diabetic neuropathy precipitated by strict glycaemic control. Acta Neuropathol 72(2):157-163. https://doi. org/10.1007/BF00685978

280. de Ferranti SD, de Boer IH, Fonseca V et al (2014) Type 1 diabetes mellitus and cardiovascular disease: a scientific statement from the American Heart Association and American Diabetes Association. Diabetes Care 37(10):2843-2863. https://doi.org/ $10.2337 / \mathrm{dc} 14-1720$

281. American Diabetes Association (2021) 15. Diabetes care in the hospital: standards of medical care in diabetes-2021. Diabetes Care 44(Suppl 1):S211-S220. https://doi.org/10.2337/dc21-S015
282. Umpierrez GE, Kitabchi AE (2003) Diabetic ketoacidosis: risk factors and management strategies. Treat Endocrinol 2(2):95108. https://doi.org/10.2165/00024677-200302020-00003

283. Galindo RJ, Umpierrez GE, Rushakoff RJ et al (2020) Continuous glucose monitors and automated insulin dosing systems in the hospital consensus guideline. J Diabetes Sci Technol 14(6): 1035-1064. https://doi.org/10.1177/1932296820954163

284. Mendez CE, Umpierrez GE (2017) Management of type 1 diabetes in the hospital setting. Curr Diab Rep 17(10):98

285. Bailon RM, Partlow BJ, Miller-Cage V et al (2009) Continuous subcutaneous insulin infusion (insulin pump) therapy can be safely used in the hospital in select patients. Endocr Pract 15(1):24-29. https://doi.org/10.4158/EP.15.1.24

286. Cook CB, Boyle ME, Cisar NS et al (2005) Use of continuous subcutaneous insulin infusion (insulin pump) therapy in the hospital setting: proposed guidelines and outcome measures. Diabetes Educ 31(6):849-857. https://doi.org/10.1177/0145721705281563

287. Nair GG, Tzanakakis ES, Hebrok M (2020) Emerging routes to the generation of functional $\beta$-cells for diabetes mellitus cell therapy. Nat Rev Endocrinol 16(9):506-518. https://doi.org/10.1038/ s41574-020-0375-3

288. Desai T, Shea LD (2017) Advances in islet encapsulation technologies. Nat Rev Drug Discov 16(5):338-350. https://doi.org/10. 1038/nrd.2016.232

289. Hendriks WT, Warren CR, Cowan CA (2016) Genome editing in human pluripotent stem cells: approaches, pitfalls, and solutions. Cell Stem Cell 18(1):53-65. https://doi.org/10.1016/j.stem.2015. 12.002

290. Dayan CM, Korah M, Tatovic D, Bundy BN, Herold KC (2019) Changing the landscape for type 1 diabetes: the first step to prevention. Lancet. 394(10205):1286-1296. https://doi.org/10. 1016/S0140-6736(19)32127-0

291. Hughes JW, Bao YK, Salam M et al (2019) Late-onset T1DM and older age predict risk of additional autoimmune disease. Diabetes Care 42(1):32-38

292. Milluzzo A, Falorni A, Brozzetti A et al (2021) Risk for coexistent autoimmune diseases in familial and sporadic type 1 diabetes is related to age at diabetes onset. Endocr Pract 27(2):110-117. https://doi.org/10.1016/j.eprac.2020.09.012

293. Bergenstal RM, Gal RL, Connor CG et al (2017) Racial differences in the relationship of glucose concentrations and hemoglobin A1c levels. Ann Intern Med 167(2):95-102. https://doi.org/10. 7326/M16-2596

Publisher's note Springer Nature remains neutral with regard to jurisdictional claims in published maps and institutional affiliations.

\section{Affiliations}

\section{Richard I. G. Holt ${ }^{1,2}$ • J. Hans DeVries ${ }^{3,4} \cdot$ Amy Hess-Fischl $^{5}$ • Irl B. Hirsch ${ }^{6} \cdot$ M. Sue Kirkman ${ }^{7}$ - Tomasz Klupa ${ }^{8}$. Barbara Ludwig ${ }^{9} \cdot$ Kirsten Nørgaard $^{10,11}$ • Jeremy Pettus ${ }^{12}$ • Eric Renard ${ }^{13,14}$ • Jay S. Skyler ${ }^{15}$ • Frank J. Snoek $^{16}$. Ruth S. Weinstock ${ }^{17}$. Anne L. Peters ${ }^{18}$}

1 Human Development and Health, Faculty of Medicine, University of Southampton, Southampton, UK

2 Southampton National Institute for Health Research Biomedical Research Centre, University Hospital Southampton NHS Foundation Trust, Southampton, UK
3 Amsterdam UMC, Internal Medicine, University of Amsterdam, Amsterdam, the Netherlands

4 Profil Institute for Metabolic Research, Neuss, Germany

5 Kovler Diabetes Center, University of Chicago, Chicago, IL, USA

6 UW Medicine Diabetes Institute, Seattle, WA, USA 
7 University of North Carolina School of Medicine, Chapel Hill, NC, USA

8 Department of Metabolic Diseases, Center for Advanced Technologies in Diabetes, Jagiellonian University Medical College, Kraków, Poland

9 University Hospital Carl Gustav Carus, Technische Universität Dresden, Dresden, Germany

10 Steno Diabetes Center Copenhagen, Gentofte, Denmark

11 University of Copenhagen, Copenhagen, Denmark

12 University of California, San Diego, CA, USA
13 Montpellier University Hospital, Montpellier, France

14 Institute of Functional Genomics, University of Montpellier, CNRS, Inserm, Montpellier, France

15 University of Miami Miller School of Medicine, Miami, FL, USA

16 Amsterdam UMC, Medical Psychology, Vrije Universiteit, Amsterdam, the Netherlands

17 SUNY Upstate Medical University, Syracuse, NY, USA

18 Keck School of Medicine of USC, Los Angeles, CA, USA 